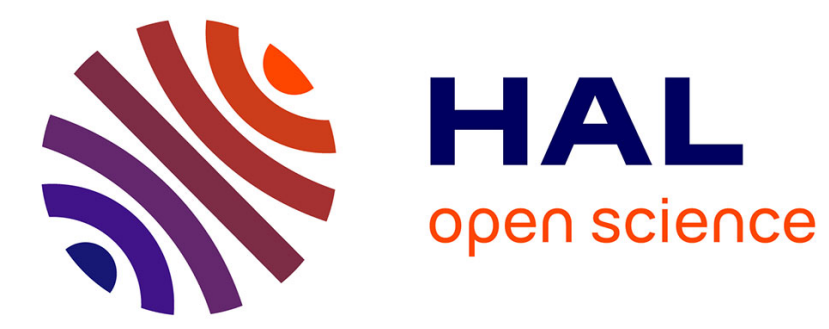

\title{
Les monnaies de Mailhac (Aude) (1931-1977)
}

Odette Taffanel, Jean Taffanel, Jean-Claude Richard

\section{To cite this version:}

Odette Taffanel, Jean Taffanel, Jean-Claude Richard. Les monnaies de Mailhac (Aude) (19311977). Gallia - Fouilles et monuments archéologiques en France métropolitaine, 1979, 37 (1), pp.1-53. 10.3406/galia.1979.1594 . hal-01935497

\section{HAL Id: hal-01935497 https://hal.science/hal-01935497}

Submitted on 4 Feb 2020

HAL is a multi-disciplinary open access archive for the deposit and dissemination of scientific research documents, whether they are published or not. The documents may come from teaching and research institutions in France or abroad, or from public or private research centers.
L'archive ouverte pluridisciplinaire HAL, est destinée au dépôt et à la diffusion de documents scientifiques de niveau recherche, publiés ou non, émanant des établissements d'enseignement et de recherche français ou étrangers, des laboratoires publics ou privés.

\section{(이) $\$$}

Distributed under a Creative Commons Attribution - NonCommercial - NoDerivatives $\mid 4.0$ 


\title{
LES MONNAIES DE MAILHAC (Aude) (1931-1977)
}

\author{
par Odette et Jean TAFFANEL et Jean-Claude RICHARD
}

Mailhac, à $20 \mathrm{~km}$ au nord-ouest de Narbonne et à $8 \mathrm{~km}$ du cours de l'Aurle (fig. 1) est un petit village de vignerons. La vigne occupe la plaine et les flanes des coteaux, la garrigue couvre les terres moins fertiles. La superficie totale de la commune est de 1051 hectares.

De 1931 a 1977, 281 monnaies ont été découvertes : 193 proviennent de fouilles. de sondages ou ont ité ramassées en surface sur l'oppidum du Cayla (nos 1-191, 277, 279), 33 d'autres points du territoire de la commune (nos 192-206, 211-213, 218-227, 232-233, $278,280-281$ ) et 8 de parcelles de terre situées sur des communes voisines : Aigne (Hérault) (nos 207-208), Oupia (Hérault) (nos 209-210) et Bize-Minervois (Aude) (n ${ }^{\text {os }} 228-231$ ). Enfin, 47 monnaies (nos 214-217, 234-276) n'ont pas de provenance précise enregistrée mais ont été découvertes dans le mème espace géographique.

Yous exposerons tout d'ahord les données archéologiques de ces découvertes monétaires et nous étudierons ensuite les diverses séries monétaires qui nous permettront de présenter la circulation monétaire a Mailhac durant l'Antiquite".

\section{A. LES DONNEES ARCHEOLOGIQLES}

\section{Les folillles de h.'Oppidum de: Ciayla ${ }^{1}$.}

Les s1 sondages ou fouilles ouverts sur le Cayla depuis 1931 nous ont permis de délimiter l'étendue de l'oppidum ol d'y reconnaître jo villages superposés. La stratigraphice

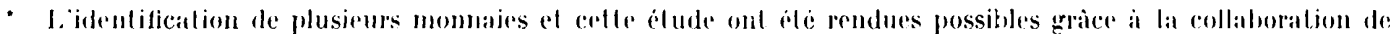
chercheurs ef amis que nous remercions ici : J. Charra, J.-B. Colbert de Beaulieu, (x. Courteaud, fr. Depeyrot, A. Deroc, M. Jhénin auquel nous sommes redevables des fiches de la monnate de Justinien I el de celles de loules Jes mounaies medievales, modernes et contemporaines), J. Hiernard, J. P. C. Kent. I. Villaronga. Ial Idrection régionale des antiquites historiques a bien voulu prende à sa charge les frais de couverture photographique de ce médailler.

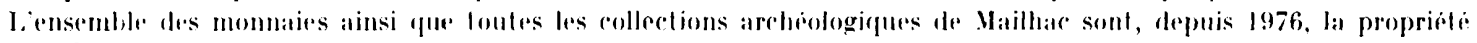
de litilt

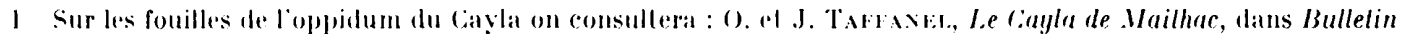
de la soriele a Éludes Scientifiques de l'Aude, 4?, 1938, p. 110-147: Les cirilisalions preromaines dans la région de 


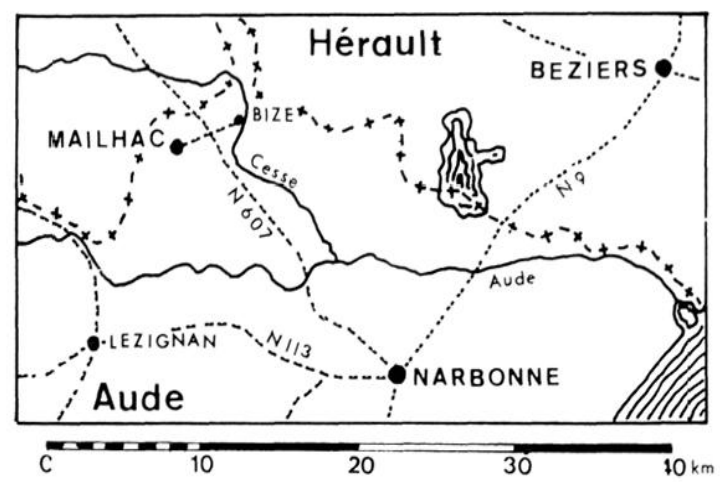

I Siluation de: Inailhac.

n'est débrouillée que dans ses grandes lignes. Chaque ville ayant duré un ou plusieurs siècles, il y a eu forcément de nombreuses variations de détails dans l'intérieur de chaque période. L'ossature calcaire de la colline affleure par endroits, surtout sur la crète. Par contre, les ruines et les détritus se sont accumulés contre le remparl, au point de ramener sensiblement à l'horizontale l'assiette de la cinquième ville, la plus récente. C’est donc au bord du plateau, le long du rempart, que la stratigraphie est la plus nette.

L'idéal serait de pousoir confronter chaque ville avec sa nécropole. Nous ne le pouvons encore que pour le Cayla l, et, en partie, pour te Giayla II.

Pour en revenir à loppidum, nous avons basé cette stratigraphie sur trois fouilles principales : la fouille 40) qui donne la superposition Calyla I, II et III (les niveaux IV et $\mathrm{V} y$ sont fragmentaires ou remaniés). la fouille 2.2, qui donne les niveaux Cayla II, III incendié, IV et $V$, et la fouille 27 qui donne la suceession Cayla I, II, 11 remanié, IV et $V^{2}$. Les petits sondages ont précisé le tracé du rempart et létendue de chaque ville.

Voici les raractéristiques et la chronologie de chaque niveau :

Cayla I. Les vestiges de cette période appartiennent au Bronze final III B (environ 875)-700 ar. J.-(i.).

Cayla II. Dans les ruines incendiées de cette ville apparaissent les premières impor-

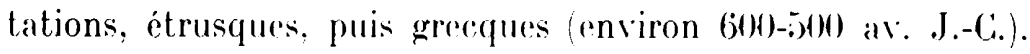

Cayla III. Less ruines de cette ville donnent une abondante céramique attique des ve et rve siècles ar. J.-C. La fin de cette période est assez indécise. Cne étude plus approfondie de la céramique grecque nous incite à la placer maintenant vers 33:) av. J.-(. Le fait que cette ville n'est que partiellement brùlée ne facilite pas les observations. Nous avions d'abord pensé que les vases grees du re s. trouvés dans la ville suivante avaient. éte récuperés dans la partie non détruite du Caỵla III. mais il semble bien que dies la lin

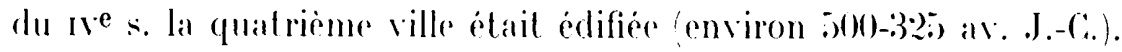

Cayla IV. Cette ville. fortement reltisée. est bâtie. all surl, sur les ruines brulées de

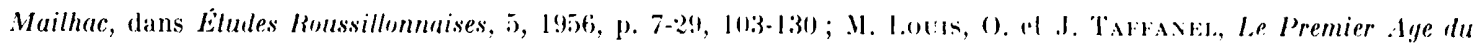

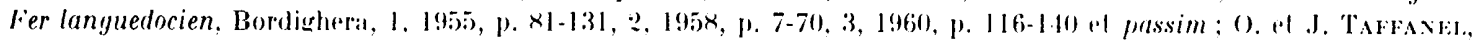
Les epées à spheres du Ciayla, à Mailhac (Aude), dans riallia 25, 1967, p. 1-10.

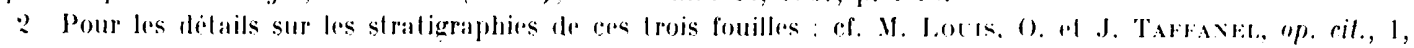
1. $\times 1-131$.
} 


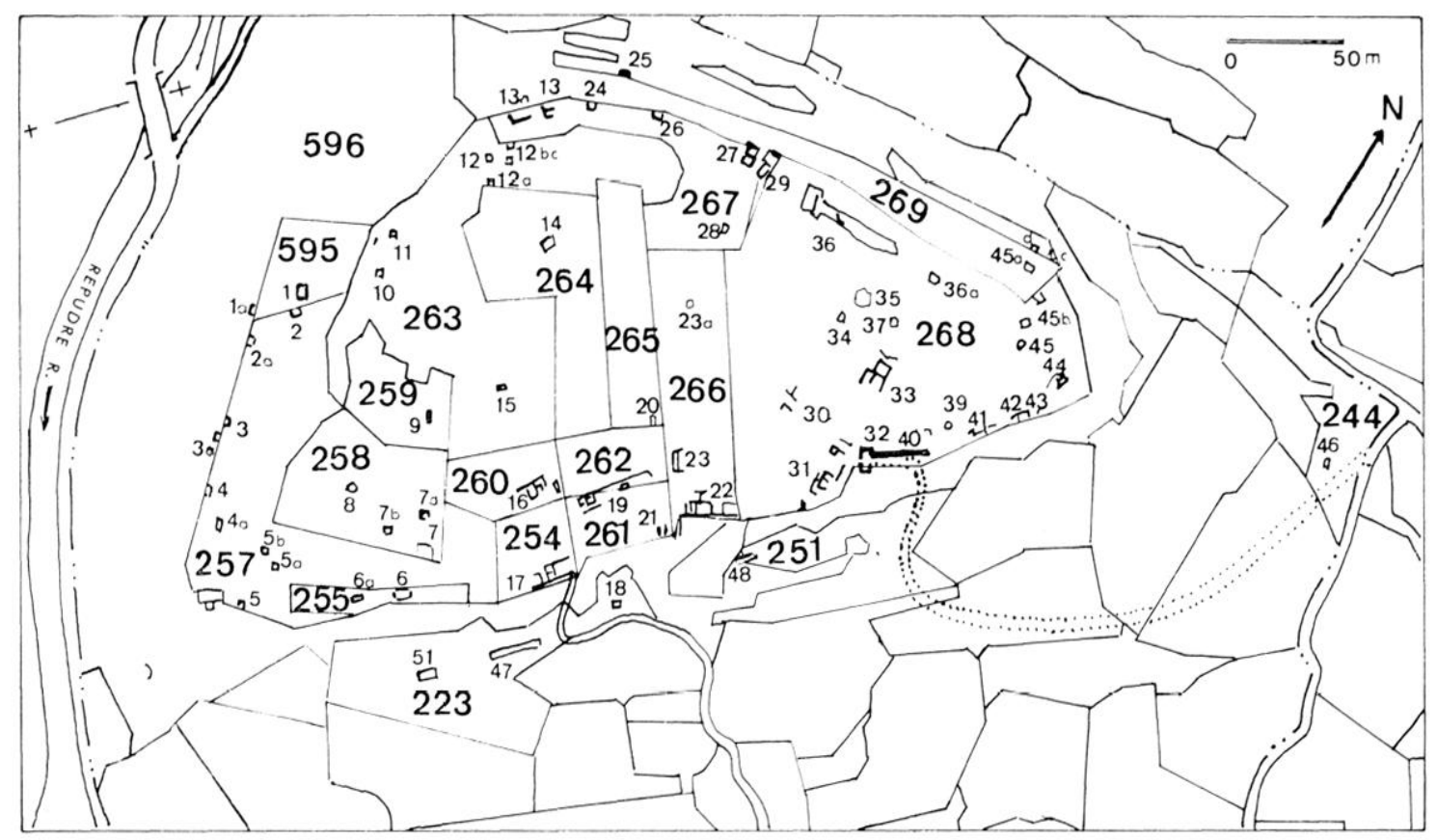

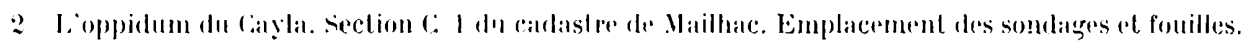

la précédente. Landis gu'au nord les maisons de la troisième ville sont simplement remaniées. Coette ville ast entièrement brùlée, of le rempart est demantelé, vers 7.) al. J.-(:. pensons-nous (3:25)-7i) environ ax. .J.-(i.).

Cayla V. Ciette derniere ville, sans remparts, donne dabondantes céramiques caractéristiques : Arezzo, Graufesenque, sigillée rlaire, etc. Les poteries placeraient l'abandon du site vers la fin du ${ }_{1} \mathrm{e}^{\mathrm{e}}$ siècle de notre ire, mais quelques monnaies semblent dénoter une occupation sporadique plus prolongée (moviron $75+2(0))$.

Xous ne mentionnerons iri que less sondages ou les foulles ayant donno des monnaiers.

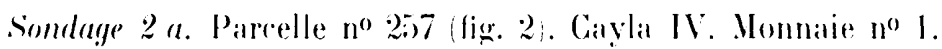

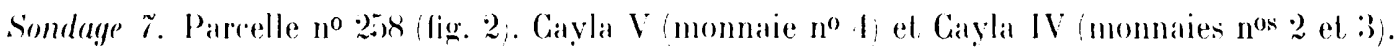

Somdage 12 a. Parcelle $\mathrm{n}^{0} 26$ (6)3 (fig. 2;. Monnaie $\mathrm{n}^{0}$ ) en surface.

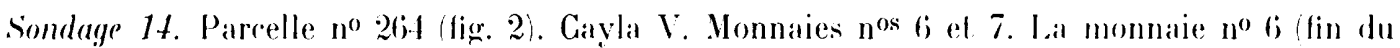

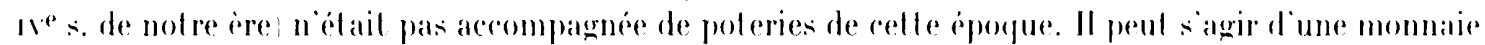
perdue elle itait dans la courbe de terre arable el re sondage a donne a $11.10 \mathrm{~m}$ de profondeur un morreau de fer à cheval. ce qui dénote un remaniement.

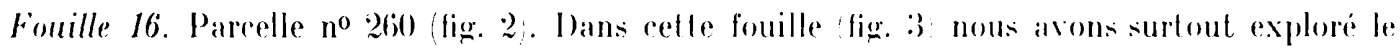
Cayla V. Les monnaies nos 8 i 17 proviennent de cel horizon. La monnaie $n^{\circ} 14$ et ait sous une sorte d'autel fait de tuiles a rebord ${ }^{3}$.

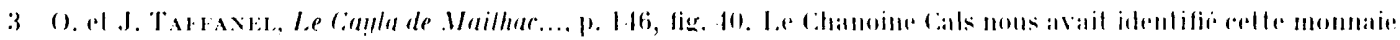
comme mente momale de Caligula. 


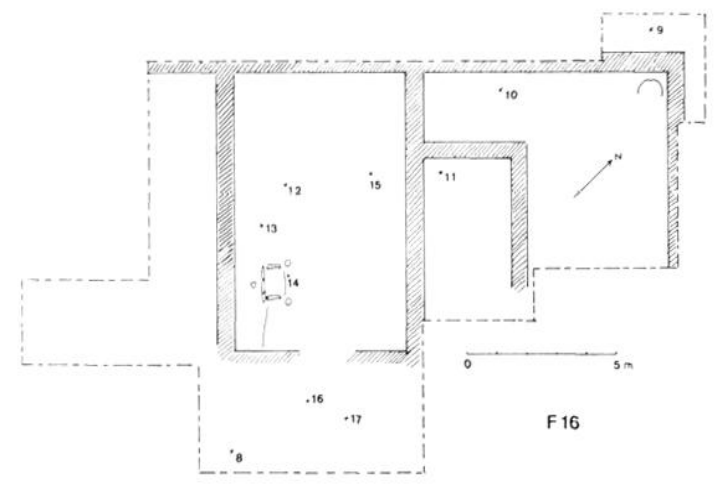

3 Fonilla lif (a) lata

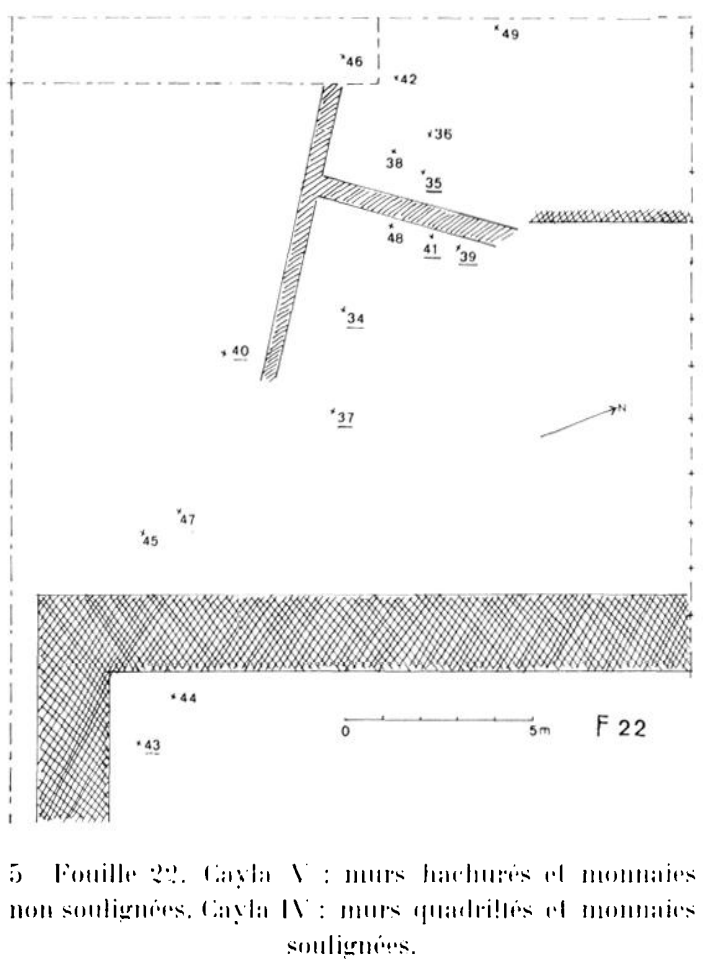

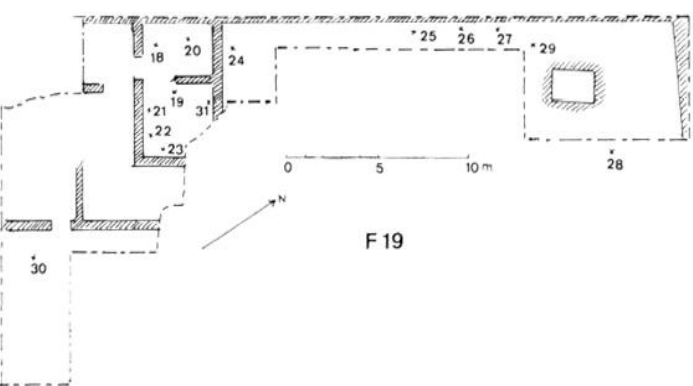

1 Finill, 19. Cisyla V.

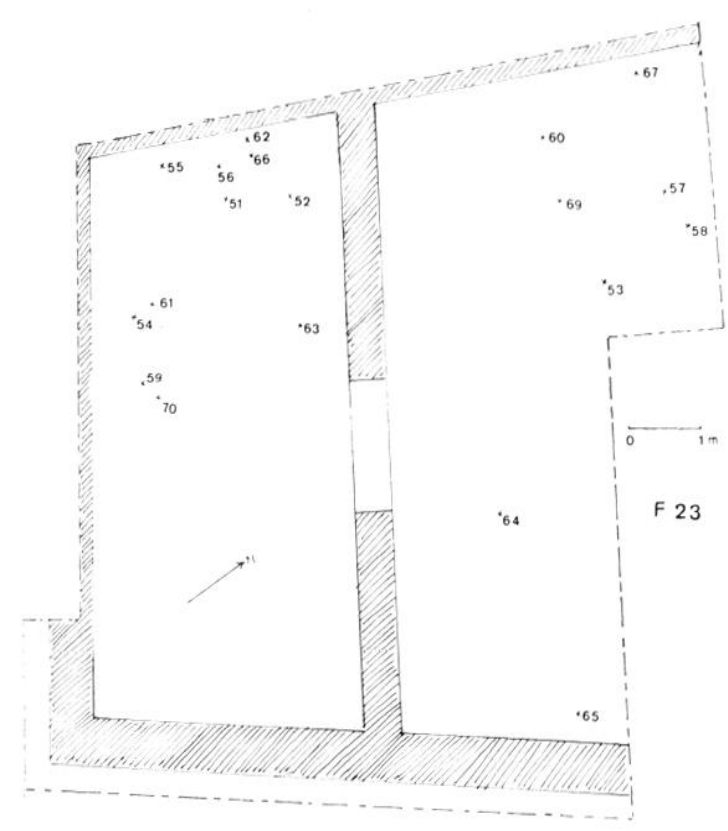

(i Fonill, :3. (aivla l.

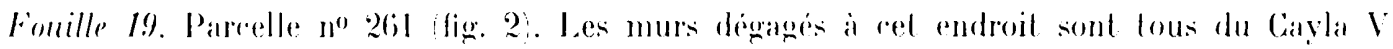
(fig. 4: Comme le sous-sol rocheux n'est pas tris has dans re secleur, les vestiges des périodes précedentes n'y sont guire représentes et ne sont pas en place. Nomnaies nos 18 a 31 .

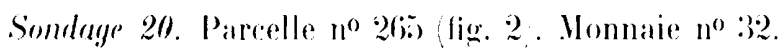

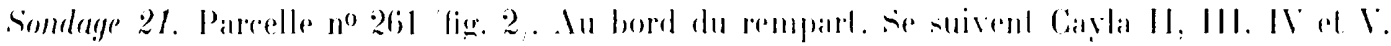

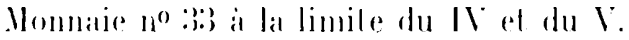

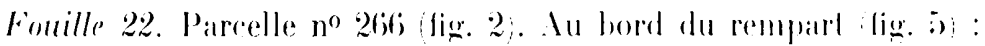

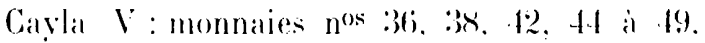

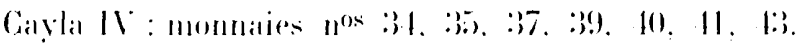

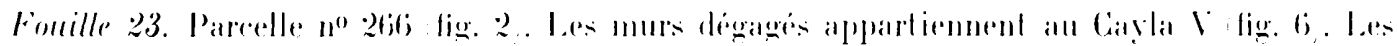

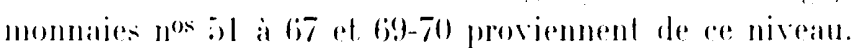



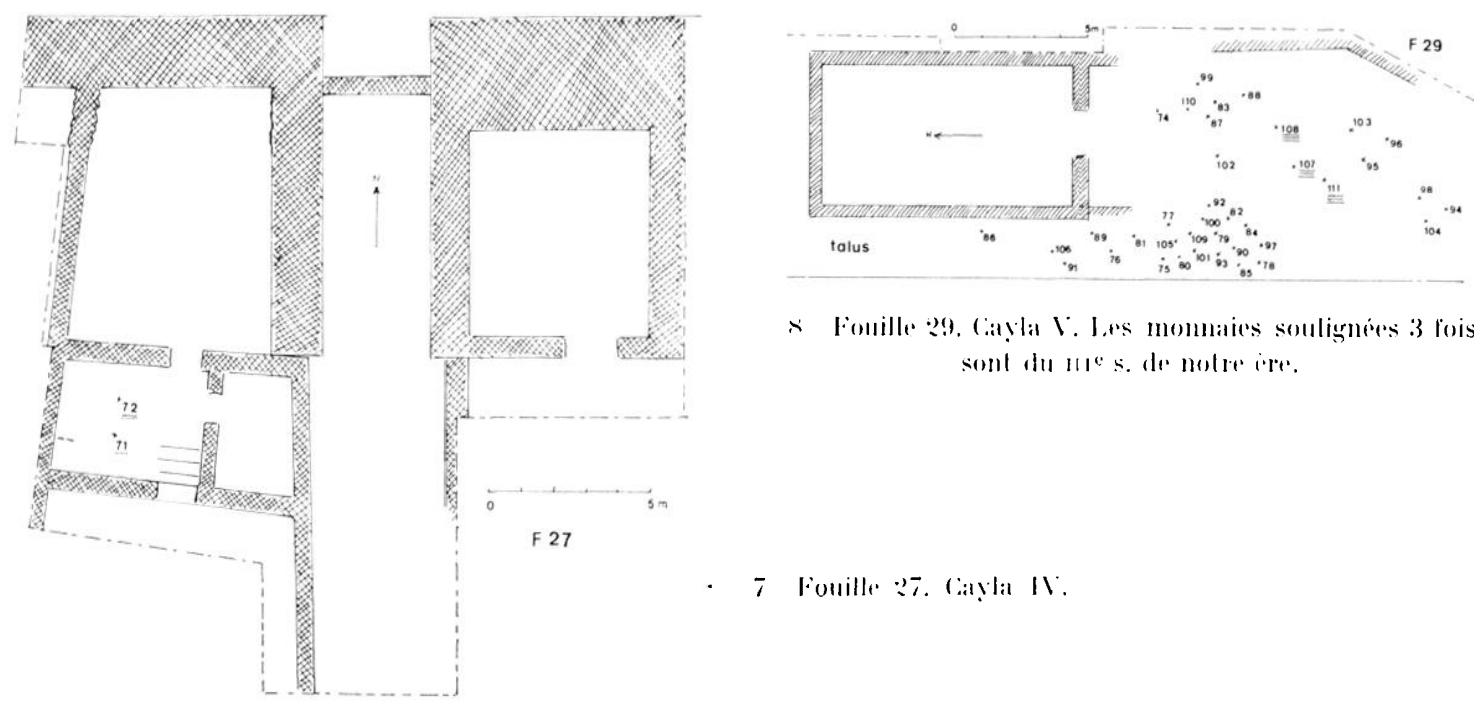

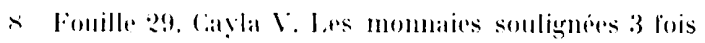
sont du Has. de molere ine.

7 Fonille :?. lavia 11.

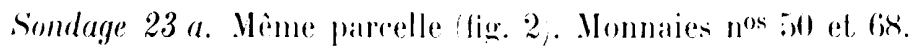

Fonille 27. Parcelle $n^{0} 267$ fig. 2. A cel endroit. une porle d'entrée du Cayla ll a alé murée au temps du Cayla IV, el une des lours remanié lig. 7 . La monnaie no 71 elait dans le niveau IV, mais la monnaie no 72 est trouvée plus has, dans le plancher d'argile hallue de cetle piece.

Sondage 28. Parcelle no 267 (lig. 2). Amorce d'un mur. Nonnaie no $7: 3$.

Fonille 29. Parcelle no 268 (fig. 2). Ciest le prolongement vers le sud de la fouille 27. I cet, endroit, le champ n० 268 surplombe de $1,50 \mathrm{~m}$ le champ no 267 . la fouille 29 est juste au bord et c'est dans le talus que nous avons trouve la plupart des monnaies (lig. 8). I'ensemble des trouvailles et des constructions appartiennent au Cayla V. La coupe du talus a donné des vestiges des niveaux II, IIJ et IV. mais ils se prolongent sous la construction du Caỵla V el il faudrait détruire cette dernicre pour les fouiller.

Presque toules res monnaies appartiennent a l'horizon Cayla V. Quelques-unes pourraient chronologiquement alre abtribueses au Cayla IV, mais le glissement des terres sur la pente n’a pas permis de faire des observations précises. Ionnaies nos 7.4 a 111 . el 277 trouves en surface. I.es monnaies 107,108 et 111, trouvées dans le mime secteur la 111 en surface) sont neltement plus

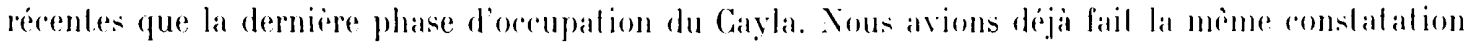

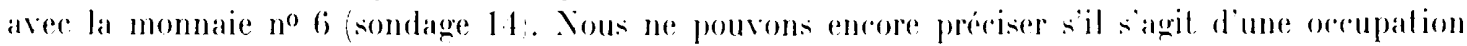
sporadique prolongée ou diune réoccupation parlielle du site.

Fonille 30. Parcelle no 268 (fig. 2). Cetle fouille étant siluée vers la ligne de faite de la colline, le niveau archéologique y est peu épais (0,30 m. I.es murs el la plupart des vestiges appartiennent au Cayla V (lig. 9), mais il a été impossible d’identifier d'autres niveaux. a part quelques lambeaux de Cayla II dans less areux du rocher. Mommies nos 112 a 125.

Fonille 31. Parcelle no 268 (fig. 2 . dans le lalus qui surmonle le champ no 2i)l, a l'emplacement presume du rempart dig. 10. Ies vestiges de murs en pierres serehes des niveans III-IV et V sy

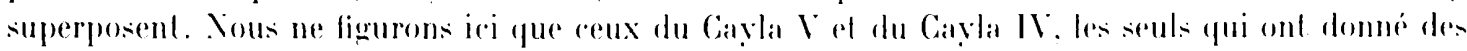
monnaies :

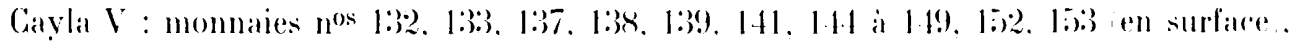

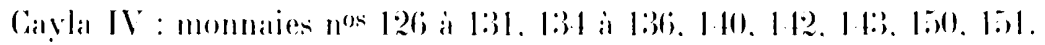

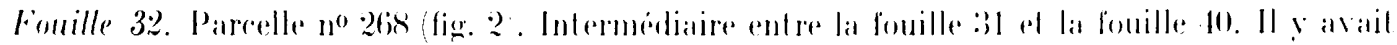
la une porte d'entrée, d'abord probablement de la deuxieme ef de la lroisieme ville. puis sans aurum 

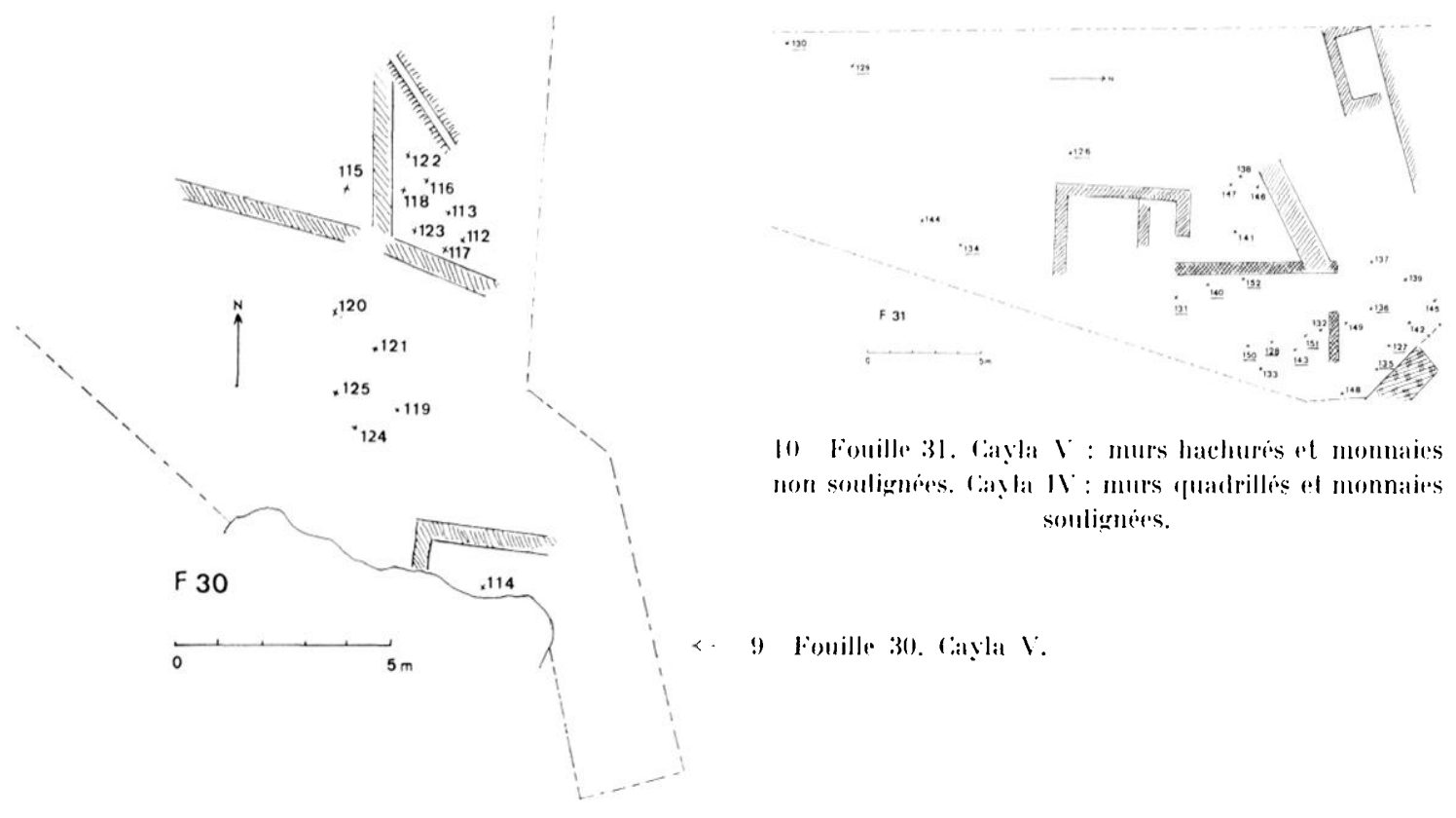

10) Fonille 31. Cayla $V$ : murs hachures et monnaies

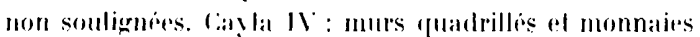
sonlienne's.

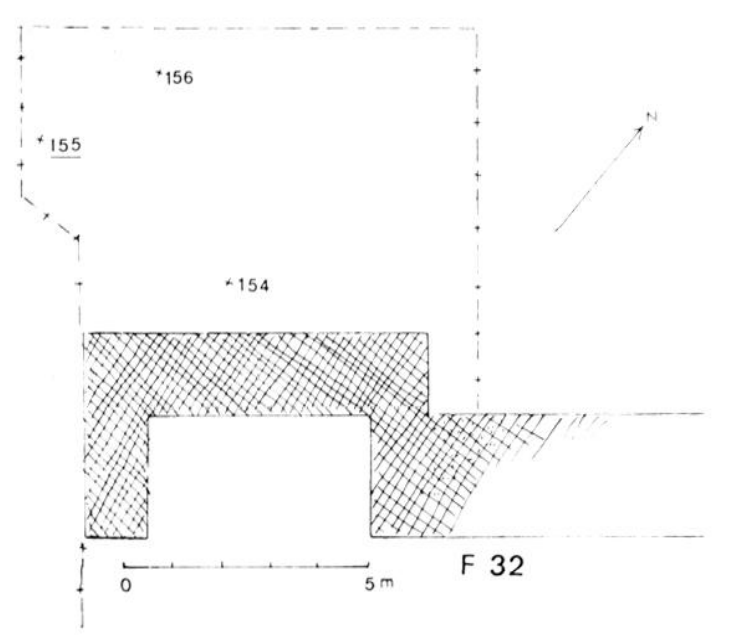

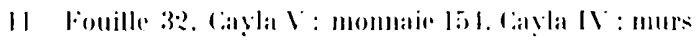

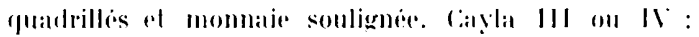
monnair lisf.

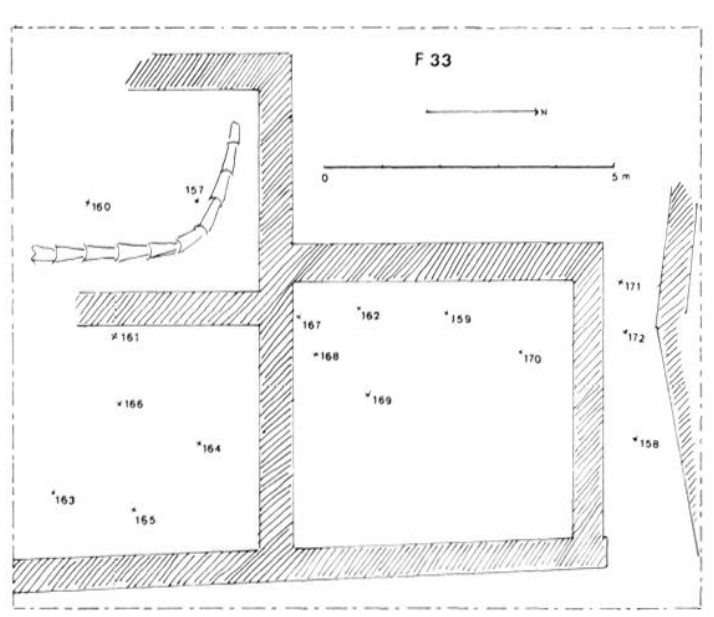

I: Fonille 33. Cayla l.

doule de la qualrieme. Ipres te démantiement du remparl. le passage complibement obstrue a

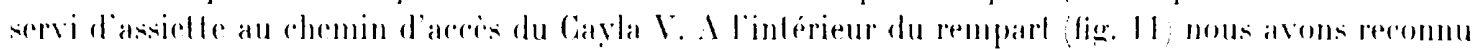
le nivean III. le IV remanie el le 1 :

Gialal V: momnaie no lis.

Ciayla IV: monnaie no lisis.

Cayla III ? : monnaie no loxi. Il y avail a proximits de cette monnaie des lessons altiques du ves. mais les couches archeologiques blaienl peu depasses a cel endroit el on ne peut pats exclure la possibilite de remaniements dus a la proximile de constructions du Cayla $V$ b.

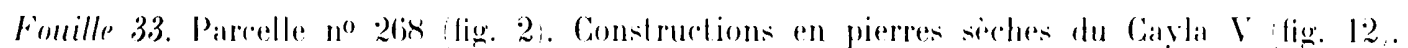
Ciralesenque of Irezo abondanls. Ionnaies nos 157 a 172. 


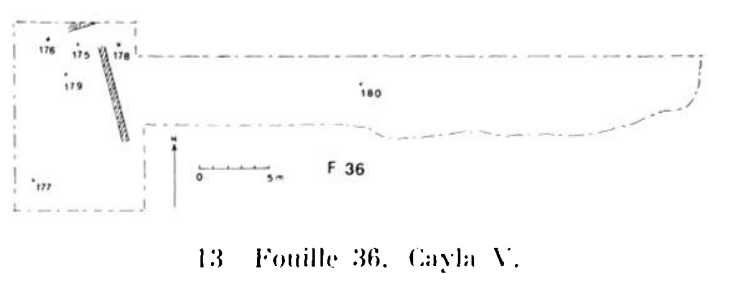

14 Fonilles 39 puits al 40. Cayla V: murs hachures al

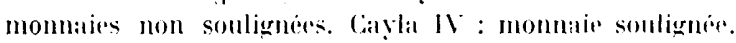
Cayla IIJ : murs pointilles at monnate somlignóne ? fois. bans le cercle, monnaie moderne?

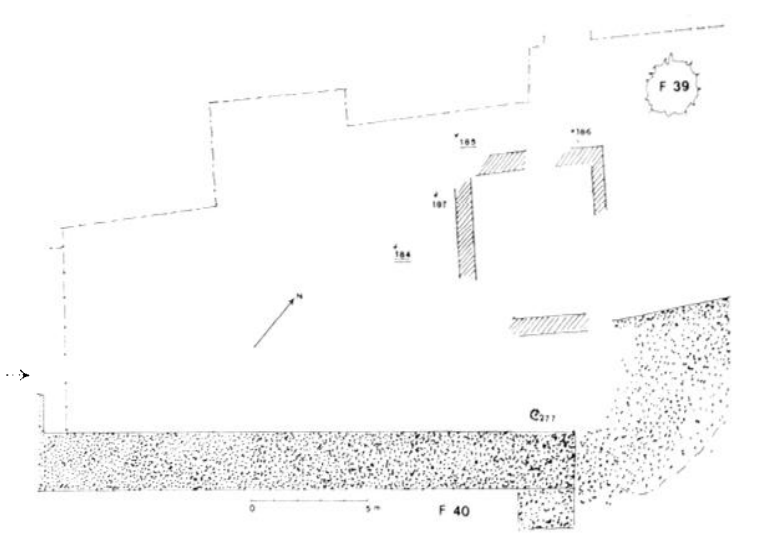

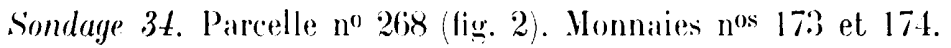

fomilles 36. Parcelle $\mathrm{n}^{0} 26 \mathrm{~s}$ (iig. 2). Importants niveatux I et II, surmontés par une couche Cayla V. Les niveaux III el, IV ont pratiquement disparu à l'endroil louillé. Cayla V : monnaies $n^{\text {os }} 17 \%$ ) is 180 (fig. $1: 3$;.

Sondage 37. Parcelle $n^{0} 268$ (fig. 2). Cayla IV (?) et V. Monnaie no 181 .

Fonille 39. Parcelle no 268 (fig. 2). Remplissage d'un puits creusé en plein roc el comblé arant, l'apparition de la poterie d'Arez:o. Pas de strationaphie. Monnaies nos 182 el 18:3.

Fouille 40. Parcelle n 06 (fig. 2), au bord du rempart (figr. 14). Importants niveaux Cayla I, Il et IIJ. Le IV et le V ont en grande partie servi a combler le puits (fonille :39). Remaniement, moderne: monnaie n $^{0} 279$ (a 0,90 m de profondeur, probablement perdue dans un trou creusé pour planter ou arracher un arbre) :

Cayla V : monnaies $\mathrm{n}^{\mathrm{os}} 1866-187$.

Cayla IV : monnaie no 185 ,

Cayla III : monnaie $\mathrm{n}^{0} 184$. A cel endroil la couche était bien caractérisée, fortement cendreuse, et renfermait ave beaucoup d'autres céramiques de nombreux tessons attiques des re et $1 \mathrm{r}^{\mathrm{e}} \mathrm{s}$. is. J.-C.

Sondage 46. Parcelle $n^{0} 244$ (fig. 2). Gayla V. Honnaie no 188.

Fomille t7. Parcelle no 22:3 (lig. 2). Ravine sous le rempart, comble apris le démantidement, du Cayla IV, en 7.$)$ av. J.-C. vraisemblablement ${ }^{4}$. Le comblement a été ensuite recouvert par un niveau Cayla $V$, qui a donné la monnaie ${ }^{0}$ 190. La monnaie ${ }^{0} 189$ étail un peu plus bas.

Sondage 51 . Parcelle no 22:3 (fig. 2). Tranchée ouverte dans un talus, sous le rempart. Vestiges mòlés des niveaux II, III, IV et V (remblai moderne destiné à redresser lat surface de cette partie de lit parcelle no 223 au moment de son exploitation par l'agriculture). Monnaie no 191.

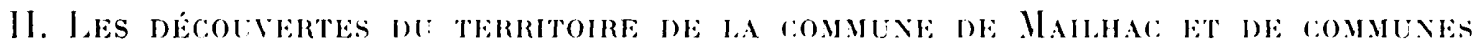 roIsines.}

Les monnaies suivantes ont eté soit trowreses on fouille hors de l'oppidum du Cayla soit ramassées en surface dans des pareelles connues.

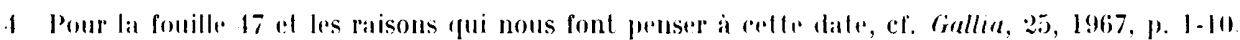




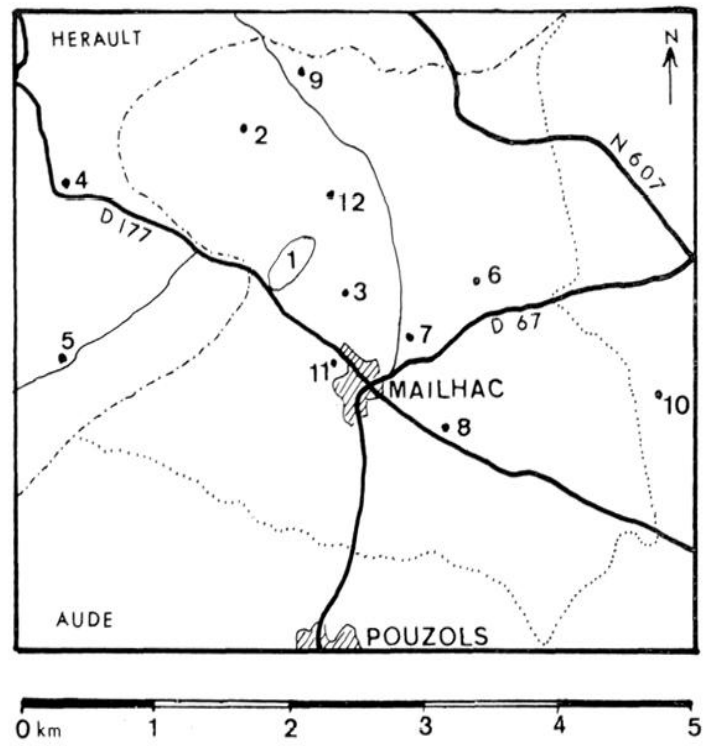

1.)

limiles div rommmumes, limile de departements. 1 la Cayla monnaies 1 a 191 . 2 Camberaut mon-

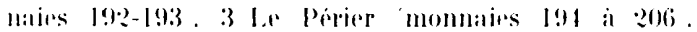

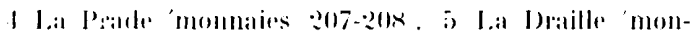

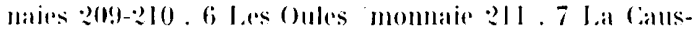

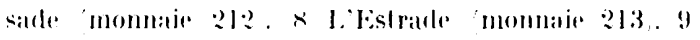

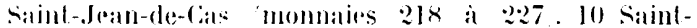
Martin monnates es a 231 . 11 Moulin de Repular

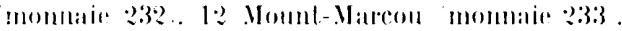

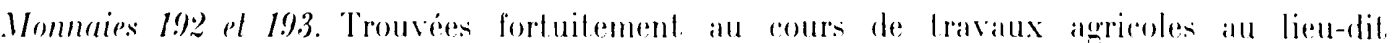

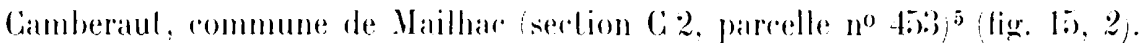

Monnaies 19t a 206. Trouves dans une fouille de sauretage apres defongage, avec un abondant mobilier céramique oi les poteries de la liraufesenque sont abondantes6, au lieu-dil le Périer, commune de Mailhac (section 11 , parcelle no 3 ) (lig. 15), 3).

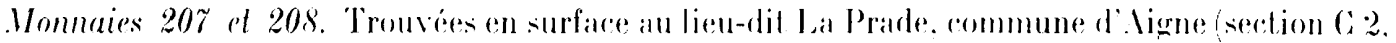

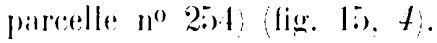

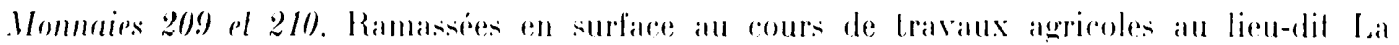
Draille, commune doupia (section .1. parrelle no lof; fig. lij, jj.

Monnaie 211. Trouve en surface au lieu-dil Les Oules, rommune de Mailhac (section B:3, parcelle $n^{\circ}$ ), 90 ! (lig. 15), 6, a proximite des vestiges d une villa gallo-romaine.

Momnaie 212. Trouvée au cours de fouilles de sauvelage, au lieu-dit la Caussarle, commune de Maillac (section C 1, parrelle no 191) (fig. 15, 7$)^{7}$.

Monnaie 213. Trouvée en surface apres défoncage. au lieu-dit L'Estrade, commune de Mailhar: (section B2, parelle no 318 (fig. 15, 8). II y avait a cet endroit de nombreux vestiges d'une importante villa gallo-romane, au bord d'un ancien chemin dit "Ghemin de Narbonne".

Monnaie 218. Trouvée au lien-dit saint-Jean-de-Cats, commune de Mailhac section B 1. parcelle no 912 (fig. 15), 9), alu cours d'une fouille de sauvetage qui a donne de nombreux vestiges gallo-romains 8 .

Monnaies 279 à 226 . Trouvées en fouilles dans la chapelle de saint-Jean-de-Cas, commune

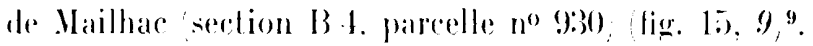

Monnaie 22\%. Ramassee an cours d'un défongrage au lieu-dit siant-Jean-de-Cats, commune de Iailhas: section B 4, parcelle no 929: fig. 15), 9j.

5 liapport cir lonilles 1971.

i) Lapport de fonilles logi.

7 Rapporl ale fonilles lagk, p. 1.

a liapport cie lomilles latis.

a Rapport de fonilles lais. 

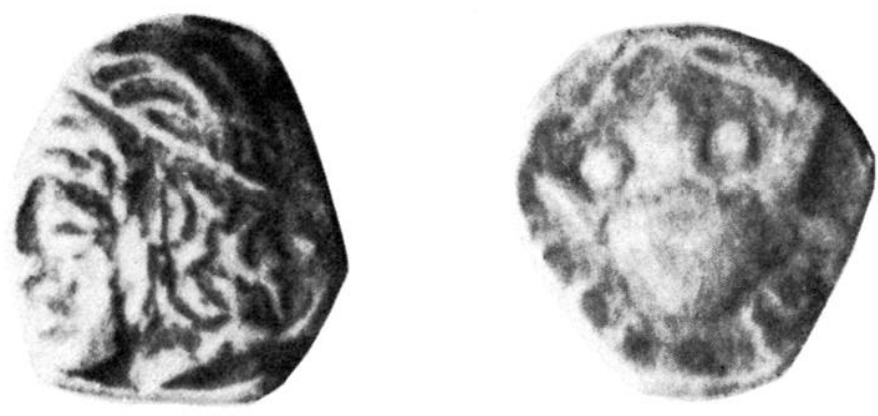

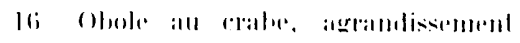

$1 \therefore 1$

Monnaies 228 a 231. Trouvées en fouille dans la rhapelle de silint-Marlin. rommune de Bize-.linervois (seclion I), parcelle no 94) (fig. 15), 10 .

Monnaie 232. Ramassée en surface au lieu-dit Ioulin de Répudre, rommune de Mailhac (section 11 , parcelle $\mathrm{n}^{\circ} 471$ ) (fig. 15, 11).

Momnaie 233. Trourée par .H. H. Martin. sous la dalle d'un dolmento au lieu-dit Mount-.lareon, commune de Mailhac (section G 1, parcelle no $7: 3$ (lig. 15), 12).

Les monnaies 214 a 217 et 231 à 276 , comme nous l'avons déjá indiqué, proviennent du lerribire de la commune y rompris loppidum du Giala et de terres des communes voisines mais il n'est plus possible aujourd'hui d'en donner les provenances précises"

\section{B. - LES DONAEES NEMISMATIQEES}

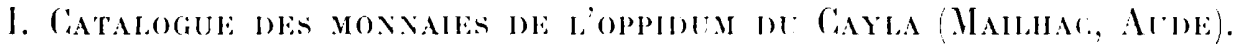

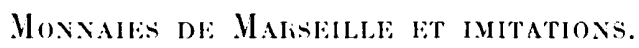

A. (obole au crabe (fig. 16 et fig. 20$)$.

1) Tate léminine Artémis? a gauche, les cheveux retenus par une bandelelte. R Crabe vu de dos, sans légende (l'étroitesse du than ne permet pas de savoir si le coin comportait la leltre. . qui figure sur cerlains exemplaires:

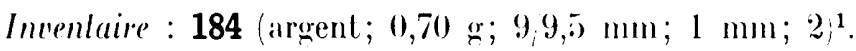

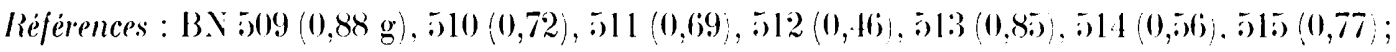
I.T, pl. II, 5l(1)-511, Ls, p. 10, nos (j-10 et pl. I. 6, 7, , 10; . IBT, p. 226-227;2 H. Rolland, Considé-

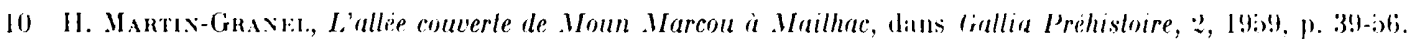

11 Les monnaies 21.1 a 217 pourraient provenir de loppidum du Cayla qui a ble longtrmps cultive : il y eut de la vigne jusqu'en loxij puis des luzernes.

1 Nous donnons, entre parentheses, a la suite de chardue numero d'inventaire qui correspond an numero de l’illustration - et dans loordre: le meilal, s’il s’agit d’argent. le poids, en grammes snivi, le cas échéant, pour les monnaies coupees, de l’indication de la partie restanle : 1/2, 1/1.., fe module et lepaisseur du flan, en millimetres, la direction des coins, en chiffes du cadran horaire. Si l'exemplair presente une particularite ou un complement par rapport a la description générale de la série, nous lajoutons an dernirre place.

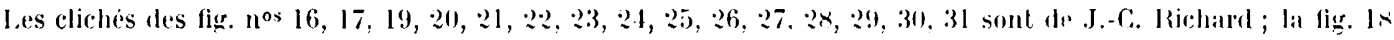
ist un cliche de la Bibliothirpue nationale.

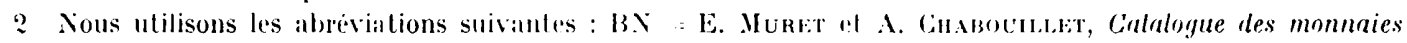

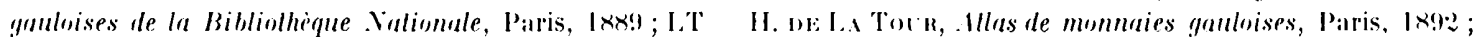


ralions sur deux oboles de Marseille, dans Revue Numismatique, fe série, 38, 19:35, p. xxu-xxı;

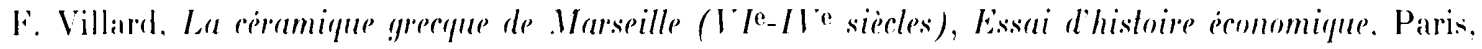

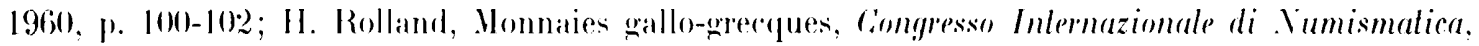
Roma 1961, I, Rome, 1961, p. 112; F. Salviat, Les monnaies de Marseille grec(que. dans Archoologia, 1978, n० 120, p. 6-2:) (avec 1. 12 la photographie d'un exemplaire du Cabinet des Médailles de Marseille - . J. Laugier, Les monnaies massalioles du Cabinet des Médailles de Marseille, Marseille,

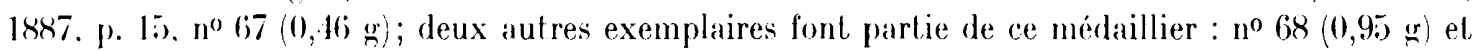
$n^{\circ}$ (i9) (0,9:) $\%$, qui sont dessinés pl. IV, 67, (78, (69). Pour une vue d'ensemble sur les monnayages de Marseille : V. Clavel-Lévèque, Marseille grecque, la dynamique d'un impérialisme marchand. Marseille. 1977, p. 41-4:3, 95-10:3.

La datation proposee par H. Rolland et F. Villard est le deuxieme quart du ve siecle av. .J.-C. L'exemplaire de Mailhace provient de la fouille 10 el du niveau Cayla III (5)(00-325) av. J.-C... II convient de remarquer que l'exemplaire de Mailhac n'a pas d'équivalent pour la lète du droit dans les monnaies acluellement publiées.

Les découvertes recensées se répartissaient sur la rive gauche du thòne et en lispagne: Glanum saint-Rémy-rle-Provence. Bourhes-du-Rhone, cing exemplaires ${ }^{4}$, Caraillon (Vaucluse, deux exemplaires. Robion (Vaucluse, un exemplairej, (Olloules (Var, un exemplaireb) el Morella fprovince de Castellon, un exemplaire au moinsi, Pont de Molins (province de Gerona, plusieurs) et Tarragone (deux exemplaires. L'exemplaire de Nailhace entre Rhone el Pyrénés, complete donce celle répartition.

B. ()boles a la roue (fig. 20).

I) Tole d'Apollon a gaurhe. R: Inoms les cantons d'une roue : II I (A posside une barre Iransicersale droile).

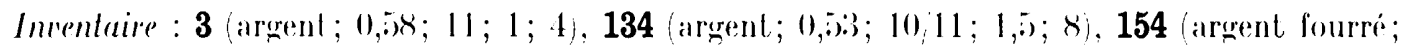
$1,11^{8} ; 11 ; 2 ; 1$; la lite est i droite), 185 (aront; 0,$\left.72 ; 1112 ; 1 ; 9\right)$.

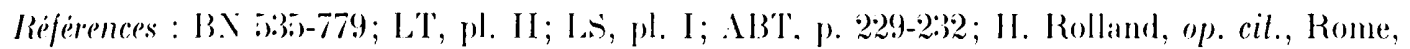

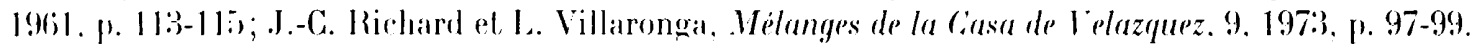

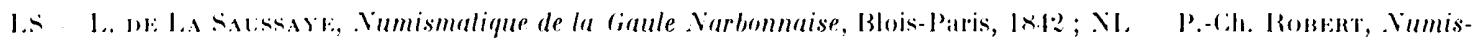

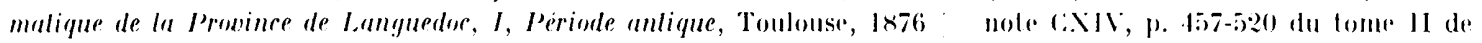

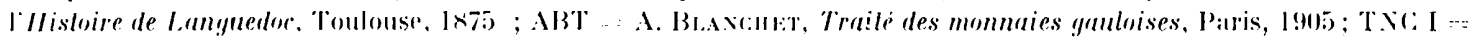

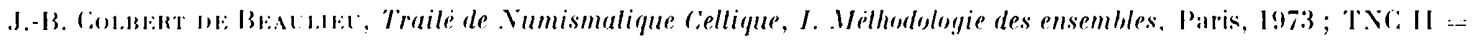

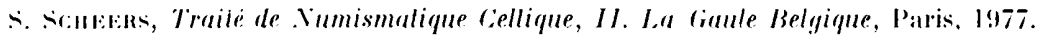

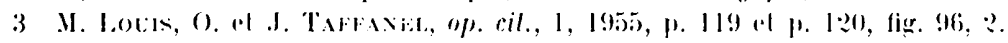

4 Qualre exemplaires ont ele publies par le Marquis de Iagoy toescriplion de quelques medailles inedites de

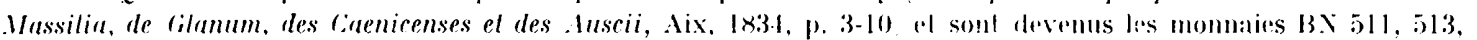
\$l,

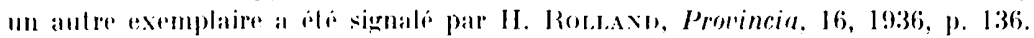

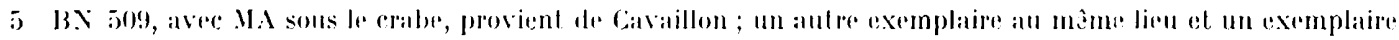

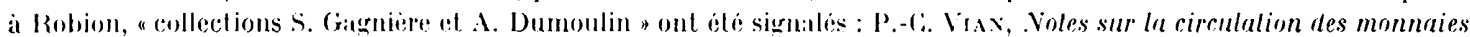

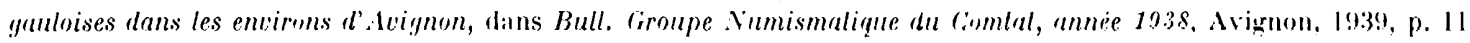

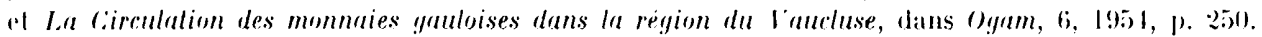

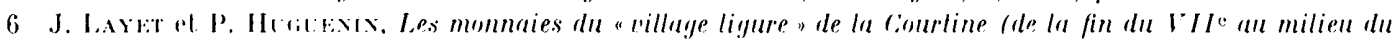

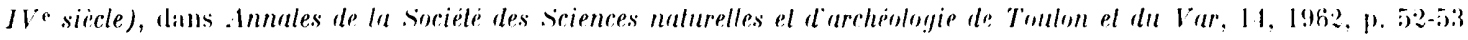
(avec II all revers.

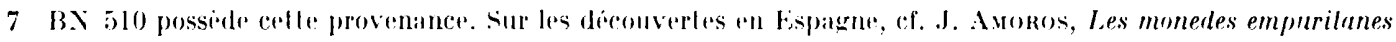

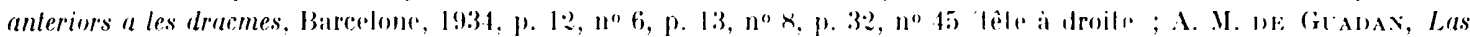
monedas de plala de Emporion !f Rhode, dans Anales y Bolelin de lis Museos de drle de Barcelonn, 12, 1955 -1956,

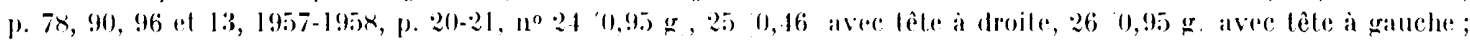

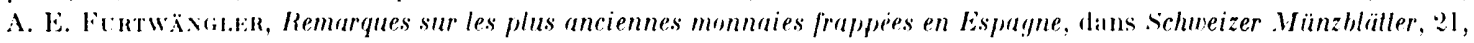
1971, p. 13-21 lonl de Molins, p. 14 ; Morellit, p. 15.

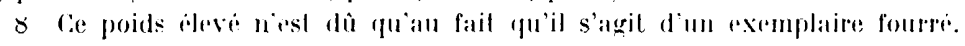



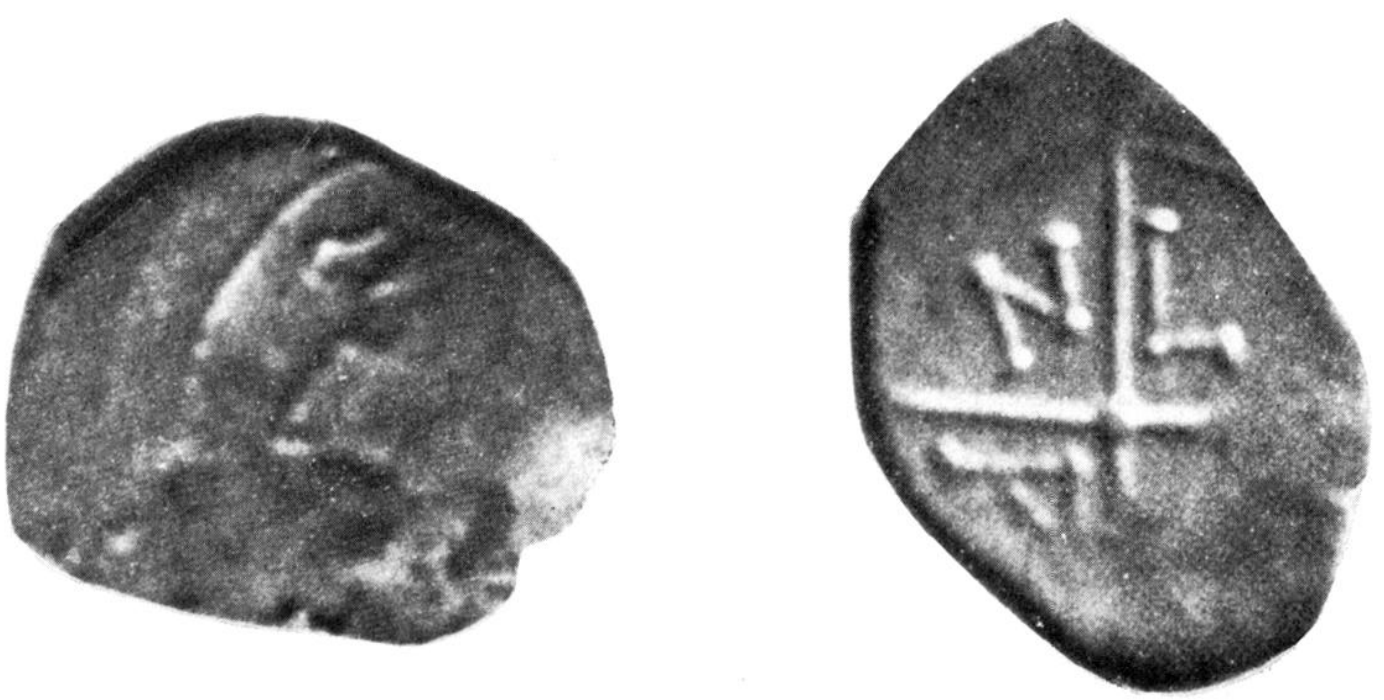

17 Inomair a ligende ANLAXI', agrandissement $5 \times 1$.

Les émissions d'oboles a la roue aver la légende. Il I se siluent entre la seconde moitié du re siecle et le $\mathrm{a}^{\mathrm{er}}$ siecle av. J.-G. I.es exemplaires nos 3 , 1:34, 185) proviennent du niveau Gayla IV (325-75) av. J.-C.) el 15) du niveau Cayla V (75) as. J.-C.-200 ap. J.-G.:.

Cous rattacherions aux divisions massalictes, sans pouroir préciser, l'exemplaire suivant, qui présente, au droit, une tète à droite et, au revers, une porlion de grènelis. L'excentration du droit et l'étal du revers nous conduisent à presenter celle allribution avec réserve.

Invenlaire : 181 (argent; $), 72 ; 8,9 ; 2 ; ?)$.

Cette monnaie provient des niveaux Cayla IV (?) et V.

C. Imilation a légende AXI. AXP des oboles de Marseille (fig. 17 et fig. 20 ).

1) Thte masculine imberbe a gauche, dans un grenetis. R/ I)ans les cantons d'une roue a

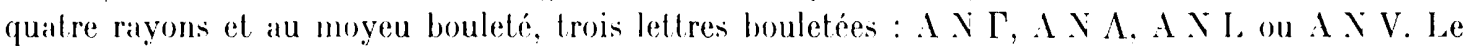
quatrieme canton est vierge.

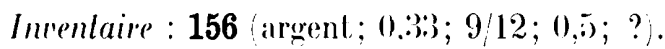

Réferences: 13X 26.5; Marquis de Iagoy, Altribution d'une nouvelle médaille aux Anatilii peuple silué aux Bourhes-du-Rhòne, dans Rerne Vumismatique, 1re série, 12, 1847, p. 397-400; F. de sauley, Iettres a V. A. de Iongpérier sur la numismalique gauloise, XXIV, Monnaies des Petrocorii, d'Apta Julia, de Nemausus el diverses incertaines, dans Revue Numismalique, $2^{e}$ série. 11, 1866;, p. 402-416, ici p. 415; 1.-C. Goudard, Monographie des monnaies frappées à Vìmes depuis le cinquième siècle alanl motre ère jusqu'à Lonis XII, Toulouse, 1893. p. 26; E. Desjardins, Géographie historique el administraliue de la (iaule romaine, 2, Paris, 1878. p. 80); 1BT p. 11 et 2:39; H. Rolland, Attributions fantaisistes de quelques monnaies de la Gaule méridionale, dans Ogam, 7, 195), p. 403410, ici p. 403-404; (i. Barruol, Les peuples preromains du Sul-list de la Ciaule, étude de géographie. historique. Paris, 1975, p. 2113, a propos du peuple des Anatilii; M. Dhénin, Nouvelle lecture d'une obole au lype massaliele : une hypothese sur son attribution, dans Bulletin de la Societe Française de Vumismalique, 32, 1977. p. 247-250 avec les pholographies des exemplaires BN 2645) et Mailhac 1:)6).

L élablissement de la légende a été rendu posisible par la confrontation de cet exemplaire aver celui du Cabinet des Médailles de Paris lig. 18. s'il s'agissail d'une inscription laline il faudrait 


\section{Illustration non autorisée à la diffusion}

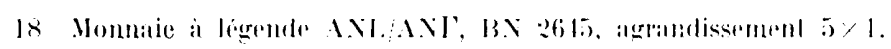
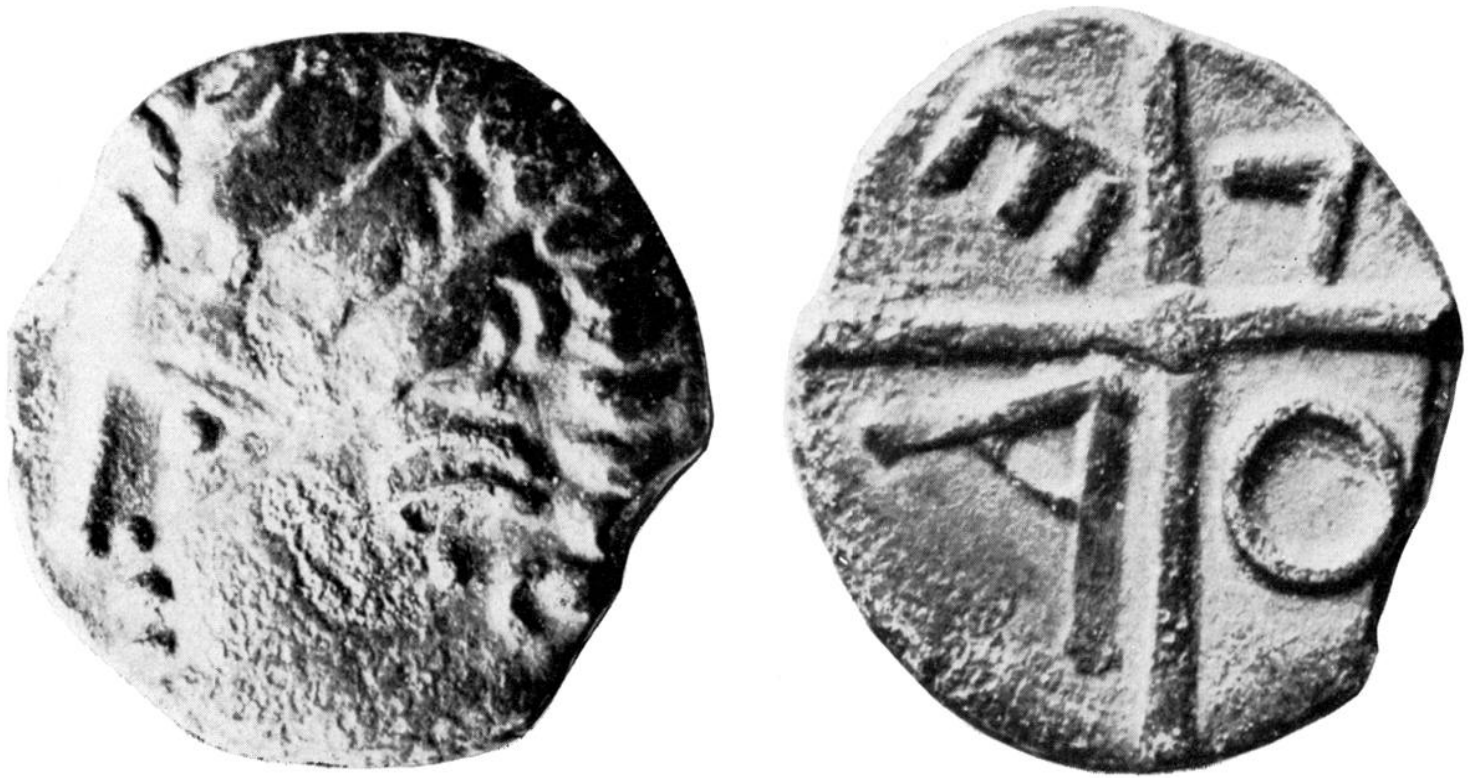

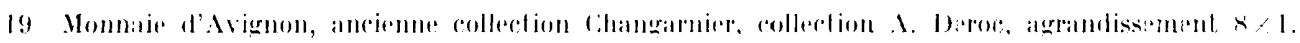

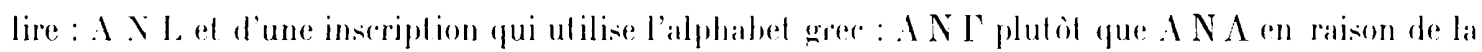
disparite des deux branches de la derniere letlre (cette lenture qui se fail dans le sens des aiguilles d'une montre, doit rétablir le 5 qui es gravé a l'envers : il sagirait d'une erreur du graveur qui n’aurail pas gravé cette lettre en miroir sur le coin . sur les deux exemplaires dont, nous disposons, le quatrième canton est vierge : il neest pas impossible, si l'on en juge par la faible ćpaisseur des llans et par les excentrations, que ce canton ait pu contenir une let tre ou un meuble el nous devons, nous semble-t-il, réserver la possibilité d'un nouvel exemplaire qui, bien centré et bien frappé sur ses deux faces, règlerait définitivement la question.

Il est en tout cas exclu de pouvoir maintenant relier cette légende qui avail bé lue au

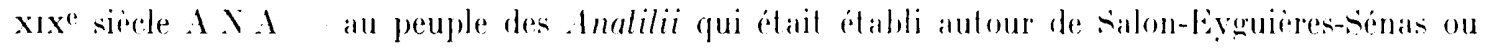
autour de siant-Rémy-de-Provence !Bouches-du-Khòne..

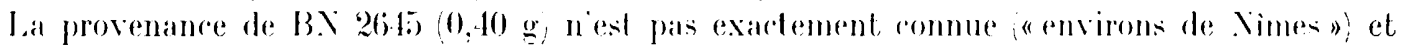


la carte de répartition, réduile arluellement a deux lieux distants de plus de $100 \mathrm{~km}$, n'est d'aucun

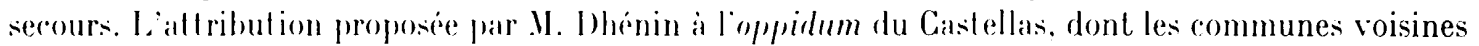
de Sages (Gard el Janglade (Bard auraient pu conserver le nom sous les formes lnagia et Anglata, reste problémalique car ces formes datent du Ioven Ige; de plus aucune mention littéraire ou épigraphique sur place ne permel de retrouver le nom romain ou préromain du site et, enfin, le médaillier de cel oppirlum ne contient aucune monnaie de ce lype. Enfin nous ne savons pas si relle légende fail référence à un lieu, un homme ou à un peuple.

La datalion archéologique pose aussi un probleme : relte monnaie a elé découverte dans la fouille 3:2, au niveau du Cayla 1 II (5)(1)-325) av. J.-C. mais le peu d'épaisseur des couches archéologiques a cet endroit ef leventualite de remaniements dus au niveau Gayla $V$ entrainent une large réserve sur une dalation ancienne.

Il convient, dautre parl, de rappeler les séries méridionales, imilées des oboles de Marseille

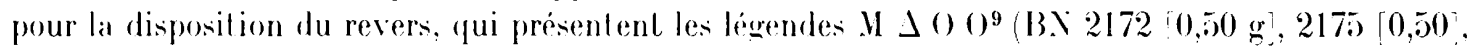
21760,51 i . II A et les deux autres cantons réunis occupés par une tite d'animal de face (BX $2176-1$

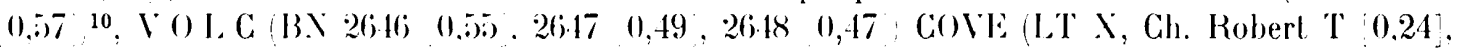

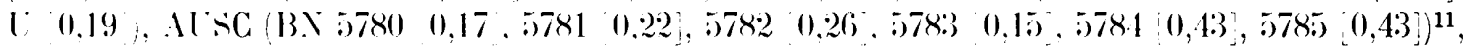

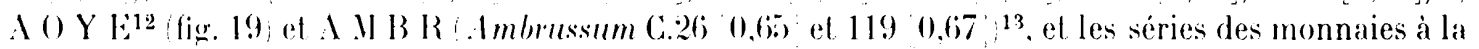

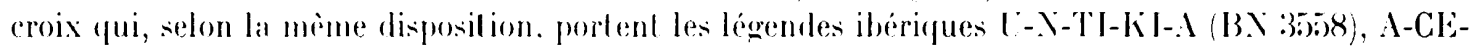

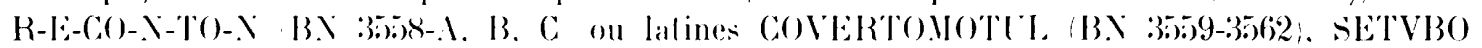

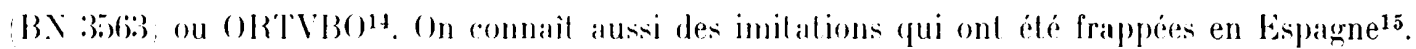

sans qu il soit posible de présenter une élude metrologique complète, nous remarquons que la plupart des imitalions de lobole de Varseille sont de poids inférieur au poids théorique de l'obole

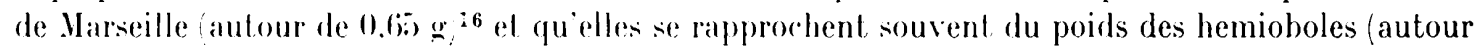
de 0.3010 .

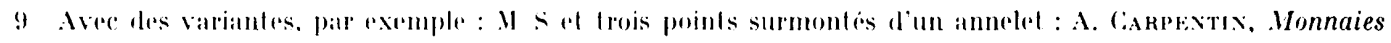

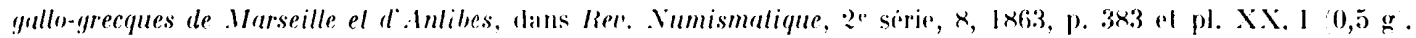

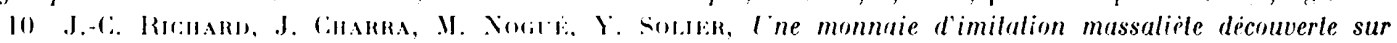

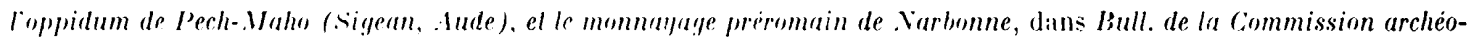

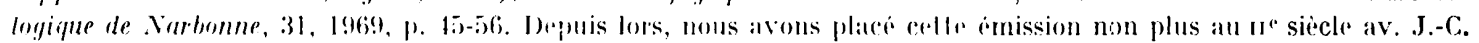

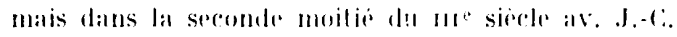

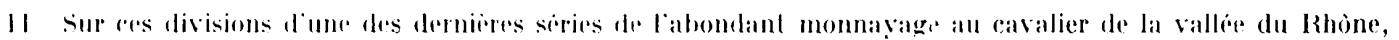

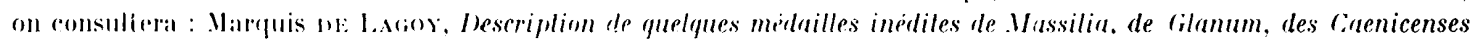

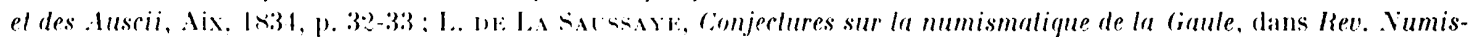

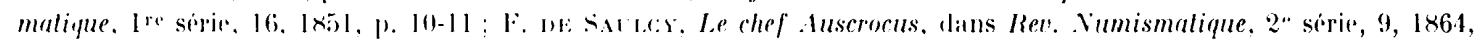

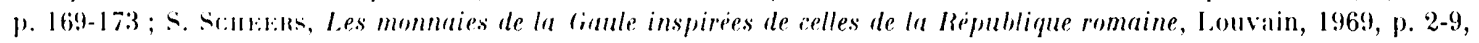

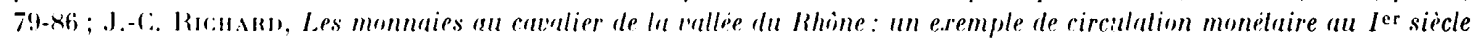

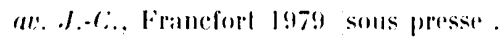

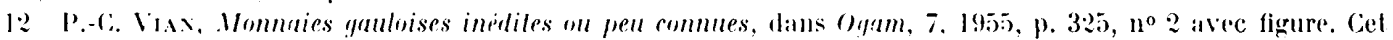

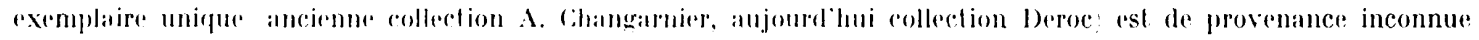

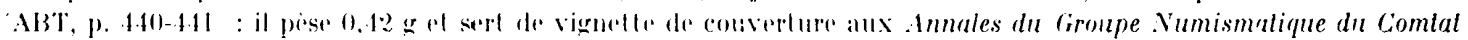

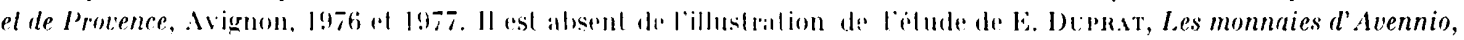

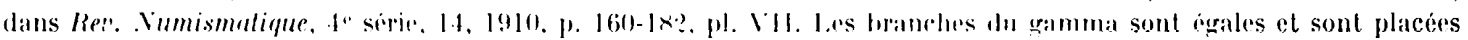
perpendiculaimement and rayous de la roure.

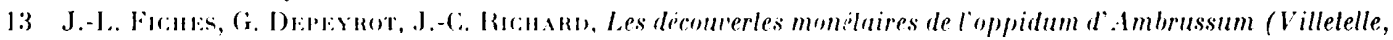

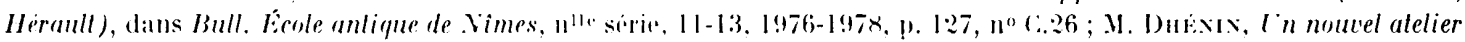

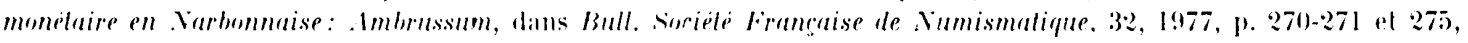
fig. A.

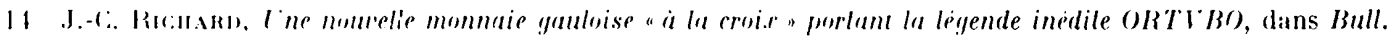
Sinciele francaise de Numismalique, :27, $1972 ., 15.151-152$.

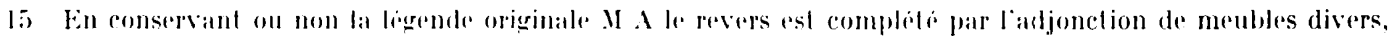

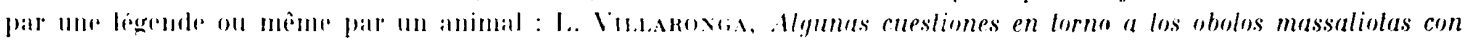
reverso rueda, dans Vumisma. XIV.69, 1961, 11. 25-34.

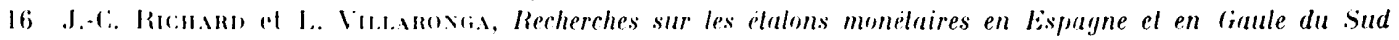

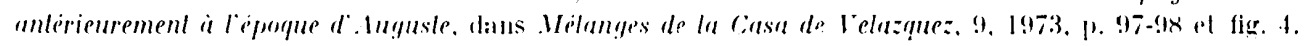




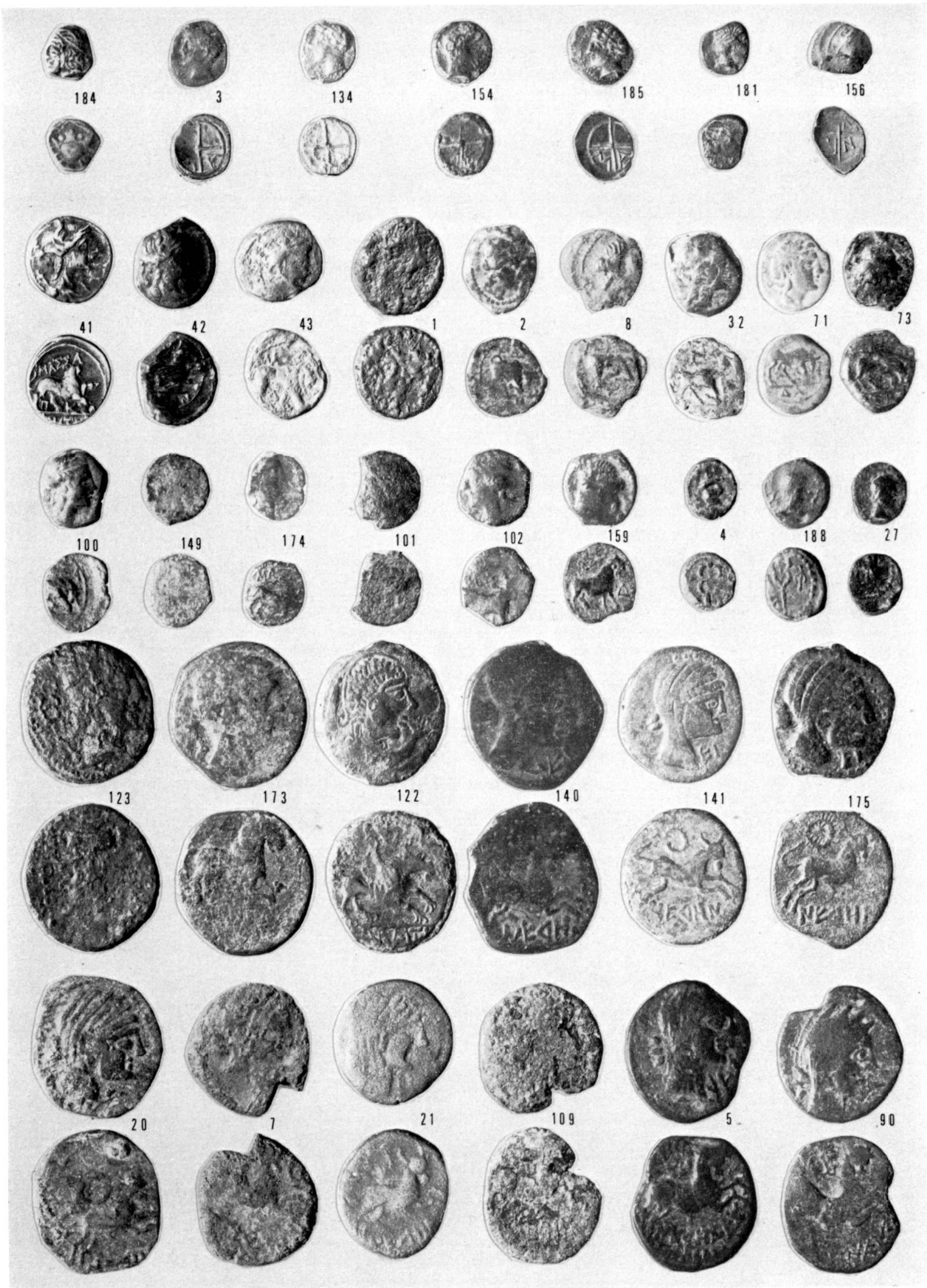

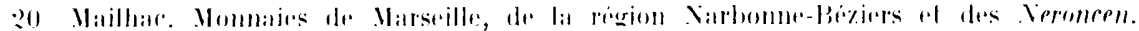




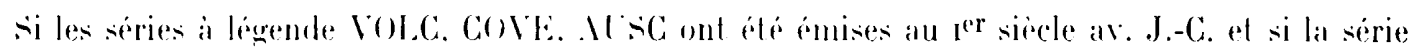

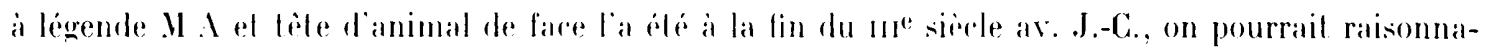

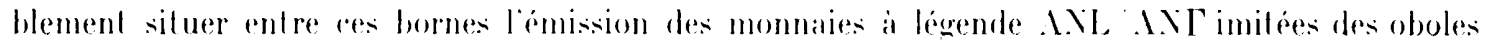
de llarseille.

I). Irarlimes tig. 201).

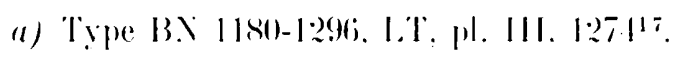

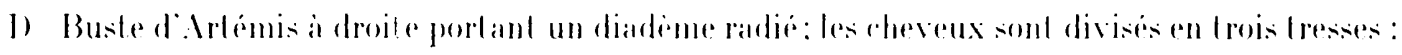

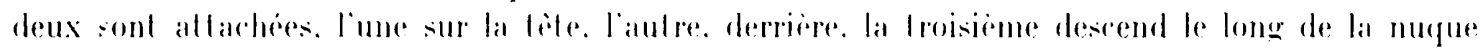

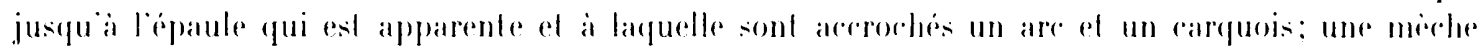
de rheveux marque la joue; au rou. un collier de perles. a l'oreille un pendant. R l.ion a droile.

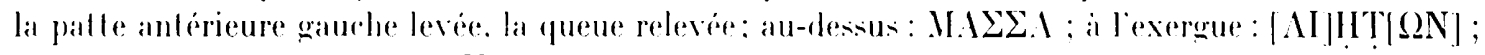
entre les palles de derriere: II. sous le ventre: K.

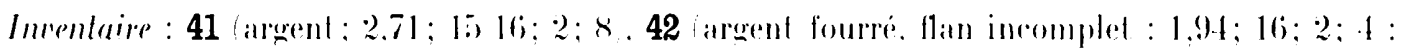

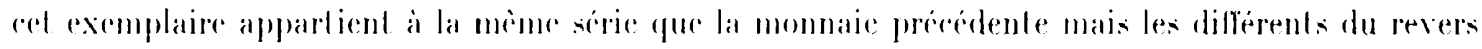
ne sont pas ici reconnaisiables: il a recu deux roups de burin qui en ont reduit le llan: .

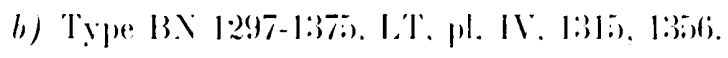

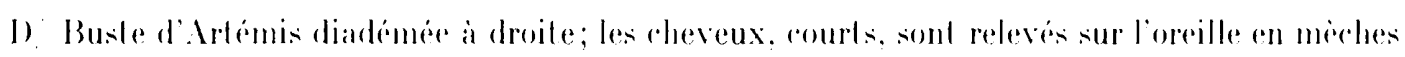
bouclese are el rarquois; collier et pendant d'oreille. In monogramme, qui napparail pas ici,

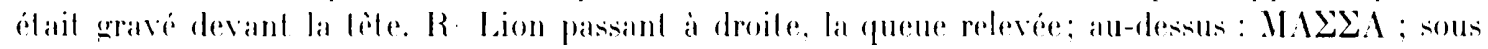
le ventre: $\Delta$; exeroue hors llan.

Imentaire : 43 (argent; 2,5); $1116 ; 2 ; \vdots$.

Xous ajouterons une qualriome drachme qui a probablement subi l'artion du feu et qui laisse

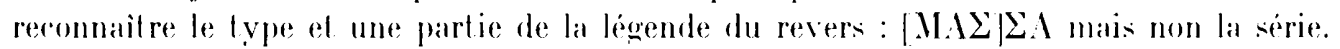

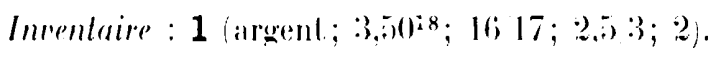

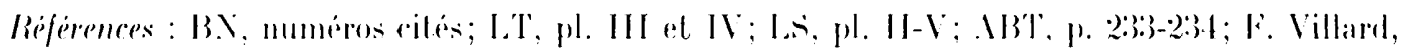

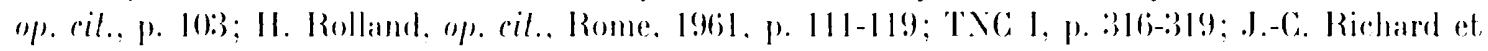

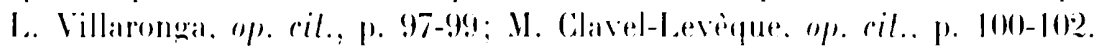

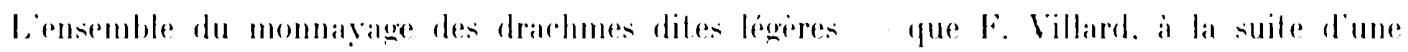

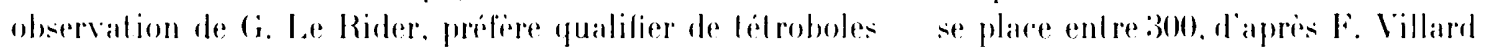

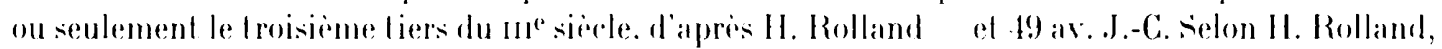

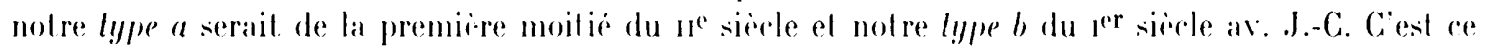

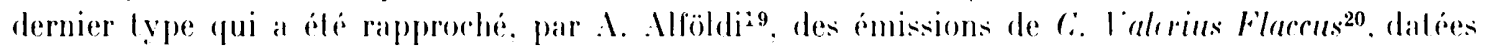
des années 80 as. J.-C.. dont il serait contemporain.

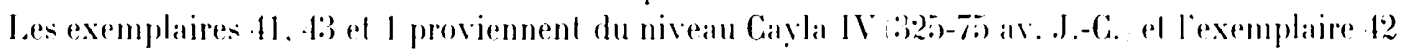

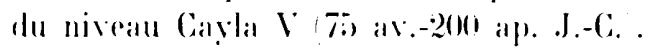

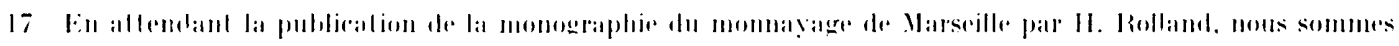

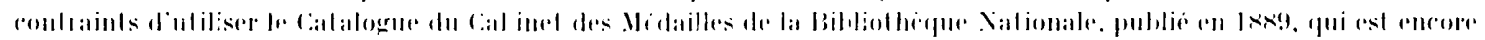

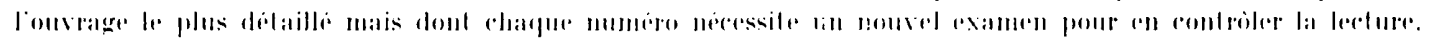

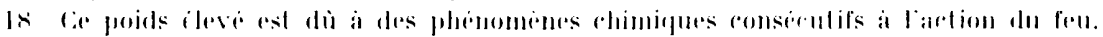

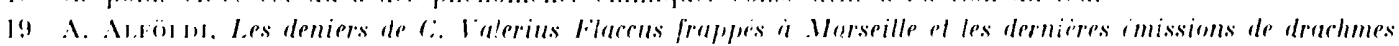

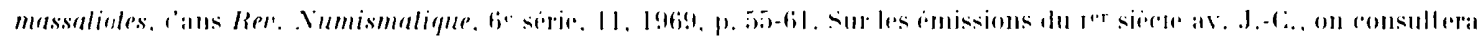

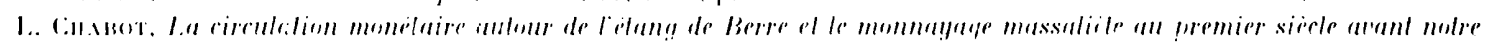

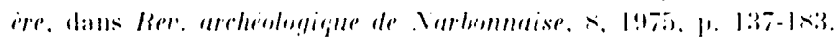

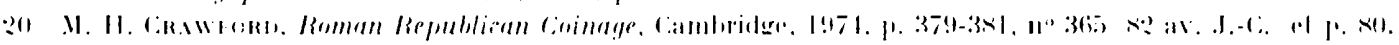




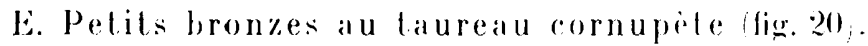

1) Tète d'Apollon à droile. $R$ Taureau cornupite a droile; au-dessus : MAZZA, a l'exeraue, suite de la lécrende du dessus : $\Lambda$ IHT $\Omega N$ ou. plus fréquemment. lettres de série.

Inventaire: $2(2,03 ; 13) 15 ; 2,5 ; 2 ;$ a l'exerque, deux barres verticales : ...ll (?) 8 (léger manque : 1,$53 ; 14 / 15 ; 2 ; 12 ;$ exergue fruste), 32 (2.:34;1415;2;9; exergue fruste), 71 (1.71;13) 14;2;1;

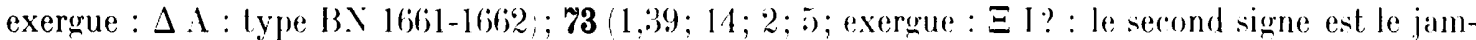

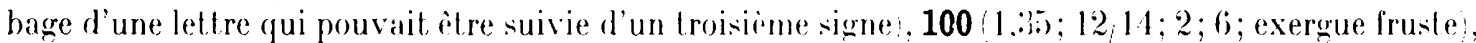

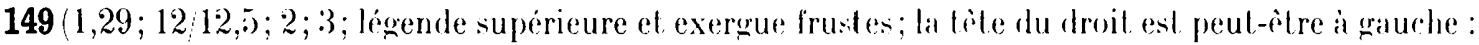
l'état de cet exemplaire ne permet pas de savoir s'il s'anil d'une émission véritablement massaliete. ou d'une imitation), $174(1,39 ; 11 ; 2 ; 11 ;$ exerque fruste).

Références : BXN 1603-1881; I.T. pl. IV. 1673; Is. pl. VI-VIII; ABT, p. 2:36; H. Rolland, op. cit., p. 116; J.-C. Richard et I. Villaronga, op. cil. p. 12:3-124 : imissions des ne et I siercles av. J.-C.

Les exemplaires $8,100,149$ proviennent du niveau Caỵla $V(7)$ ax.-201) ap. J.-C. . 2 et 71 du niveau Gayla IV (325-75) et32.73. 174 n ont pas été recueillis dans une couche bien individualisée.

F. Pelils bronzes a laureau passant (fig. 2!).

I) Tôte d'Apollon a gauche. R Taureau pasianl a droile: an-desisu : $11 \Lambda 22 \Lambda$, devanl et à l'exergue, éventuellement, lettres de série.

Inventaire : 101 (incomplet : 1,$11 ; 13) 14 ; 2 ; 6), 102(1,24 ; 1: 14 ; 1,5 ; 7), 159(1.77 ; 13 ; 14 ; 2 ; 7$; devant le taureau : $\Delta$; a l'exeroue : II... (?): type I3X 195)-1956;.

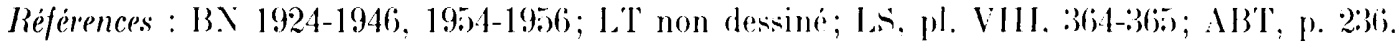

Cette série est attribuée traditionnellement a Varseile et elle est datée du fer siere ar. J.-C. ${ }^{23}$.

Les exemplaires 101 et 102 viennent du niveau Cayla V fplutot que IV et lexemplaire lis? du mème niveau (7) av-200 ap. J.-C.).

G. Petits bron\%es au caduróe (lig. 20) .

1) Tête asquée a droite (les exemplaires bien frappes onl, devant la lite, la légende MAL ou M:LC. R Jans un grinetis, caducee; de part ef diatre, eventuellement, lettres.

Inentaire : $4(1.5): 10 ; 2.53 ; 1.188(2.87 ; 11.512 ; 1: 11$; a droile du carduce : $\Phi$, en bats, a gauche, leltre (A?) peut-etre surmontée d'une troisiome lellre?

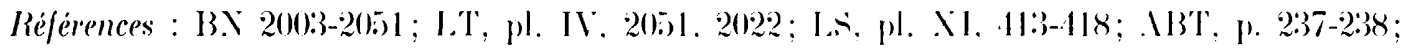
J.-G. Richard el I. Villaronga, op. cil., p. 12:3-124.

Ces monnaies ont élé émises au ger siocle ar. J.-C. et il n'est pas impossible qu elles soient postérieures au siege de Marseille par César. A Mailhar. elles proviemment du niveau Caỵla V(7:) av.200 ap. J.-G.).

H. Petit bronze au lion (?) (fig. 20 :

I) Tète casquée à droile. R l)ans un grinetis, animal (lion?, à droile; a l'exergue : ....X (?).

Imenlaire: $24(1,4) ; 11 ; 2.3 ; 3$.

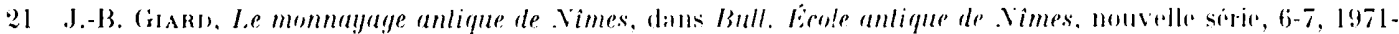

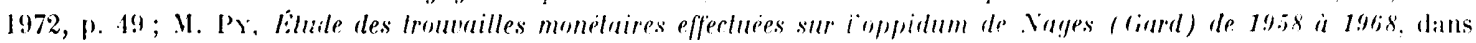

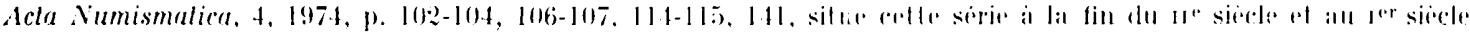

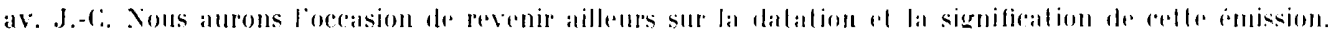




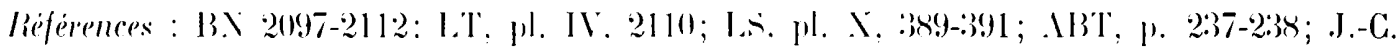
Richard et I. Villaronga, op. cil. p. 12:3-124.

Sous arons clasife cette monnate parmi les petits bronzes au lion bien que son état el l'excentration du revers rendent laall ribution difficile. Cette serie appartient à la mime époque d'émission que la serie précédente. I Vailhac, elle provient aussi du nivea Caỵla V (75) av.-200 ap. J.-C.).

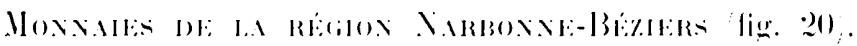

1. I. Ingostalines.

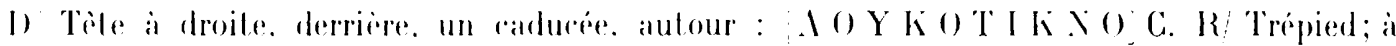

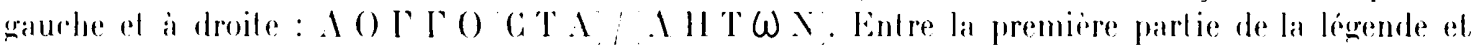

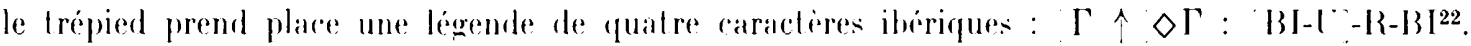

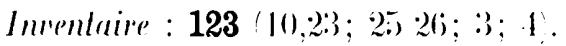

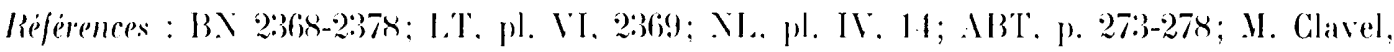

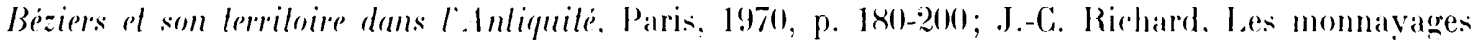
indigrenes de Jarbonne el sa région, dans . Varbonne, archéologie el hisloire, 1, Montpellier. 1973. p. 13:-1.19; TXC 1. p. 206-21:3; 11. Labrousse. Monnaies des Longostaletes a Vieille-Toulouse el ¿ Toulouse, dans . Icla . Nimismaliea, 7, 1977. p. 57-70.

L'émission des lomgostalides a de frappée dans la region de Narbome-beziers qui est relle de la plus forte concentration de découvertes bien que nous ignorions loujours le lieu exact de l'atelier. Elle se situe, dapris. J. B. Colbert de Beaulieu, romme les emissions de bronze de celle région. entre la fondalion de Sarbonne el la guerre des Gaules. Elle a connu une longue durée d'utilisalion jusqu'a la prérode augusteenne. I Vailhare cet exemplaire provient du niveau Cayla $\mathrm{V}$ (7) av.-201 ap. J.-C.).

\section{Chef gaulois.}

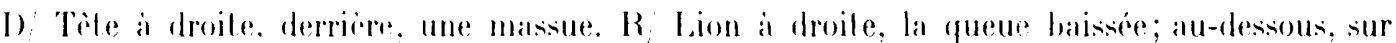

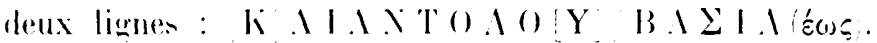

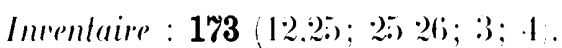

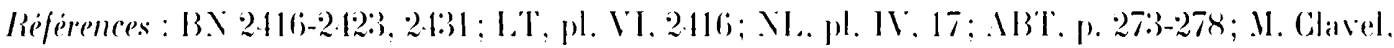
op. cil. p. 180-200; J.-C. Richard. op. cil., p. 13)-1.19; T.VG I. p. 206-213; J.-C. Richard el I. Villaronga, op. cil., p. 121-125.

Le lieu démission et la datation sont identiques à reux de la série précédente. A Mailhac. refle momnaie na pas de niveatu straligraphique individualiso.

c. Beziers.

I) Tabe a droile. une main leve: derribe une massue. R, Lion a droile, la quene relevé;

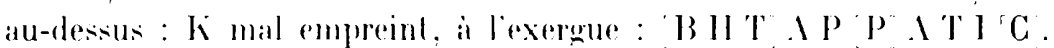

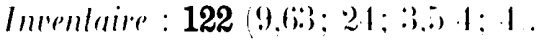

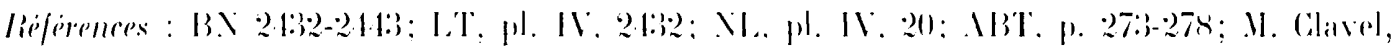

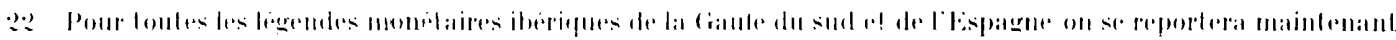

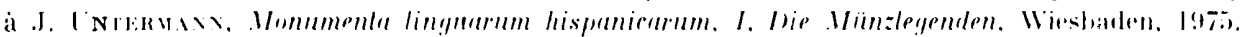


op. cil., p. 180-200; J.-G. Richard. op. cil. p. 135-1.19; T.YG I. p. 206-21:3; J.-G. Richard et I.. Villaronga, op. cil. p. 121-125.

Cette série a été émise à Béziers durant la mòme période que celle des deux séries précédentes.

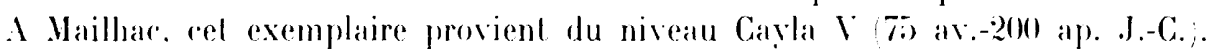

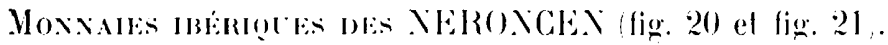

A. Série à légende iberique NERONGE. EBA.

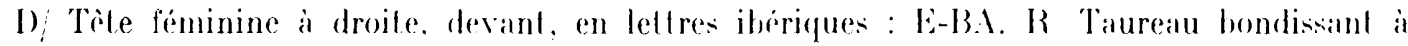
droile; au-dessus couronne; au-dessous, en leltres ibériques : X-L-R-()-X-CE-..

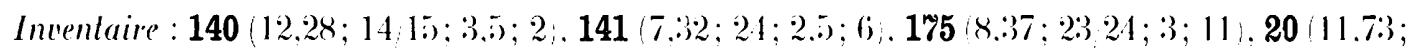

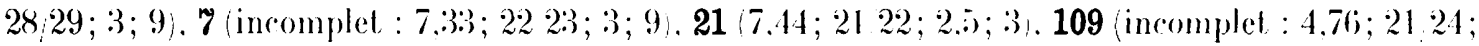
$2 ; ?)$.

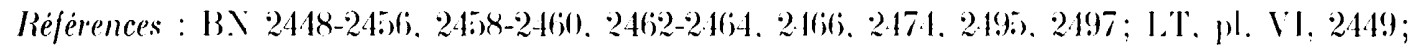
XL, pl. IV. 2\%.

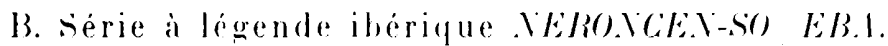

Description identique a celle de la série précédente; an revers. la légende est en deux lignes: X-E-R-()-N-Cli-N, i-()

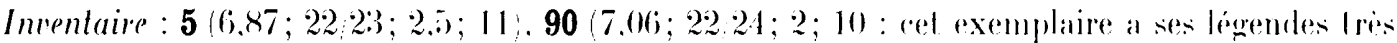
eftacées mais il doit appartenir à la série (?: :

Références: BN 2488-2490; I.T. pl. VI, $2488 ;$ VI.

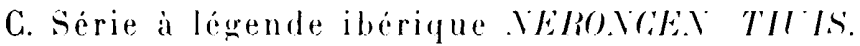

Description identique à relle des séries précédentes; au droil. a la plare de Li-BSA. láxende: TI-Ĺ-I-s

Imentrire : 187 (incomplet : 11,15; 22:2); $4: 9$ :

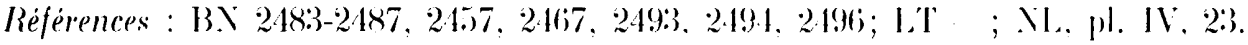

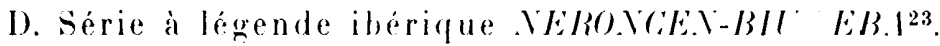

I) Tète féminine a droile, devant : E-B.S. R Taureau bondi-sant a droile, au-desils. cou-

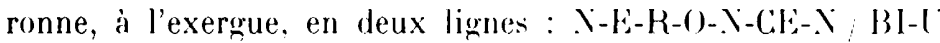

Inventaire : $89(11.21 ; 2627 ; 3 ; 11)$

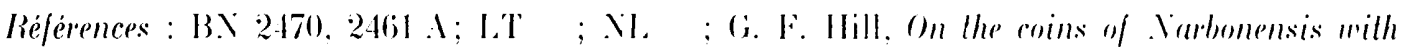
iberian inscriptions. New York. 19:30, p. 8-9 et pl. I. 6: (). ol .J. Talfanel. Bulletin de la sociele d'Études Scientifiques de l'Aude. 42, 19:38, p. 13:3. fig. 25.

E. Imilation.

I) Tòte féminine à gauche dans un grenetis aux perles lres espances. R Taureau bondissant a gauche: au-dessus rouronne: au-rlessous. deus lettres ibfirigues : ...()-R...

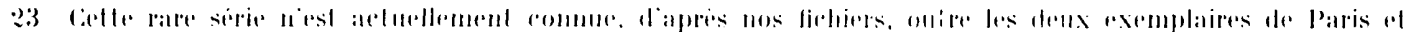

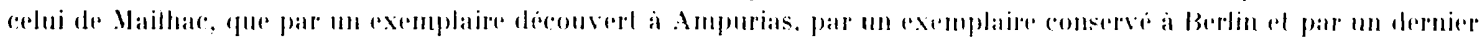

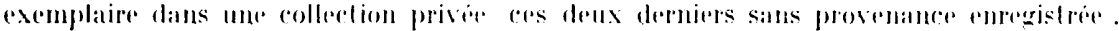



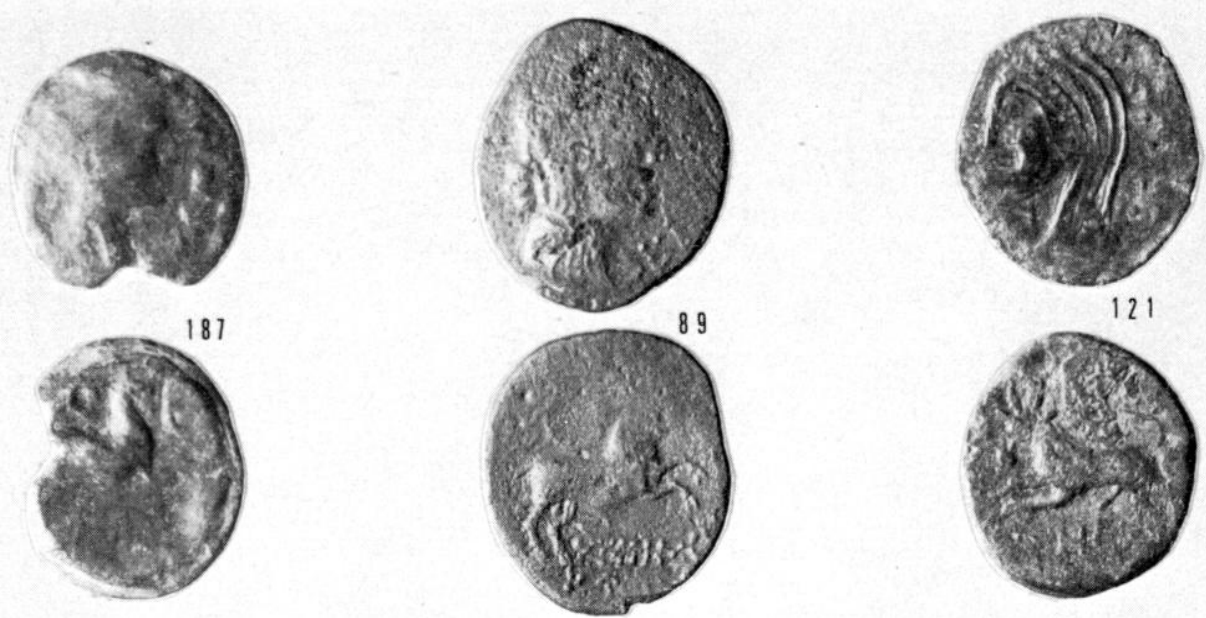

13
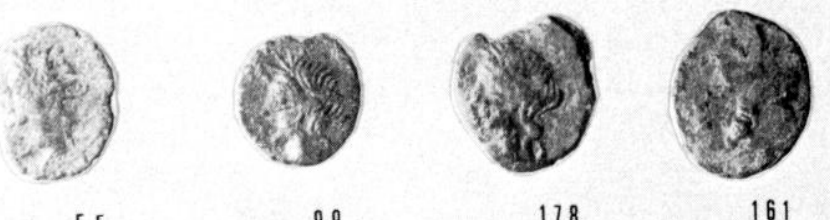

26

54

55

99
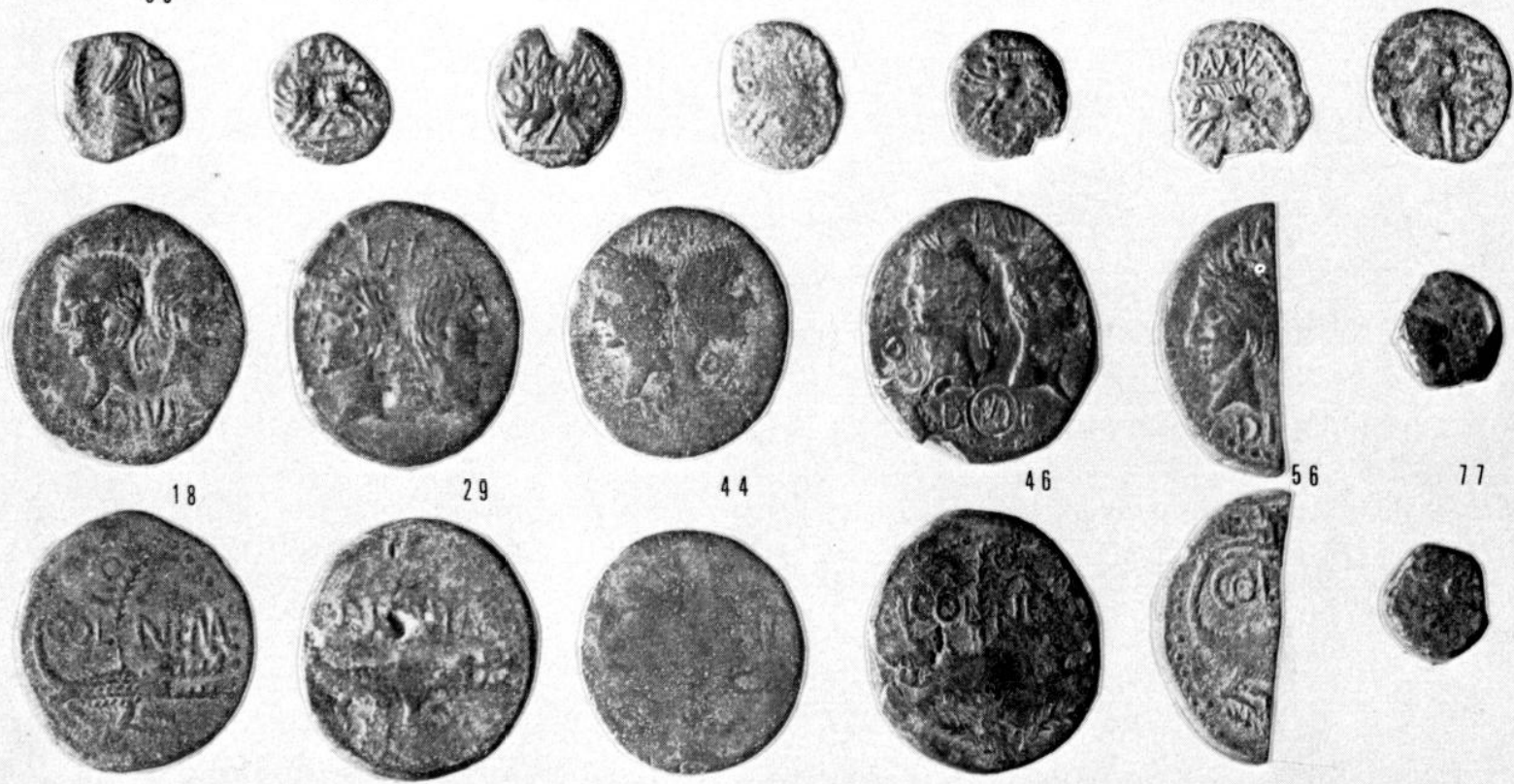

11
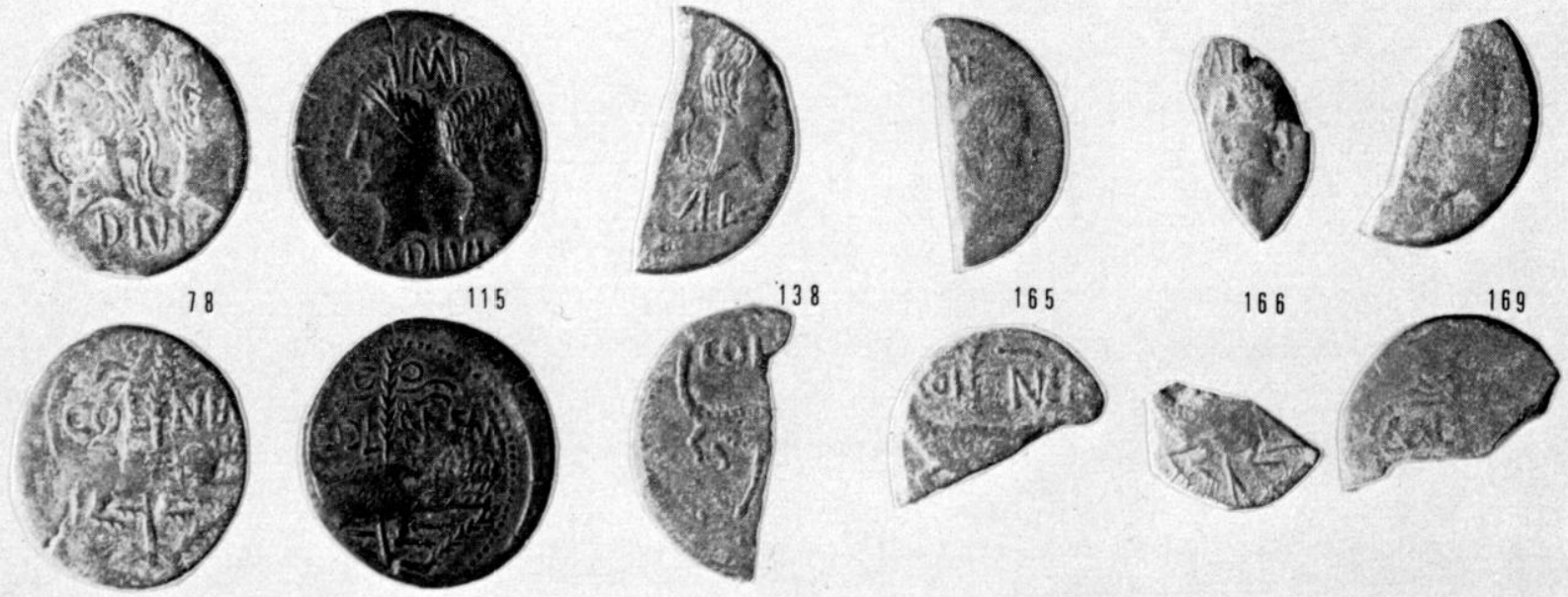

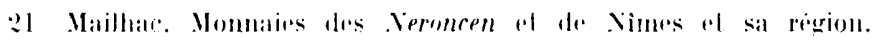


Imenlaire : $121(7.38 ; 15) 16 ; 2 ; 11$.

Il sagil d'une imitation, frappée par un coin qui na pas éte gravé en miroir, de la série a légende . Vermeen ou de la série, non représentée a Mailhac, a légende ibérique Seloncen (13X 2468$21699^{24}$. I'exemplaire $3 \times 2492$, imilé de la série à légende Neroncen, présente, lui aussi. le droil orienté vers la gauche.

References : II3T, p. 276-278; T.VG I, p. 206-213; J.-C. Richard, op. cil., p. 142-143; II. Iabrousse, Monnaies des Neroncen trouvés a Vieille-Toulouse, dans Varbonne, archéologie el histoire, I, Montpellier, 1973, p. 159-161; J.-G. Richard et I. Villaronga, op. cil., p. 124-125.

Les monnaies à légende Neroncen, comme les autres séries de hronze de la région NarbonneBeziers, ont éti plarées par J.-B. Colbert de Beaulieu entre la fondation de Narbonne et la wuerre des Ciaules.

Les exemplaires 141, 175, 20, 7, 21, 109, 187, 121 proviennent du niveau Gayla V (75) av.$2(10$ ap. J.-C.). 140 du niveau Cayla IV (325)-75) et 5, 90, 69 onl elé découverts hors d'un contexte archéologique.

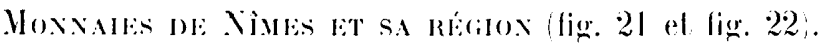

A. Pelif bronze des Volques Irécomiques an personnage en loge.

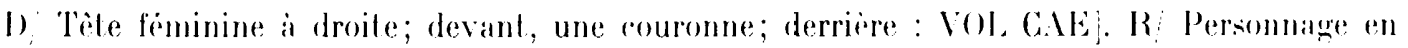
Loge debout a qauche, devant. une palme; a droite : I $\mathrm{K} \mathrm{FC}$

Intentaire : $36(1,4) ; 13) 13,5 ; 2 ; 5)$.

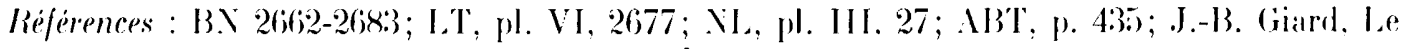
monnayage antique de Nimes. dans Bulletin de l'Ecole anlique de Vimes. nouvelle série. 6-7, 1971-

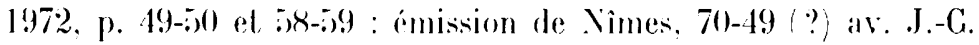

A Vailhare, cette monnaie appartient au niveau Cayla V (T) as.-200) ap. .J.-C...

B. Petits bronzes de Nîmes au sanglier.

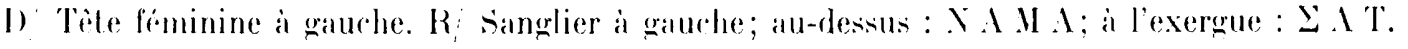

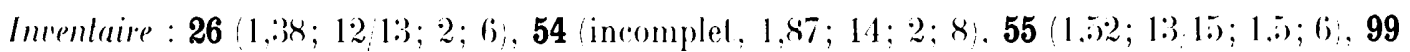
$(1.72 ; 1:) ; 2.5 ; 7) .178$ (incomplet. $1.87 ; 1415 ; 2 ; 7$ ).

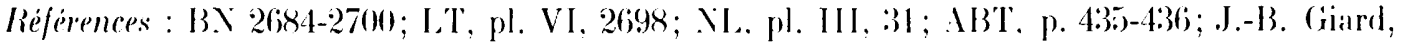
"p. cil. p. 49 el 57 : émission de Nîmes, avant 49 av. J.-C. Pour . V. Py (Acta Numismalica, 4, 1974. p. 105, 109-111. 124-126. 144), cette série se placerait entre 120 110 el 7060 a1. J.-C., d'apres les résultals de la stratigraphic de Xages (fiard.

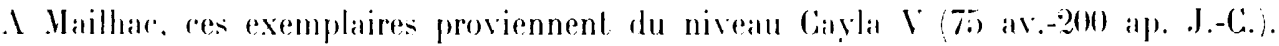

C. Semis de Nìmes à la legende NE.M CoL.

1) Tole asqué a droile, derriere : $\therefore$. R Personnage deboul a quache appuyé sur une

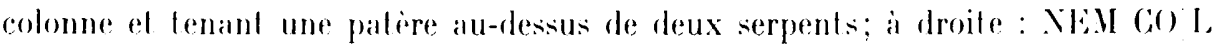

Ineentaire : 161 (1,6i3; 15) $16 ; 1,5 ;$ ? : le droit est fruste.

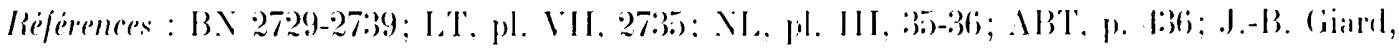

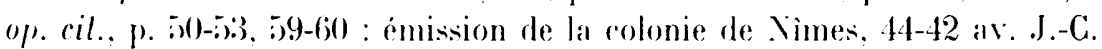

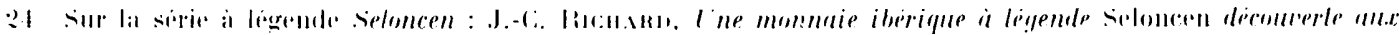

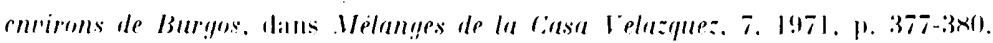




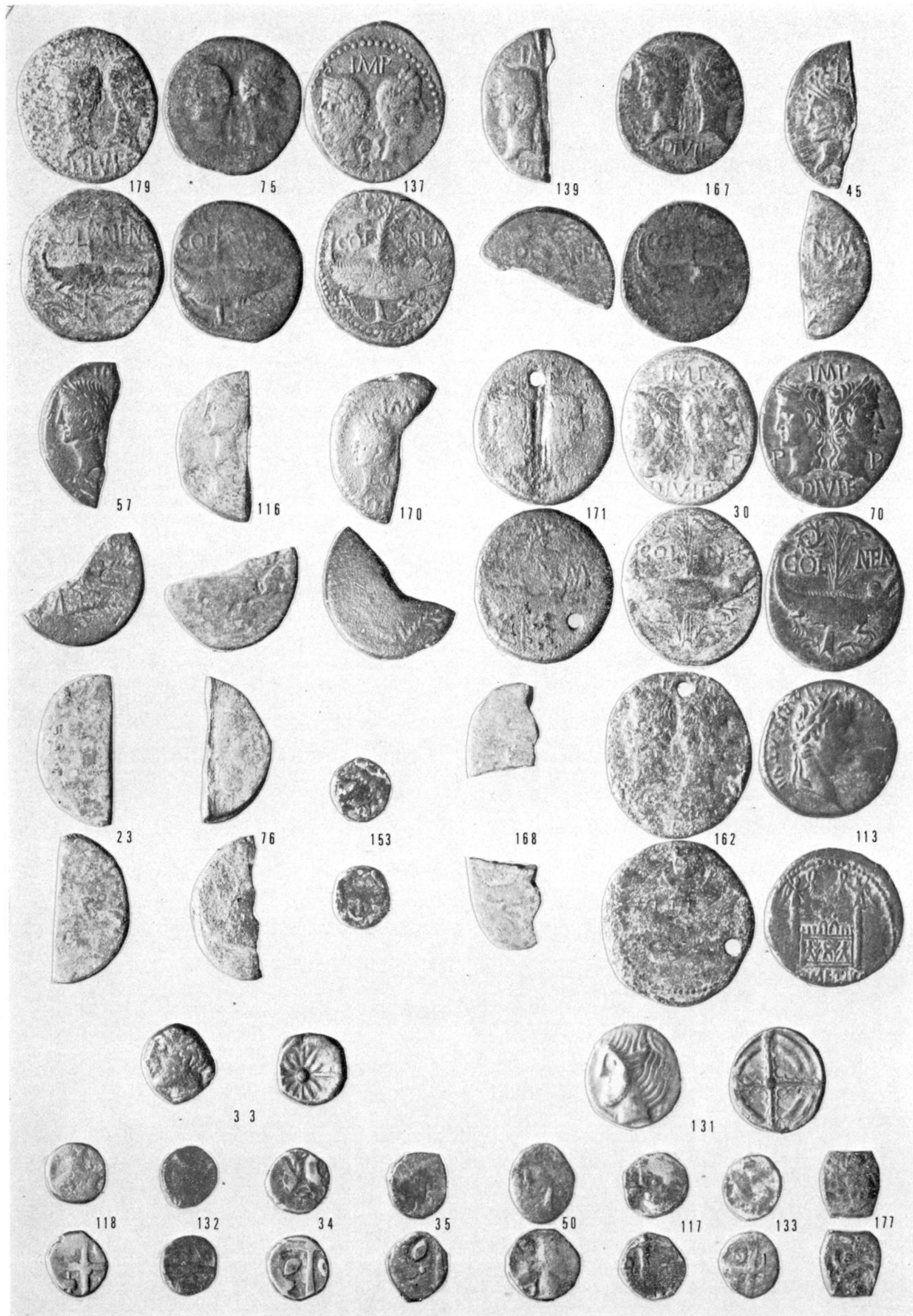

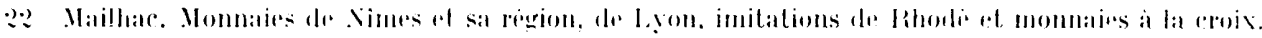


1). As de Nimes a crocodile.

a) fer type $2 x 27-9$ av. J.-C...

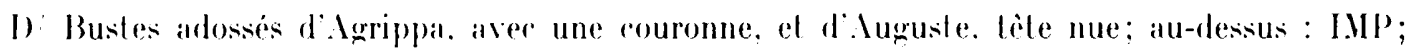

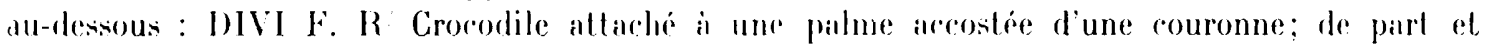
d'iulre : COI, NEM

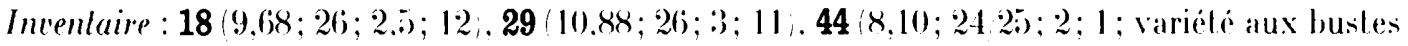
reliés par la base; au droit, contremarque circulaire aver les letlres D I) séparées par une palme. $46(11,22 ; 25) 26 ; 3 ; 8$; au droit. contremarque circulaire avec les leltres I) I) séparées par une palme

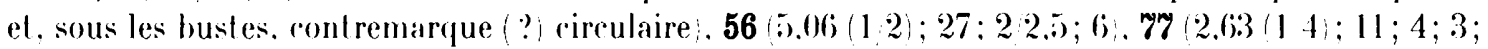
cette fraction a été obtenue par délachement d'un flan mais les hords ont été volontairement arrondis). 78 (13.07; 25) $26 ; 3,5) ; 7$; au droil. contremarque (irculaire avec les lettres I) 1) siparees par une palme). $115(13) .45 ; 26,27 ; 3 ; 11 ;$ variélé dite au cimier). $138(6.93)(12) ; 26 ; 3 ; 11) .165$ $(4.39(12) ; 24 ; 2.5 ; 10), 166(2,90(13) ; 20: 11 ; 2.5) ; 3 ;$ le mélal a l'apparence de l'argenl); 169 $(5,72(12) ; 25 ; 3 ; 9 ; 179(12,12 ; 2627 ; 3 ; 11$.

References: I3X 2740-2817; I.T. pl. VII, 2778; NI. pl. IV. 1-7; AB'T. p. 4;37-439; .J.-13. Giard,

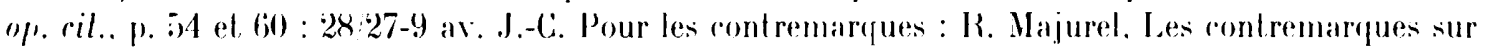
as nimois, dans Ogam. 17, 196i), p. 2103-278.

b) 2e type (8-:3)(?) ar. J.-C.).

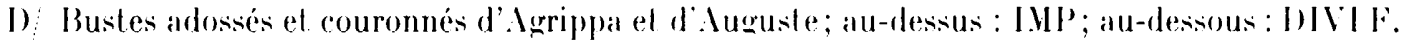
R Crocodile attaché à une palme accostée d'une couronne, de part el d'autre : COL XEM

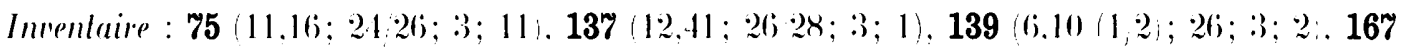
$13.3 .3 ; 2424.5 ; 4 ; 6$ :.

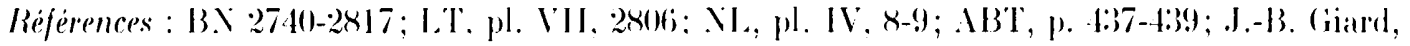
op. cit.. p. :4 et 60 : : 8 -:3 (?) ar. J.-C.

Les exemplaires suivants appartiennent au ler ou au 2 e lype : $45(6,70(1 / 2) ; 25 ; 3 ; 12) .54$

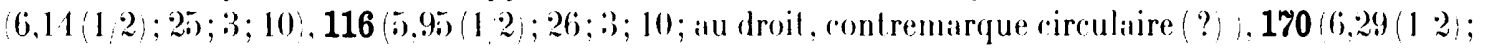
$26 ; .3 ; 6$; au droit, rontremarque circulaire aver les lellres I)? I) séparés par une palme:. 171 (percee. 17,2:): 26; 4; 8: 1er lype probable:

c) 3e lype (10)? -1.41:) ap. J.-C.).

1) Bustes adossés el couronnés d'Igrippa el d'Auguste; au-dessus : I.MP; alu-dessous : I)IVI lF; le part el d'autre : P P. R Crocodile altachi i une palme acosstée d'une couronne, de part et d'autre: Col. . NEM

Invenlaire : 30 (13.114;27; :3; $1 ; .70$ (12.78; 27; 3; 11 .

lieferences: BX 2818-2846; I'T. pl. VII, 28:37; NI. pl. IV. I0-11; AB'T, p. 137-139; .J.-B. Giard,

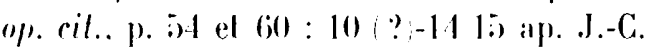

les exemplaires suivants ne peuvent pas ilre altribues a l'un des trois types : $23(7.37(1)$;

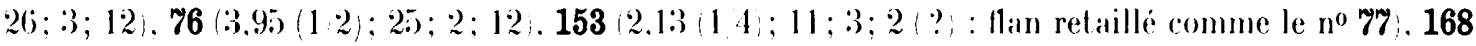
$(3,47(14) ; 1415 ; 3 ; ?)$

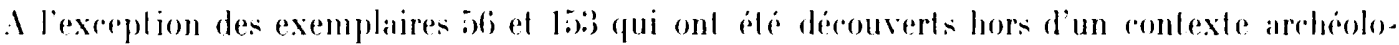

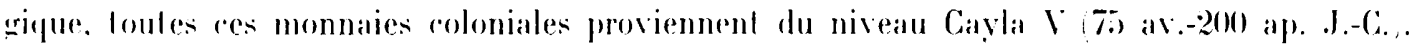

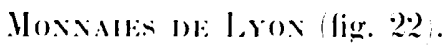

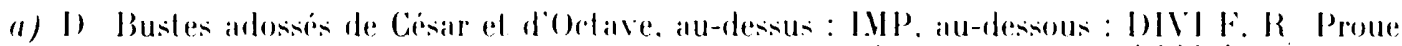
¿ droile; au-dessus. dans un cercle lite de hélier ?. 
Inventaire : 162 !percée, $18,21: 29 ;: 3,54 ; 8:$

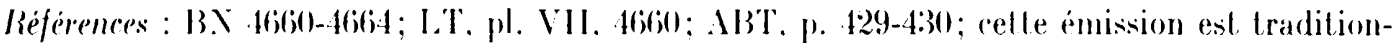
nellement altribue i Lugdumum. entre 40 et 27 as. J.-C. Pour une attribution possible a Orange : II. Cirant. From Imperium lo Auctorilas. Cambridge. 1946. p. 20(18-210.

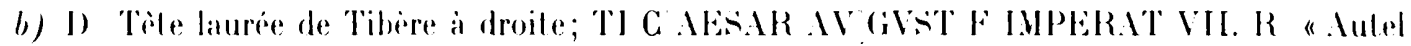
de Lyon composé d'une plate-forme llanquée de deux Vicloires qui se tiennent rharune sur une colonne; sur le devant de la plate-lorme. la couronne civique entre deux branches de laurier et deux lares; au-dessus, des objets indéfinissables"y. a l'exergue : RO M ET AVG;

Imentaire : 113 (11.17;24:27:3; 1;.

Réferences: as, atelier de Lyon. 133 ap. J.-C.-débul du rógne de Tibere (?) : J.-B. Ciiard. Biblio-

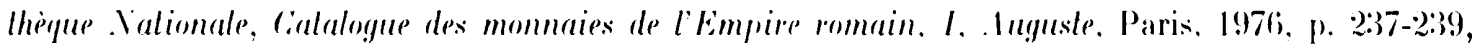
$\mathrm{n}^{0 \mathrm{~s}} 1769-179 \%$ ).

A Vailhar les exemplaires 162 el 113 proviennent du niveau Cayla V (7) as.-2(10) ap. .J.-(i...

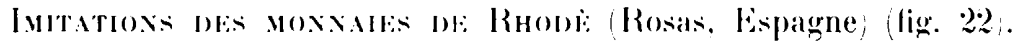

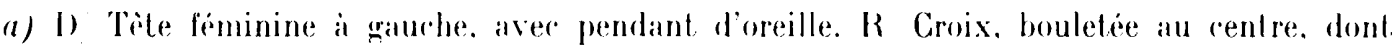
les bras coupent un cerrle (hors-flan iri et qui est laboutissement des bordures extérieures des quatre pélales intérieurs de la rose imitée qu'ils divisent en quatre cantons occupés par les barbelures. sur des exemplaires au than plus large apparaissent. au-dela. les bordures des quatre pélales extérieurs:

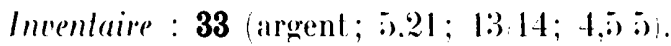

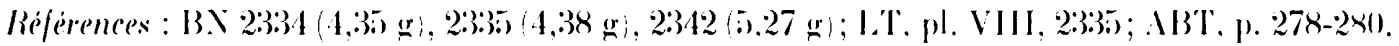

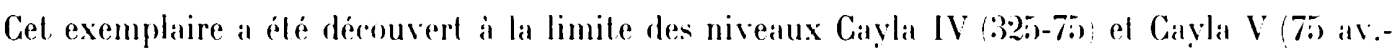
2(1) ap. J.-C.).

b) I) Tite féminine a gatuche. la chevelure en longues miches; un petit relief derriere le rou el les traces d'un pendant d'oreille sur le cou. $R$ Croix, bouletée au centre, avere les bras feuillus qui deberminent quatre dantons dans chacun desquels prennent place deux reliefs allongis ef courbés (qui représentent les extrémités des pétales intérieurs et exterieurs imites..

Imenlaire : 131 (argent; 4,6;); 18 19;2.5:3).

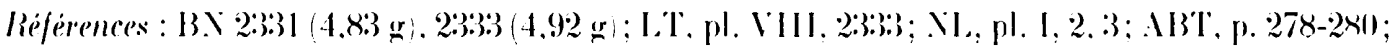
1. Soutou. Ogam. 20. 1968, p. 104-10\%).

Cel exemplaire provient du niveau Cayla IV (325)-75) ar. .J.-C.).

Les deux monnaies appartiennent aux imilalions qui ont été frappées en ciaule du sud, en s̈inspirant du monnayage de Khodi25. Ces imilalions sont probablement postérieures aux émissions

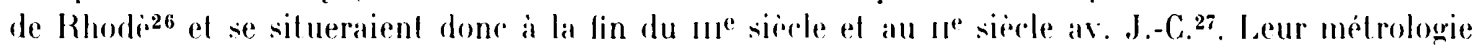

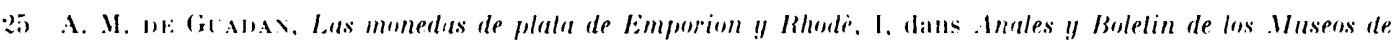

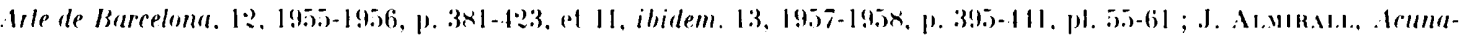
riones greco-hispanas de Rhorli e imilacimes barbaras, dans dola . Vumismalica, 1. 1971, p. 25-37.

26 A. M. de Cinadan 'Numismaliea iberica e ibere-romana. Madrid, 1969, p. 16? silue l'arlivile de l'atelier

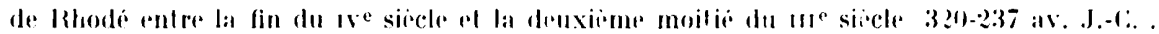

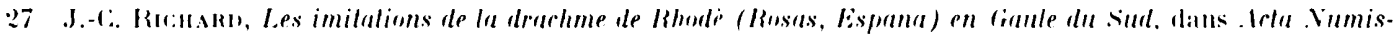
muliera, 1, 1971, 1. 3!)-14. 


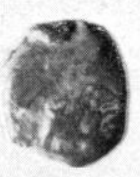

105

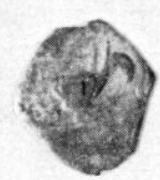

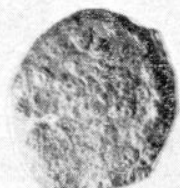

106

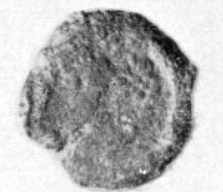

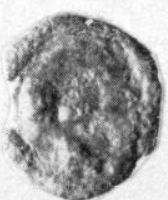

147
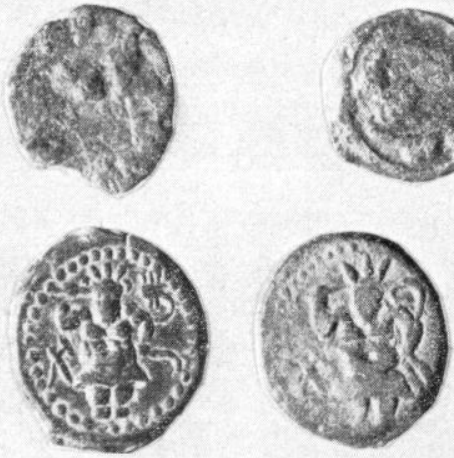

135
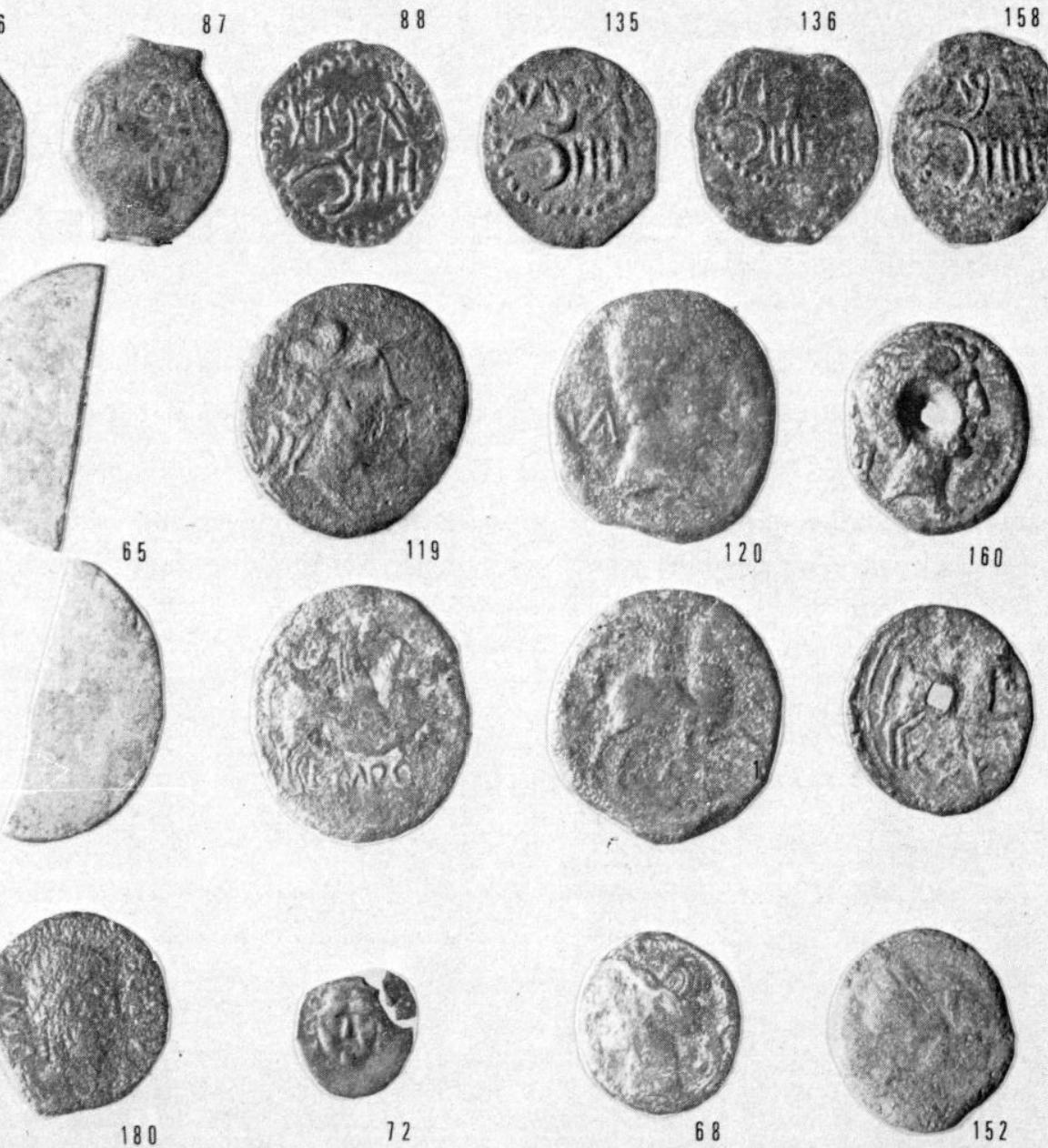

180
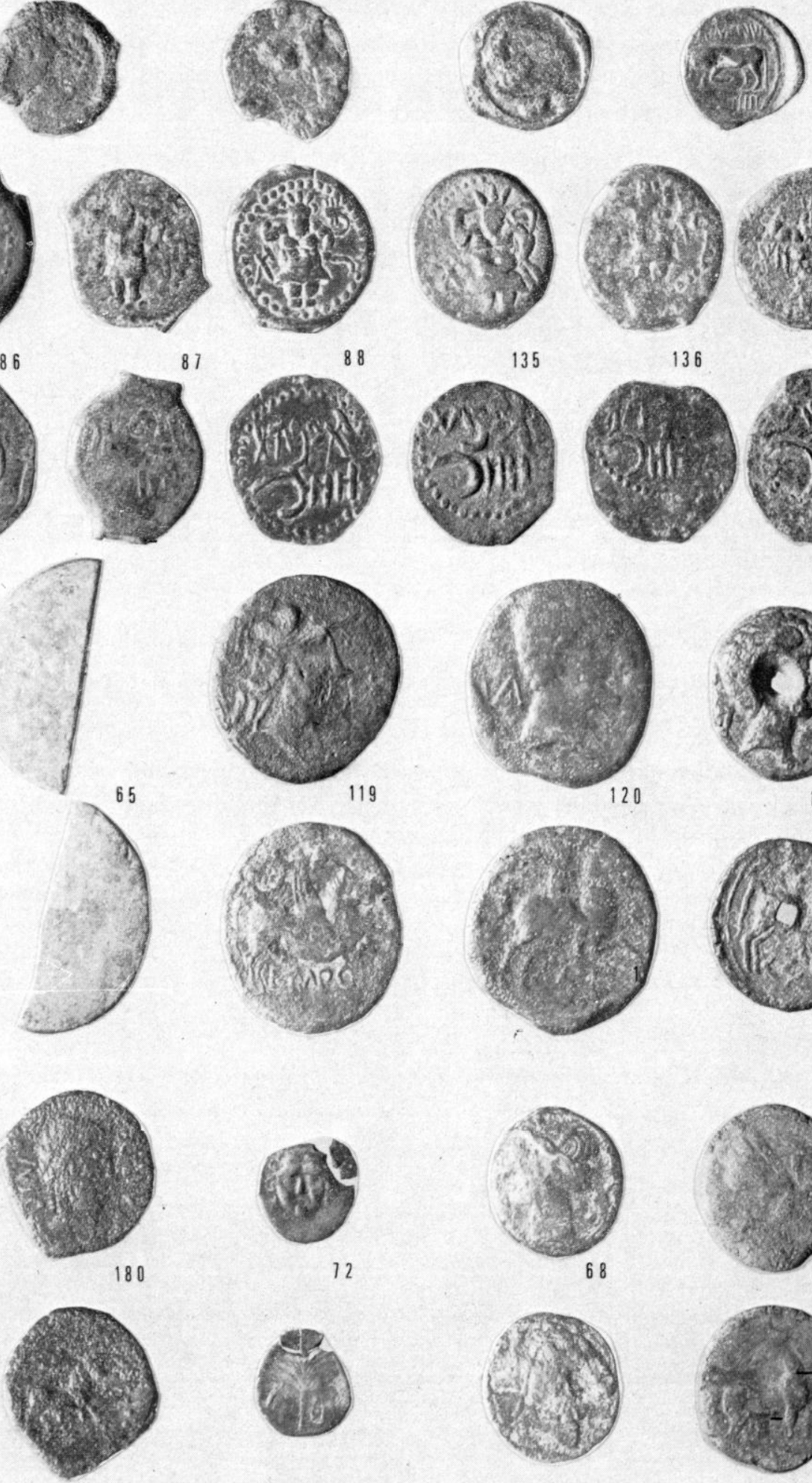
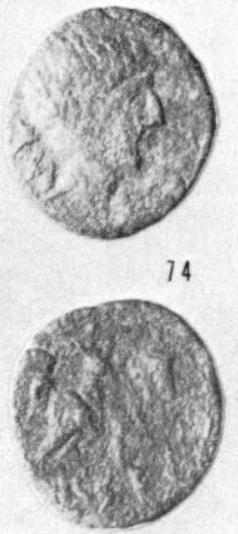

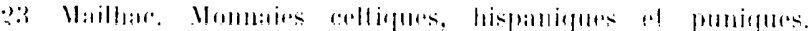




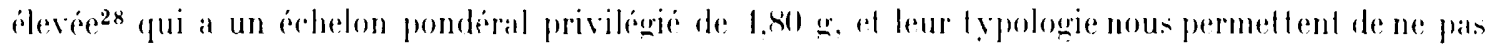
les considerer comme de veritables monnates a la rojix alles correspondent. prensons-nous, a un moment de lhistoire de la région duranl lequel des modiles ont été suivis, quelle que soit leur origine. en altendant la reration diun véritable monnayage propre.

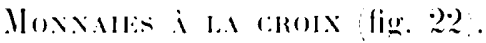

I) Eliments plus ou moins complets appartenanl i une lible a gatuche, de slyle dit, "cubiste». K l)ans les cantons dune roix, hache. olive, ellipse, rosisant... parliellement visibles en raison de la dimension du llan el de l'excentration.

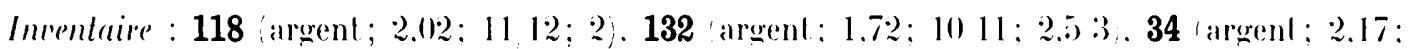

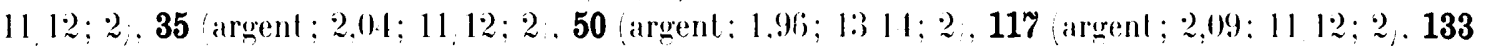
argent; $1,5 f ; 11,12 ; 2,198$ argent; 2,$28 ; 11,11.5: 3$.

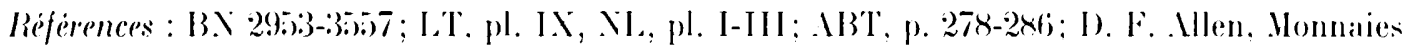
a la croix, dans . Vumismalic Chromicle, 7e serie, 9, 1969. dig. 2(= J.-G. Richard, Acla . Numismalica. 2, 197\%, p. 103, fig. 2; J.-B. Colbert de Beaulieu, T.C. I, p. 28; ; . -C. Richard, I es monnaies a

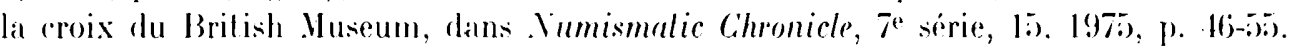

1) appres J.-B. Colbert de Beaulieu, les exemplaires de Vailhar. par leur poids, se siluent dans

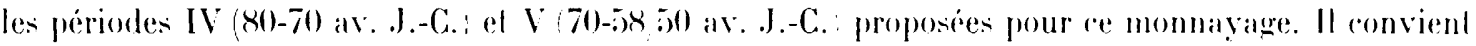
de remarquer que res exemplaires sont, la plupart du lemps. de bas argent.

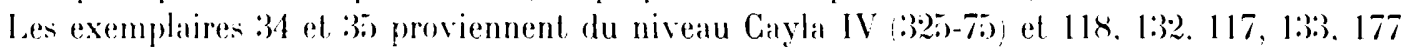

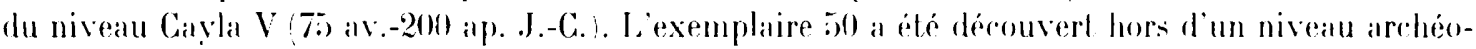
logique.

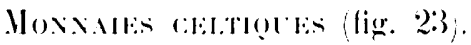

1. Pelil bronze i logende I I I OS, attribue aux Arvernes.

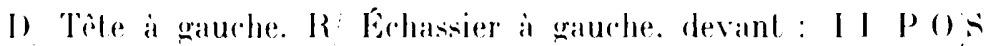

Inrenlaire : $105(2.0: 3) ; 1415) ; 2 ; 2$.

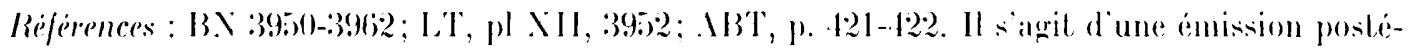
rieure a la guerre des Ciaules. (i. Cientric Recensemenl des monnates gauloises de la "Gallia Comala"

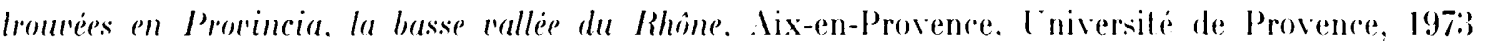
inédit, p. 27-29, donne les provenances suivantes : Lat Roche-Blanche (Puy-de-l)òme, oppidum de (ierovie), Corent Puy-de-l)ome, 2 exemplaires), Lvignon Vaucluse. Bolline (Vaucluse. 2 exemplaires, Saint-Rémy-de-Provence (Bouches-du-Rhònel. Marseille (Bouches-du-Rhòne;. Nìmes Gard, Nages (Gard, 2 exemplaires. Brignon (Gard, Ilons (Gard. oppidum de Vié-Cioulat). Latles (Hérault, 2 exemplaires; auxquelles il ronvient d'ajouter : Murviel-les-.Montpellier (Ilérault: J.-C. Richard et, P. soyris, Revue archéologique de . Varbonnais:. 9, 1976, p. 224, Magalas (Herault, oppidum de Ilontfo; calalogue en preparalion ${ }^{30}$.

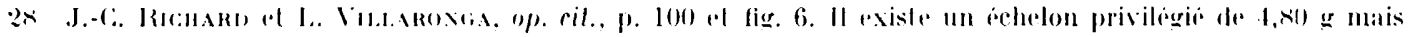

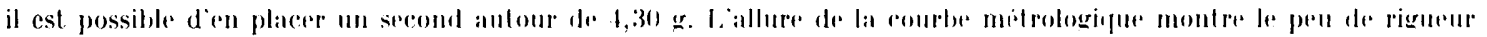
le ces imilations.

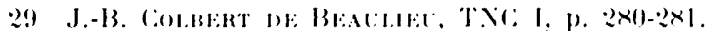

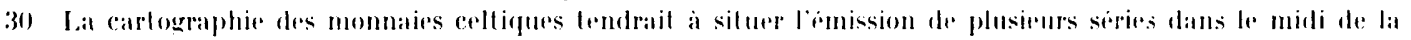

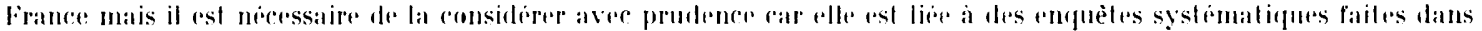

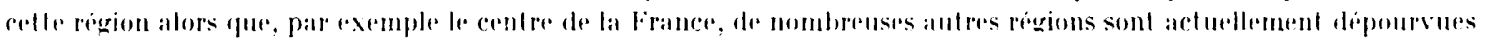
de dalalogues modermes de siles areheologiques. 
B. Pelil brome aux annelels de la sicie "anongme des Biluriges".

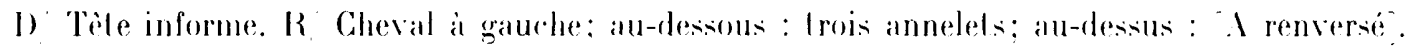
Invenlaire: $106(4,18 ; 1719 ;: 3 ; ?)$

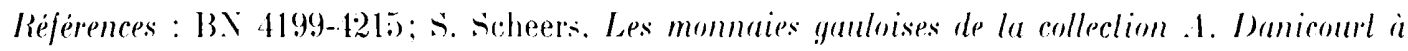
Peronne (France. Somme), Bruxelles, 1975, p. 50, no 147 : (i. Cientric, op. cil. p. 42-46. Il s'agit d'une série tardive postérieure à la guerre des baules. Les provenances sonl les suivanles : Fondelles (Indre-el-Ioires. Chateauroux Indre, ranton de Berne suisse; environs de Bouraes (Cher). Bollene (Vaucluse, 2 exemplaires/, Caraillon (Vaurluse, 2 exemplaires, sérignan (Vaucluse).

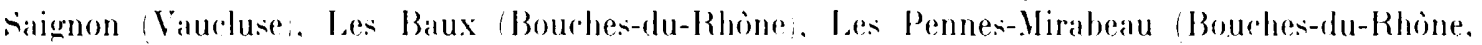
oppidum de la Cloche, sainl-Rémy-de-Provence Bouches-du-Rhòne, Villeneuve-les-drignon (Gard), Latles Hérault, 2 exemplaires. Villetelle Héraull. oppidum d'Ambrusim. :3 exemplaires: J.-I. Fiches. G. Depeyrot. J.-C. Richard, Les dérouvertes monétaires de l'oppidum d'Ambrussum (Villetelle, llérault, dans Bulletin de lEcole antique de Vimes, nouvelle sierie. 11-1:3, 1976-1978, p. 111-141), Murviel-les-.Montpellier Hérault : J.-C. Richard et P. Soyris, op. cit., p. 224), Belesta Ariige, oppidum du Mayné:

\section{Polins.}

Le droil et he revers sont a peu pres frustes mais le met al et le bourrelet qui limite le llan sont sulfisamment raractéristiques pour relle identilicalion.

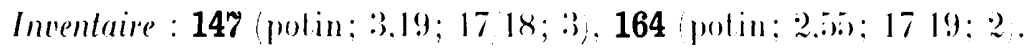

Références : pour l'ensemble des questions el la datation postérieure al la querre des ciaules de ces monnaies : J.-B. Colbert de Beaulieu, Les polins dits "a la tête diabolique ", un monnayge, indigine de la liaule en voie de romanisation. dans Rerue Belge de Vumismalique, 116, 1970. p. 9712:3, el. Chronologie des bronzes gaulois al Brilish Polin Coins. ibidem. 119, 197:3, p. 5-11.

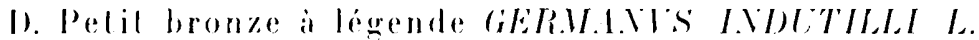

I) Thle a droile. R Taureau a gauche, sur une ligne de sol. la patle anterieure anuche replice;

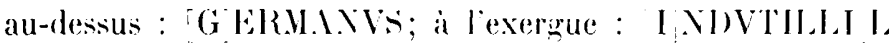

Inventaive : $97(2,57 ; 16) 18 ; 2 ; 11)$.

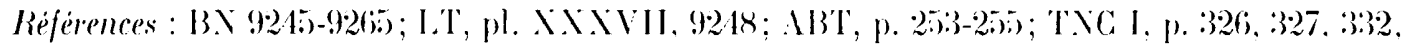

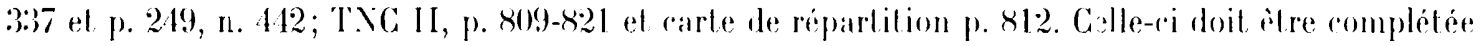
par les exemplaires suivants : Liverdun Weurthe-et-Moselle, Comples rendus de la Sociélé Firançatse

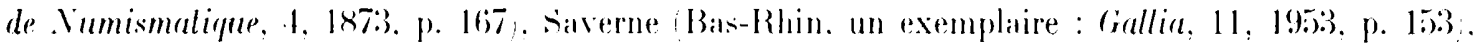

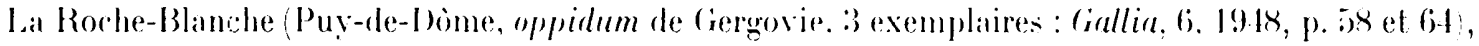
Beaumes-de-Venise Vaurluse, un exemplaire collection privés. sant-Rémy-de-Provence Bouchesdu-Rhòne, un exemplaire : G. Gentric. op. cil. p. 99/. Balarur-le-Vieux Héraull. un exemplaire. collection privie, Narbonne (Aude, 2 exemplaires, Gruissan Aude, un exemplaire, collection prives.

Celte émission date de l'époque alugustéenne el elle a connu une diffusion considerable à I ravers loule la Giale.

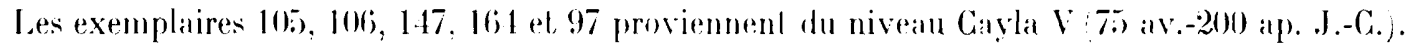




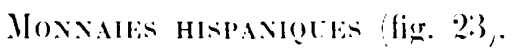

A. IInnaies d'Ibi\%a.

1) Le dieu Bis de fare tenant une masise el un serpent, a gauche, signe punique. R Inscription punique, en deux lignes : ybshm (" Iybushim ») j).

Inenlaire : $28(6,41 ; 1922 ; 3 ; 1) .86(7,73 ; 22 ; 3 ; 4), 87(7,47 ; 2022 ; 3,5 ; 7), 88(5,77 ; 22 ;$ 2.); 7). 135 (6.4); 20,5) 21,3); 2). $136(7,13 ; 2022 ; 3 ; 2), 158(6.30 ; 2122 ; 2,5 ; 3)$.

Références: : II. Campo. Las monedas de Ebusus, Barcelone, 1976, p. 30-34 (pour l'interprétation des légendes; le (hiflre s) indique la laille des monnaies par rapport a la livre romaine), p. 45-48 (dalation : (. 125)-7:) ar. J.-C., el interprétation des signes du droit) el p. 132-139 (catalogue du groupe XIX).

L.es exemplaires $28,86,87,8 x, 15 x$ proviennent ru niveau Cayla $V(75)$ av.-200 ap. J.-C.) et 1:35), 133 du niveau Cayla IV (325)-75).

B. Monnaies d'. Impurias.

a) série à légende ibérique.

I) Tòte casquée à droite. devant, en lettres ibériques, E-B A. K/ Pégase à droite surmonté d'une couronne (placée entre l'aile et la tetej; a l'exergue : C-N-I)[-GE-S-CL-X

Intentaire: $176(19.12 ; 30) 31 ; 3,5 ; 9.65(10,13(12) ; 30 ; 4 ; 12)$.

References : 1. Villaronga, The aes coinage of Emporion, Londres, 1977, p. 42-60 : $\mathrm{II}^{\mathrm{e}}$ siècle

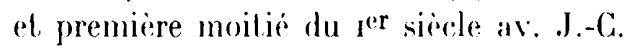

b) Série à légende latine.

1) Téte casquée à droite; devant : une légende eflacée (G.. . ?). R/ Pégase à droite surmonté d'une couronne, à gauche de l'aile; a l'exerque : EMPO ${ }_{L}^{-} R \ldots j$

Inrenlaire : $119(9,3: 3 ; 27 ; 2,5 ; \vdots)$.

Références: I. Villaronga, op. cit., p. 62-71 (de 27 avant J.-C. a 30 ap. J.-C.).

C. Monnaies de Cese.

I) Tòte masculine a droite, derriore, lettres ibériques. K/ Cavalier avec palme à droite; à lexergue : Cli-si-E

Ineentaire : $120(12.75 ; 27 ; 3 ; 10 ;$ au droit : 1)I), 160 (percée, 7,10;22/22,5; 3; 1; au droit: A), $74(7,17 ; 222: 3 ; 2,5 ; 3 ; 2 ;$ au droit : 'TI-KI).

Références : A. Vives y Escurdero, La moneda hisprinica, Madrid, 1924-1926, pl. XXXV, 5, 10, 11 ; F. Gimeno Rua. la ceca de Kese, Sistemática y ordenación de sus materiales, dans .Vumisma, 10 , 1960. p. 9-105 et 18, 1968, p. 9-228; 1. .1. de Guadan, . Nusmismitica ibérica e ibero romana, Madrid, 1969. p. 137 (I) : période V, 10.5-82 av. J.-C.). p. 14:3-144 (A el TI-KI : période VI, 82-40 av. J.-C.) et p. 19:3; J.-C. Richard, Revue archeologique de Narbonnaise, 8, 197:), p. 270-271.

I). Ionnaie d'obulco.

I) Tète a droite; derrire : XI C; devant : () B V L. IR Taureau à droite; au-dessus : rroissant; exerrue fruste.

Invenlaire : $180(5,93 ; 21 ; 2 ; 10)$. 
(1. EYT J. T.MFE.ANEL, J.GL. RICH.MRI)

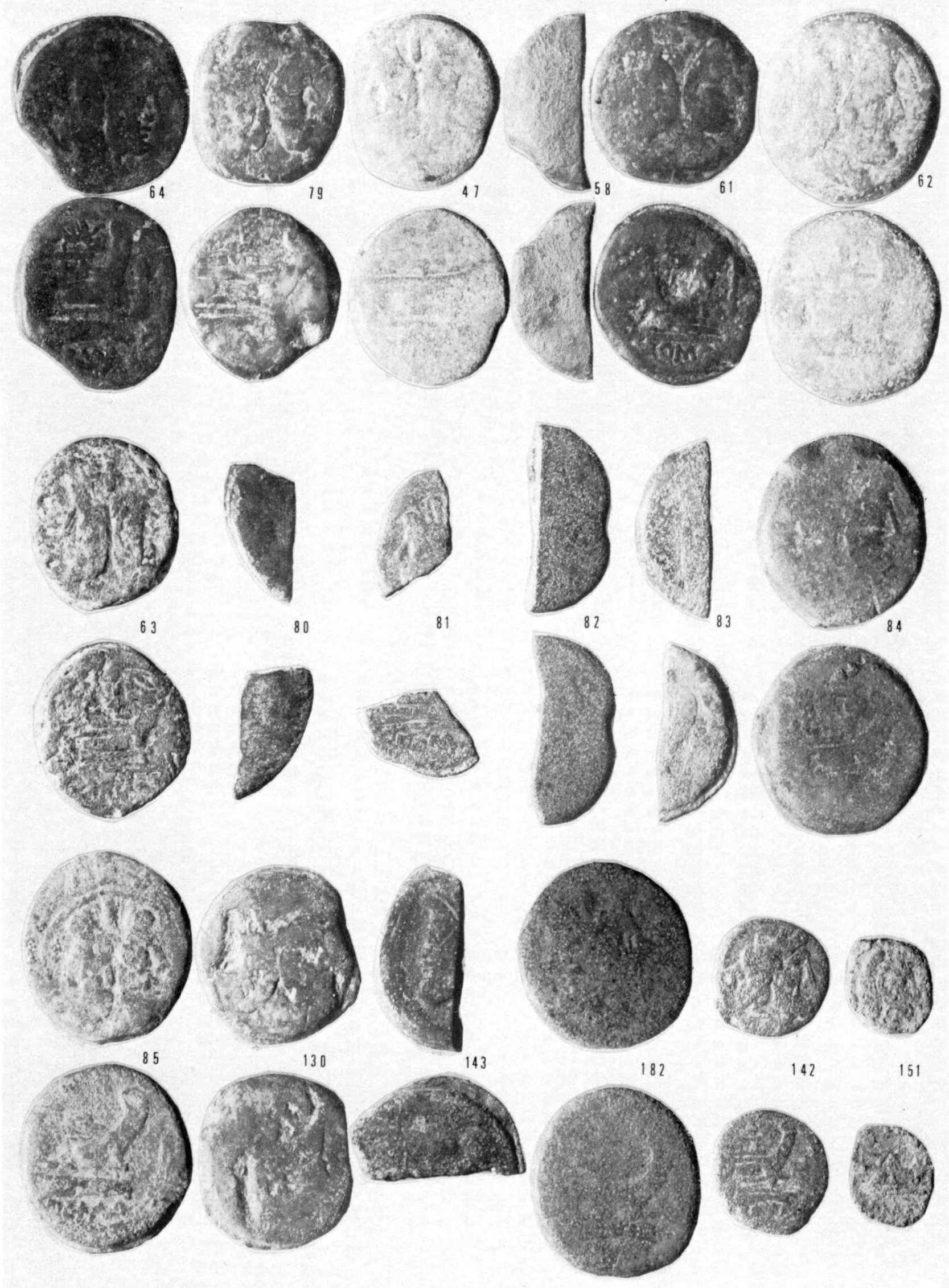


Références : .1. Vives y Escudero, op. cit., pl. XGVIII; A. M. de Guadan, op. cit., p. 143 et 180 (monnaie divisionnaire de la période VI, 82-40 av. J.-C. I. J.-C..).

L.es monnaies d'. Impurias, Cese et Obulco proviennent du niveau Cayla V (75 av.-200 ap.

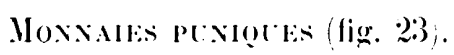

a) I) Tr̀te de Véduse de face. $\mathrm{K} /$ Palmier el inscription punique de quatre signes : MTWA

Inventaire : 72 (argent, brisée accidentellement en trois morceaux : 0,57;1:3/14;1;11).

Références : M. Louis-(). et J. Tallanel. op. cil., 1, 1955, p. 127, fig. 105; B. V. Head, Historia Vumorum, Oxford, 1911, p. 158 : émission de Motya (Sicile), ca. 413-397 av. J.-G.; Sylloge Nummorum Giraecorum, Copenhague, no 484, I)reer Klagenfurt, no 463, Grèce Evelpidis, no 547, Ashmolean Museum Oxford, no 1862; Filzuilliam .Yuseum Ciambridge, nos 110:3-1105.

Cet exemplaire provient du niveau Cayla IV (325-75) dans un sol d'argile ${ }^{31}$.

b) I) Tète de Tanit à gauche. H/ Buste de cheval a droite; devant l'encolure, lettre ou différent.

Inventaire : $68(3,78 ; 19 ; 20 ; 2 ; 9)$.

c) I) Tête de Tanit à gauche. R: Cheval arrèté à droite, la tête retournée vers l'arrière; entre les pattes, lettres possibles.

Inventaire: $152(6,44 ; 21 ; 2.5 ; 1)$.

Références: : G. K. Jenkins. Sylloge Nummorum Graecorum, The royal collection of coins and medals, Inanish . National Museum, 42, . Vorth Africa, Syrtica-Mauretania, Copenhague, 1969, pl. 6, $11,12:$ III $^{\mathrm{e}}$ siècle av. J.-C. sur les monnaies puniques en Gaule : TXC I, p. 333-342 et B. Fischer, Les monnaies anliques d'Afrique du Yord trouvées en Gaule ${ }^{32}$, Paris, 1978, Suppl. 36 à Gallia; en Espagne : L. Villaronga, Las monedas hispano-cartaginesas, Barcelone, 1973; en Sardaigne : E. Birocchi, La monetazione punico-sarda, dans Sludi Sardi, 1935, II, p. 64-164; L. Forteleoni, Le emissioni monetali della Sardegna punica, Sassari, 1961; E. Acquaro, Le monete puniche del Museo nazionale di Ciagliari. Rome, 197.

L'exemplaire 152 provient du niveau Cayla V (75 av.-200 ap. J.-C.) et 68 a été découvert hors d'un contexte archéologique.

Monnates de ta Ríptiblgue romaine (figr. 24 et fig. 25 ).

A. Bronze, atelier de Rome.

a) As oncial (u siecte-91 ar. J.-G.).

1) Tîle de Janus, au-dessus : I. R/ Proue à droite, à l'exergue : ROMA; lettres ou différents.

Références : M. H. Crawford, Roman republican coinage. Cambridge, 1974 (= RRC).

31 Celle monnaie a ete identifiee, pour la premiere fois, par M. le Dr H. A. Cahn (lettre du 12 juin 1950 ) auquel nous adressons nos plus sinceres remerciements. Sur ces monnaies : cf. A. M. Bisi, Le monele con leggenda punica e neopunica del .Museo . Vazionale di Napoli, dans .1nnali del Isliluto Ilaliano di Numismatica, 16-17, 19691970 , p. $76-79$.

32 Sur les deux exemplaires à Lattes Hérault, J.-C. Hıch ard, Les monnaies du sile anlique de Lalles (Hérault) (1964-1965), dans Acla Numismalica, 8, 1978, p. 68. 


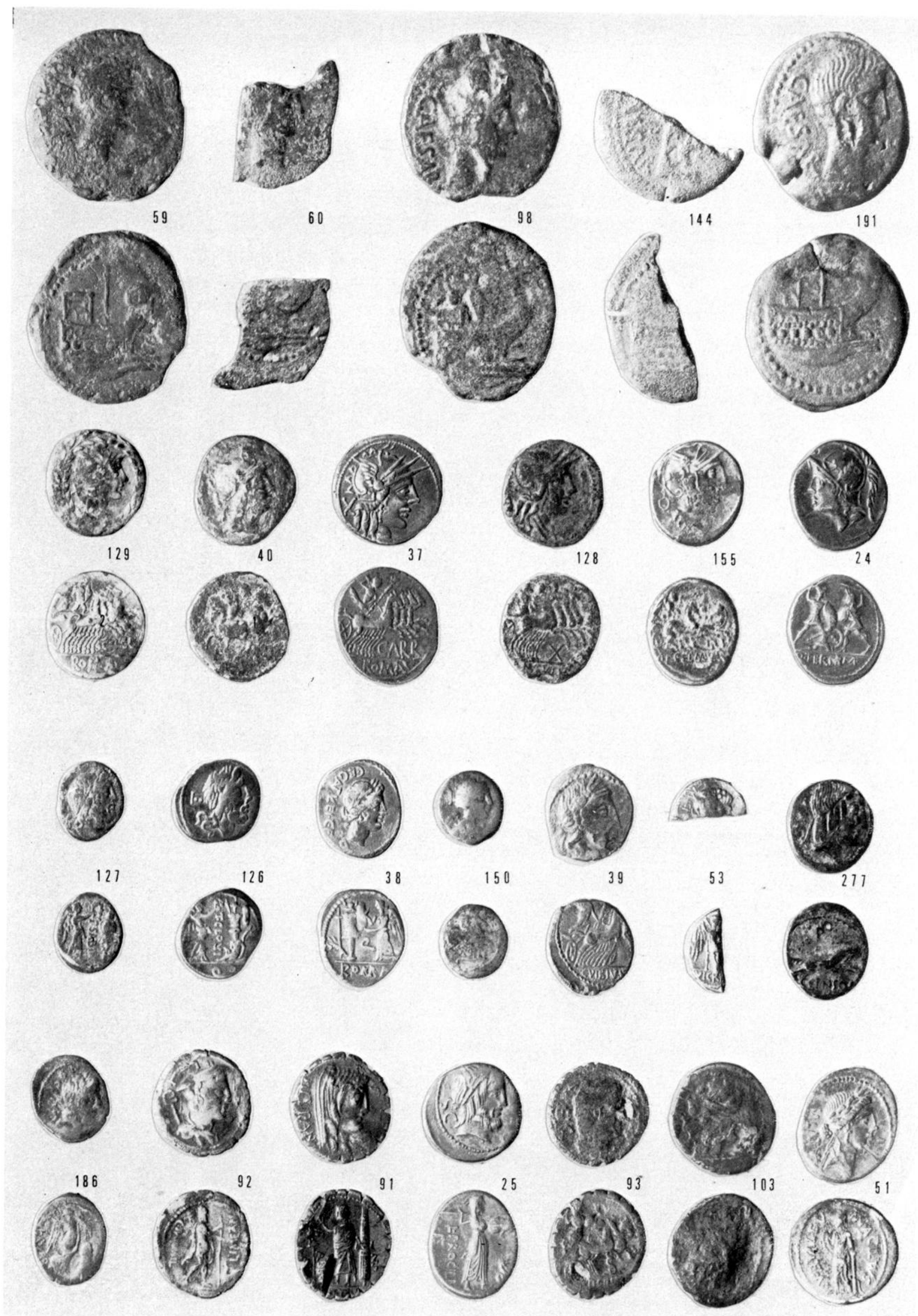

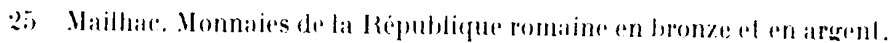




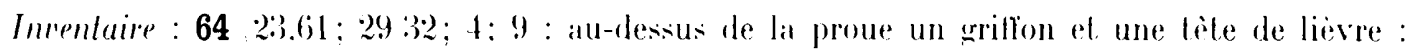

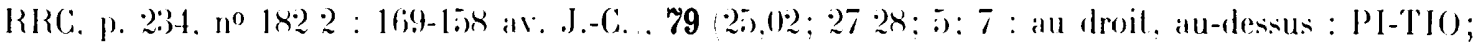

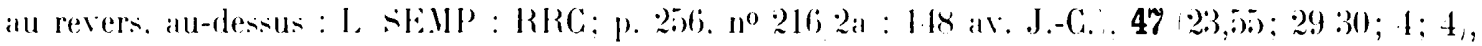

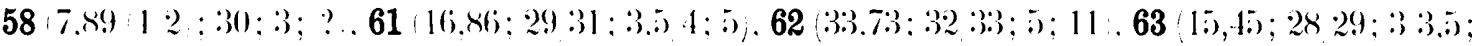

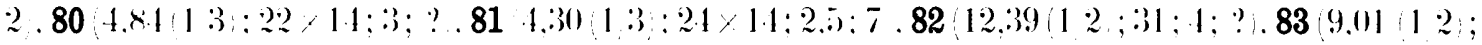

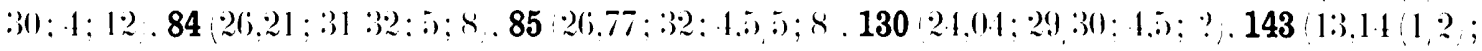
:32; $4 ; 3$. $182(31,39 ;: 31 ; 32 ; 5 ;: 33$

b) Semis, atclier de Rome.

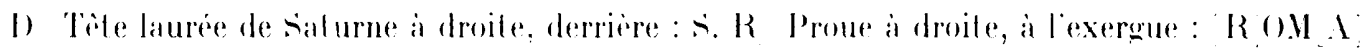
Inrentuire : $142(5,91 ; 2022 ; 2 ; 11$.

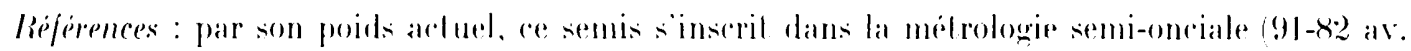
J.-C. mais si l'on tient compte de lusure il pourrail idre rall arche a la met rologie onciale, et serait donc anlérieur à 91.

c) Guadrans, alelier de Rome.

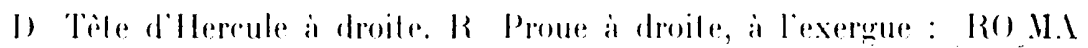

Inrentuire: $151: 3.15 ; 16 ; 17 ; 2: 2$.

lieferences: d'alpris le poids il sagirait d'un quadrans semi-oncial $91-x 2$, mais, comme lexemplaire precedent. il pourrait itre plus ancien.

L.exemplaires 130, 143. 142, 151 proviennent du niveau Cayla IV (325-70) et tous les autres du niveau Calyla V (7.) av.-2001 alp. J.-C., à l'exception du 182 qui n a pas de conlexte archéologique.

B. Bronte, altelier en diaule.

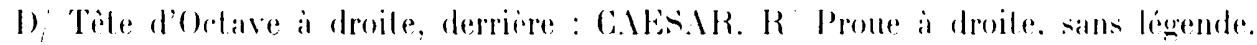

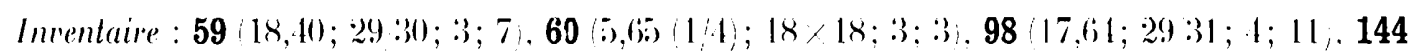
$(7,59) \div 12 ; 29 ; 3 ; 9 ;, 191(16,91) ; 30 ; 4 ; 5)$.

References: B.1 2948. 2948-1. 2949. 2949-1-2-3-1: H. Gohen. Hescription historique des monnaies

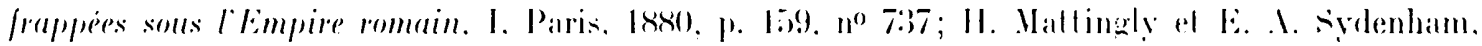
The roman imperial coinage. I. Londres. 192:3. p. 1:3: 101-28 as. J.-C.

les exemplaires 59, 60. 9k, 1.14 proviennent du niveau Cayla V (75) ar.-200 ap. J.-C. el 191 $n$ a pas de contexte archéologique.

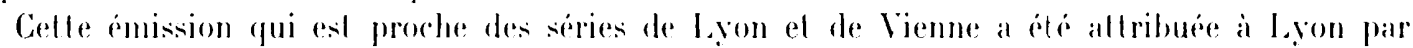
II. Mallingly et k. A. Sydenham a la suite de II. Cohen, a Vienne par L. de La salussaye (LS,

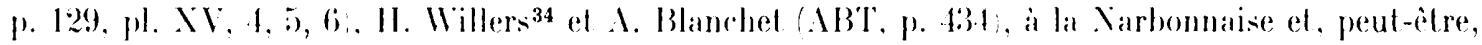
¿ Arles par .1. Cirant ${ }^{35}$. Cous avons recensé les provenances nouvelles suivantes : Amélie-les-Bains

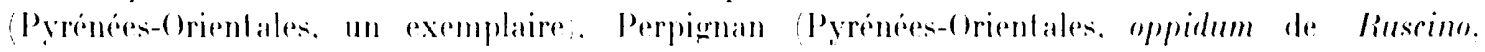

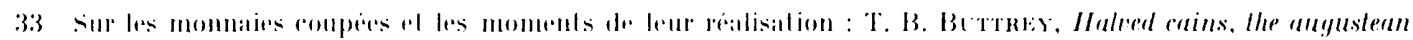

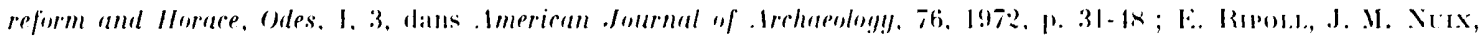

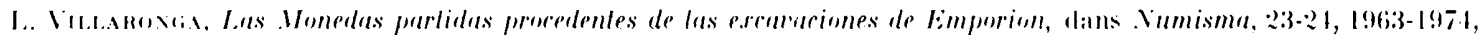
p. $75-911$.

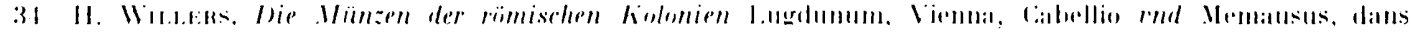

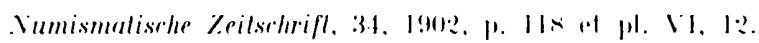

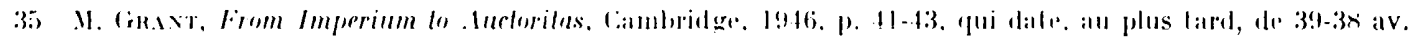

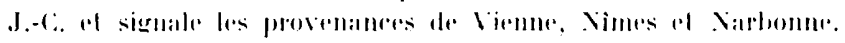


5 exemplaires', Bram (Aude, un exemplaire), Narbonne (Aude, 8 exemplaires $^{36}$ ), Villerouge-laCrémade (Aude, un exemplaire ${ }^{37}$ ), Mailhac (Aude, 5 exemplaires), Ceilhes (Hérault, 3 exemplaires), Murviel-les-Montpellier (Hérault, un exemplaire), Ampurias (Espagne. 7 exemplaires), Tarragone (Espagne, un exemplaire) auxquels il faut ajouter les provenances signalées par M. (irant : Vienne (Isère, 3 exemplaires), Nìmes (Gard, 2 exemplaires) et Narbonne (Aude, 2 exemplaires) ${ }^{38}$. En se fondant sur cette carte de répartition et sur un dossier difficile à constituer, car cette émission est souvent confondue avec d'autres dans les publications, nous proposerions, du moins comme hypothèse de travail, une attribution a Narbonne qui demandera à ctre confirmée par de nouvelles découverles ${ }^{39}$.

C. Argent, deniers et quinaires, atelier de Rome $\mathrm{e}^{40}$.

a) Denier G. GELI

$\mathrm{D} /$ Tête de Rome casquée à droite dans une couronne de laurier; derrière : $\mathrm{X}$. $\mathrm{H}_{i}$ Guerrier et captif dans un quadrige à droite; au-dessous : G.. GE L., a l'exergue : ROM.L

Inventaire : 129 (fourré; 3,$40 ; 18 / 19 ; 2 ; 6)^{41}$.

Références : $\mathrm{RRG}$, p. 265, no 232/1 : 138 av. J.-G.

b) Denier G SERVEILI M F.

D/ Tête casquée de Rome à droite, derrière : couronne et $(*)$; dessous: $R O M \Lambda_{\text {J }}$. R/ Iloscures à cheval; à l'exergue : [G.SERVEILI.M.F.]

Inventaire : 40 (fourré; 3,$08 ; 18 / 19 ; 2 ; 11$ ).

Références : RRC, p. 270, no 239/1 : 136 av. J.-C.

c) Denier CARBO

D) Tête de Rome casquée à droite, derrière : X. K Jupiter dans un quadrige à droite; audessous : CARB; à l'exergue : ROMA

Inventaire: $\mathbf{3 7}(3,84 ; 20 ; 1,5 ; 4)$.

Références: RRC, p. 296, no 279/1:121 av. J.-C.

d) Denier M TVLLI

D/ Tête Rome casquée à droite; derrière : R()MA. R/ Victoire dans un quadrige à droite; dessous : X; à l'exergue : M. TVLLLI

Inventaire : 128 (âme d'un denier fourré; 3,$16 ; 19 ; 2 ; 2$ ).

Références : RRC, p. 297, no $280 / 1: 120$ av. J.-C.

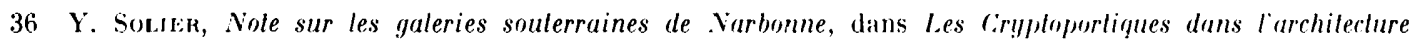
romaine, Rome, 1973 , p. 319.

37 Y. Sol.IEн, Bulletin de la Commission archéologique de Varbonne, 3:, 1970, 1. 157.

38 A. Baxt et L. Simoxkrt, Corpus Nummorum Romanorum, 7, 1975, p. 165-166 signalent (iny eximpliares, sans provenance, dont deux portent, au droit, CASAR au lien de CAKSAR.

39 Nous avons pu observer, malgré leur mauvais etat, que les exemplaires qui proviennent de lhorreum de Narbonne offrent des liaisons de coin.

40 Nous avons volontairement donne une description sommaire du droit et du revers de chaque monnaie: on trouvera une description complite à la reférence correspondante du RRC.

41 Sur les monnaies d'argent de la République romaine fourrés, cf. V. H. CRaworu, Plated coins, false

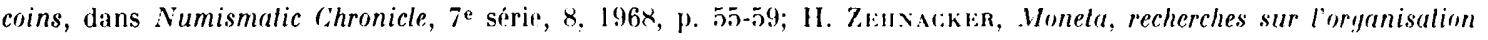
et l'art des émissions monétaires de la Republique romaine (289.31 av. J.-6..), Homr, 1973, 1. 42-48. 
e) Henier AP CiL, T M.AL on T M.I.M., (y VR

I) Tète casque de Rome a droite. R Victoire dans un trige a droite; a lexergue : AP.Cl. T.M.ML lies (0.VR lies.

Incentaire: 155 fourre: :3:0: 17,$18 ; 2: 4$.

Riferences: : RRC, p. :312, no 2999 1: : 111 ou 110 ar. J.-C.

1) Denier (I THEKM II F

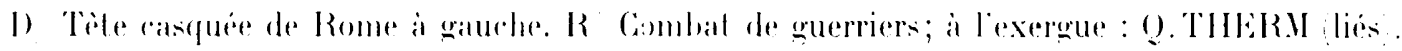
III: lies:

Inrentuire : $24(3,2 ; ; 19 ; 2 ; 2$.

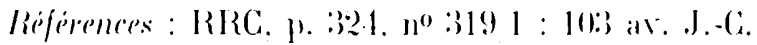

g) Quinaire P'S.IBIN (9

I) Tele laure de Jupiler a droite; derribe : letlre. R Victoire a droite couronnant un

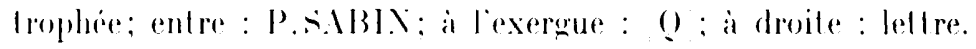

Inrenlaire : 127 (1.75; $13.11 ; 2 ; 5$.

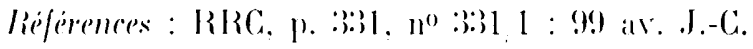

h) Quinaire T' Clotila

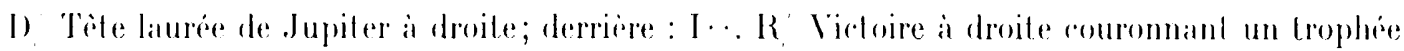
devant lequel est assis un "aptil' entre : T.CLOVLl (liés; ; l'exergue : Q

Ineenlaire : $126(1.74 ; 1.117 ; 1,5 ; 2)$.

Rejerences: RRC, p. 3:31, no 3:32:1: : 98 as. J.-C.

i) Guinaire C L(iNATVLEI G F: ()

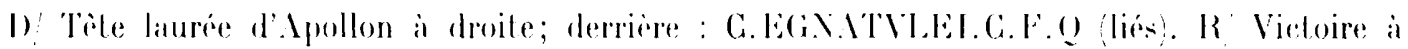

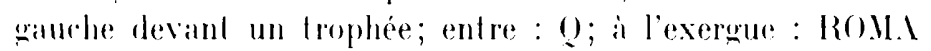

Inrentaire : $38(1.78 ; 16.17 ; 1 ; 1)$.

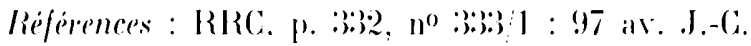

j) Quinaire () TITI

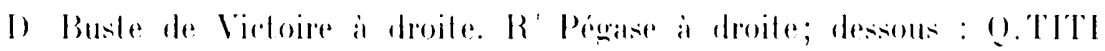

Intentaire : $150 ; 1.80 ; 1: i ; 2 ; 7$.

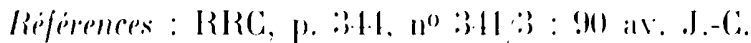

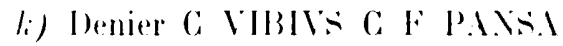

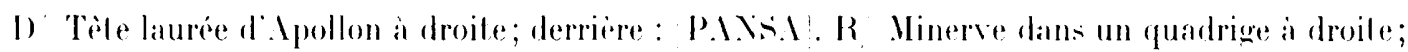
a lexerque : C. VIIBISti. C. F.

Ineentuire : 39 fourré (?; : 3.13; 16; 17; 2.5; 6 .

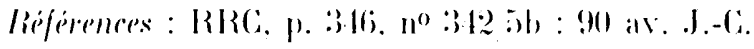

1) Quinaire .I Ci.lTo

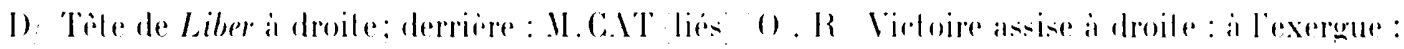
VICTR IX liés.

Inentaire: $530.791: 2 ; 1.1 ; 1.5 ; 3$,

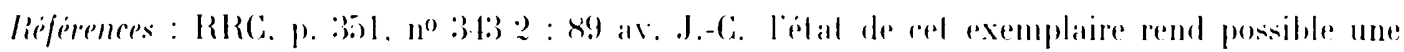

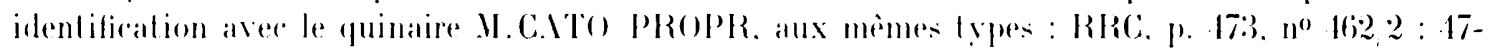

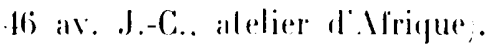


m) Denier G GENSORIX

D) Tète diadémée d'Apollon a droite; derrière : marque de contròle (?) $\mathrm{R}$ Cheval galopant à droite; au-dessous : C. CELsio() RI ; au-dessus : P

Inrentaire : 279 (fourré; $32.25 ; 16 ; 2 ; 4)$.

liéférences : RRC, p. 3is7, no $346,2 \mathrm{~b}: 88$ ar. J.-C.

n) Quinaire L RVBRI IOOSSENI

D/ Tête laurée de Neptune à droite aver: un Irident sur l'épaule: derrière : Iossist: $\mathrm{N}, \mathrm{B}$ / Victoire à droite devant un autel entouré d'un serpent; derriere : L.RVIBLI!

Inventaire : $186(1,51 ; 14 / 16 ; 1 ; 2)$.

Références: : RRC, p. 362, no $3484: 87$ ar. J.-C.

o) Denier C MAMIL, LIMETANVS C F

I) Buste de Mercure à droite aver un caducée sur lépaule; derribre : I. R llysse a droite et son chien; a gauche : C.M.AMIL; a droite LIMETAN (lies).

Inventaire : 92 (fourré; 3,$54 ; 18: 19 ; 2 ; 2$ ).

Références: RRG. p. 375, $\mathrm{n}^{0} 362: 1: 82$ av. J.-C.

p) Denier A POST A F i I ALBIX

D/ Tête de l'Espagne à droite portant un voile; derribe : HISPAX. $R_{\text {i }}$ Personnage en toge debout à gauche entre des faisceaux et un aigle légionnaire; à l'exergue: A.POST. L. F.; ; droite : S.X.; ; grauche : ALBIX (liés).

Inventaire : 91 (fourré; 3,$26 ; 19 ; 2 ; 1 ;$ au revers, un coup de burin).

Références : RRG, p. 389, $\mathrm{n}^{0}: 372: 2: 81$ av. J.-G.

q) Denier I. PRoCII.I F

I) Tête laurée de Jupiter a droite; derriere : s.C. R. Juno sospita a droite devant un serpent; à gauche : L.PRoCILI F

Inventaire : $25(3,61 ; 1719 ; 2 ; 4)$.

Références: RRC, p. 396. n 3791 : 81) à. J.-C.

r) Denier L PROCII.I F:

D) Tète de Juno sospita i droite; derriere : s.C. H Juno sospila dans un bige a droite, dessous, un serpent; a l'exergue : L.PR(JCILI. F:

Inventaire: 93 (fourré et percé; 3,$23 ; 18 / 19 ; 2 ; 2$ ).

Références: RRC. p. 396, no $3792: 80$ av. J.-G.

s) Denier P YPSAL

D Buste de Leuconoe is droite; derriere : dauphin; devant: P.YP S.lF.t.G. R Jupiter dans un quadrige à gauche; dessous : C.YPSAL.COS PRIV; a droite : CEPIT'

Ineentaire : 103 (fourré; $2.58 ; 19: 20 ; 2 ; ?$

Références: $\mathrm{RRC}$, p. 444, no $4202 \mathrm{a}:$ : 60 ar. J.-C.

1) Denier MN ACILIVS IIIVIR

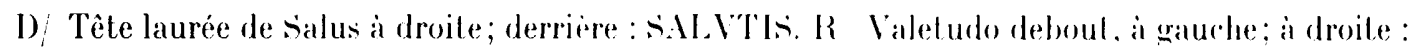
M.N (liés).ACILIVs; a gauche : III.VIR.VAIETY (liés.

Inventaire : 51 fourre; $3.06 \%$; $1821 ; 1.5 ; 2$. 


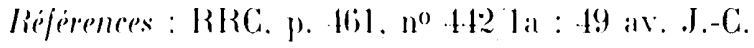

Les exemplaires 129. 40, 37, 124. 15\%, 127. 126, 38, 150, 39 proviennent du niveau Cayla IV

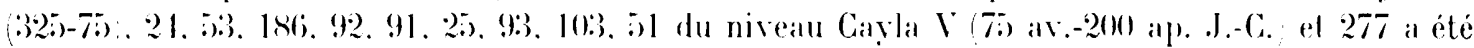
decouvert en surface.

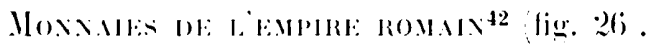

1. $\operatorname{lng} 11 \leqslant 10$.

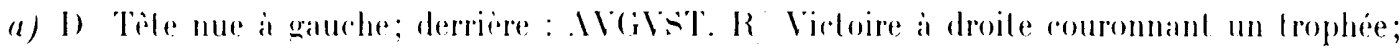
a gauche: P C.lRIsI; a droite: I.ECi

Inrentriure: 94 (argent; $1.75 ; 1: 315 ; 1.5 ; 3)$

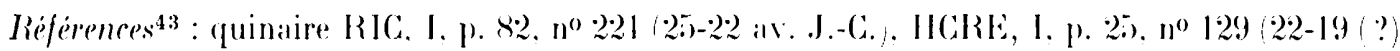

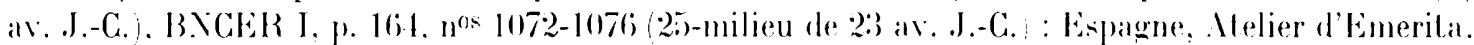

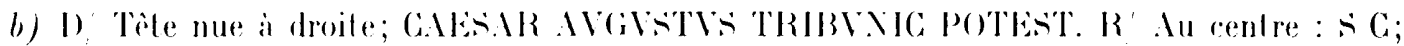

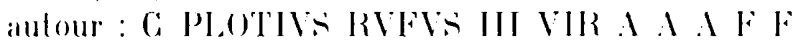

Intenlaire : 96 (7.27; 25); 2; (i.

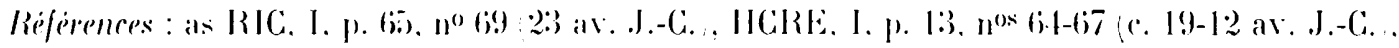

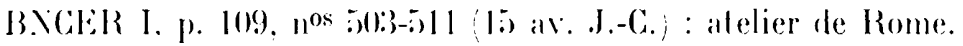

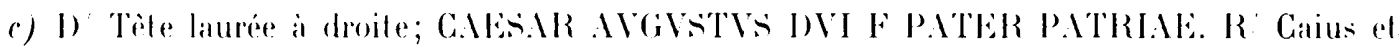
Lurius debout. lenant une épie et un bourlier; dans le champ un simpulum et un liluns a l'exergue:

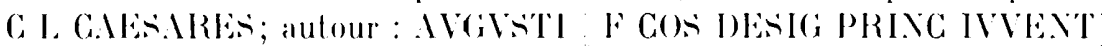

Inentuire : 158 (argent; :3.15); 19 19.5); 2; 11 .

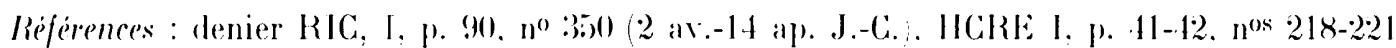

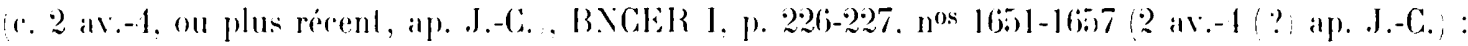
atelier de L,yon.

B. Caligulal.

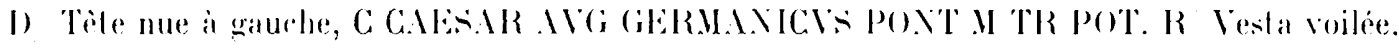
assise a gauche tenant une patire el un sceptre. VEstat is

Intenluire : 95 (10.32; $2(6,27 ; 3: 7,190 ; 9,38 ; 262.27 ; 3 ; 3$.

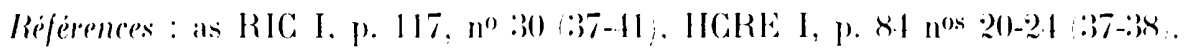

C. Cilature.

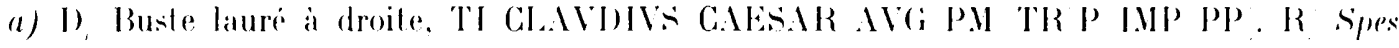

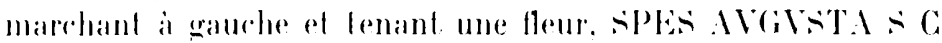

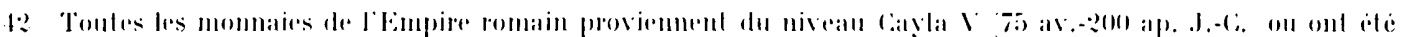

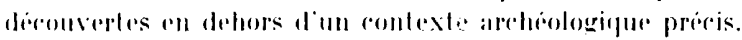

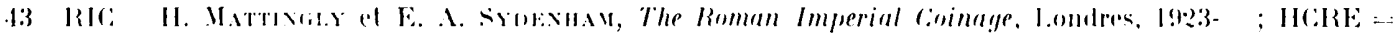

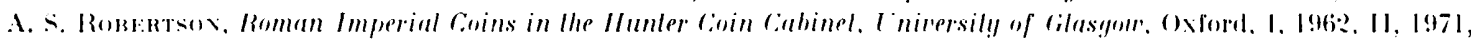

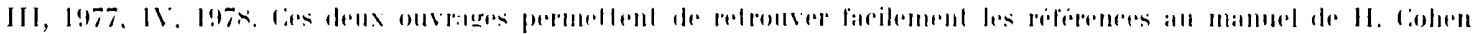

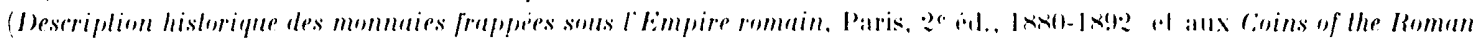

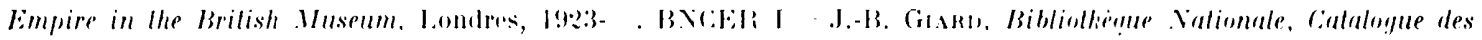

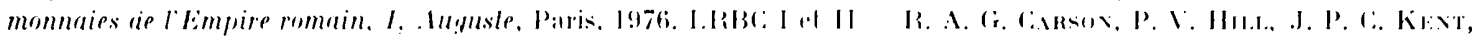

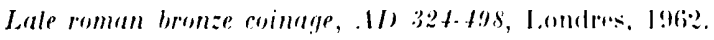




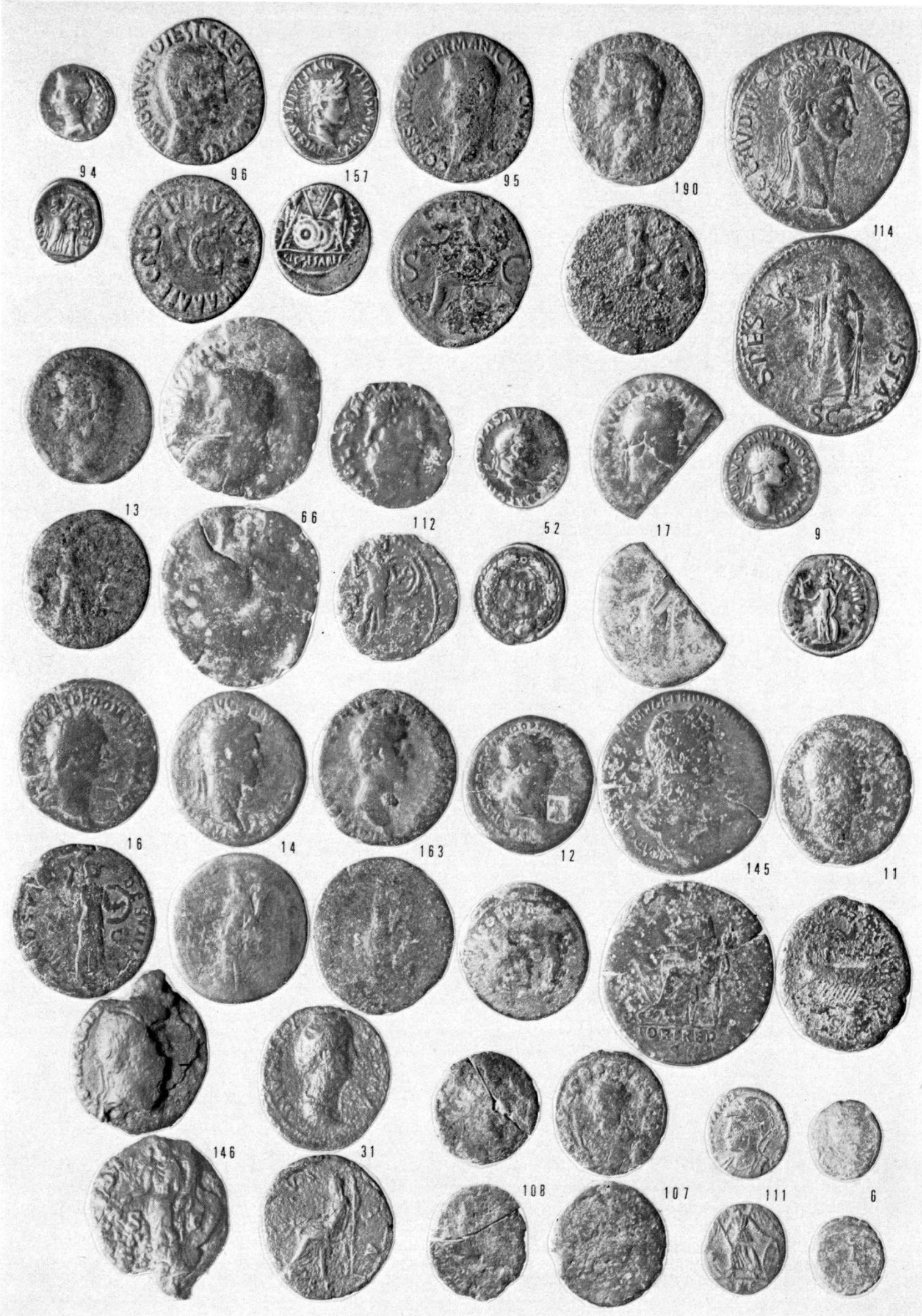

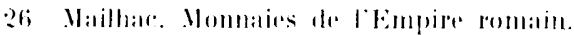


Ineenlaire : $114: 27.40 ;: 34: 35 ; 4 ; 6$.

liéferences : sestere RIC I. p. 129. no (i.t 41-52, IICRE I. p. 101, no so it2-44 ou plus récenl).

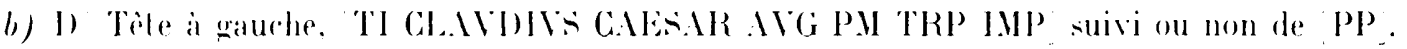
R Vinerve a droile, lenant une lance el un bouclier, s $C^{2}$

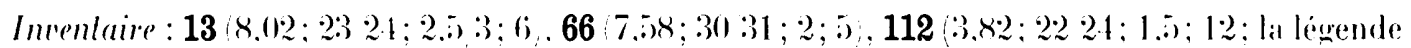

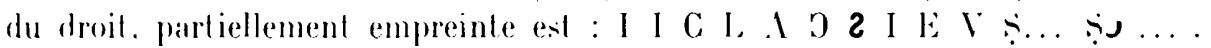

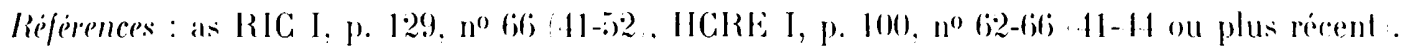

Le monnayage ofliciel de Claude a domne lieu a de nombreuses imitations : J.-B. Ciard. Pouvoir rentral el libertes locales. le momnayage en bronze de Claude avant jol ap. J.-C.. dans Remue Iumismalique, fie serie, 12, 1970, p. 3i)-6il, qui les date de la période 11-iol ap. J.-G.44.

1). Vespasien.

a) Denier de Vespasien.

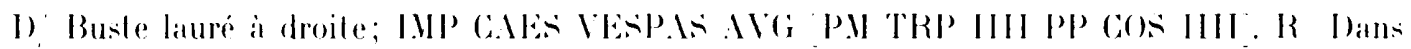
me couromne. SP(y) ()B $\mathrm{C}$ :

Imenlaire : 52 argent fourre: : 2, $,: 3: 1 \times: 2 ; 7$.

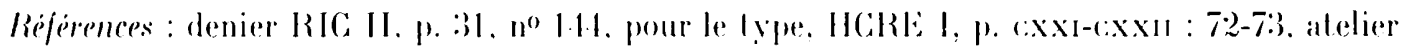
de liaule (L,yon?)

b) As de tomitien imis sous Vespisien.

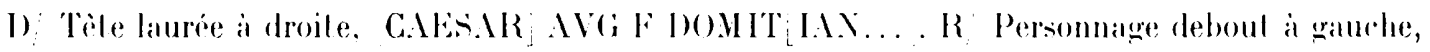
probablement FELICITAS PVBIICII] S

Inventaire : $17(7.29(1: 2 ; 2(j, 5) ; 3 ;(j)$.

Riferences: as RIC II, p. 96-100 (7:3-79;, HCRE I, p. 219-2i) (73)-7x).

li. Homilien.

a) Denier de Donilien.

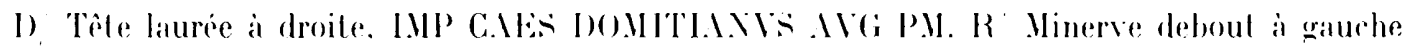

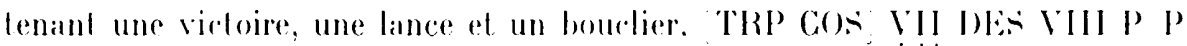

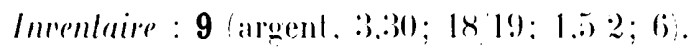

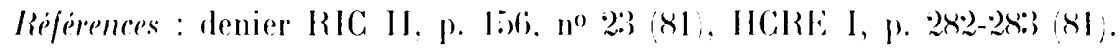

44 Sos trois exemplaires ont de bonnes chances dêtre des imilalions. On remarequera, en particulier, l'exemplaire 112, en raison de la Jégende du droit tres alterie mais aussi de la tête gui ne serail pas sans rappelere cerlle

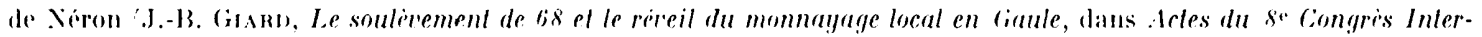

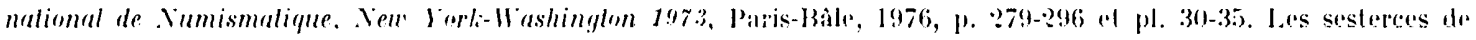

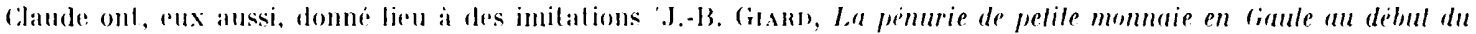

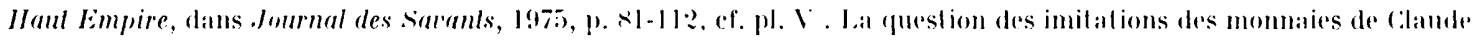

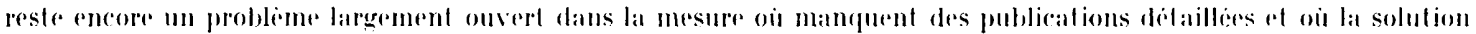

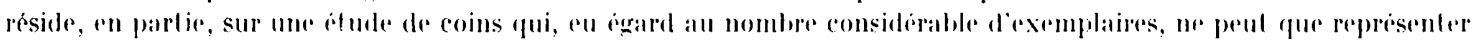

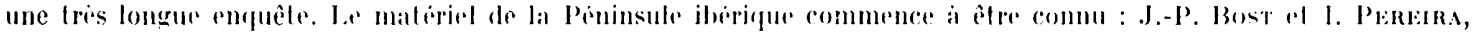

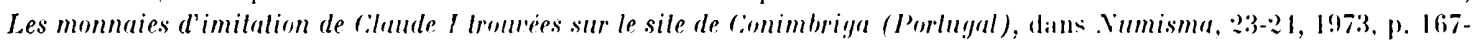

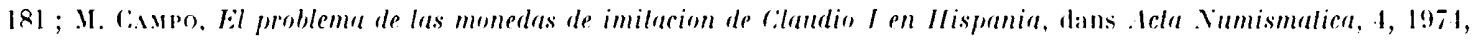

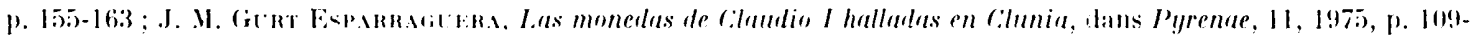

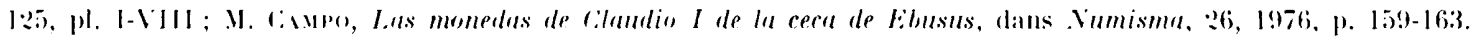

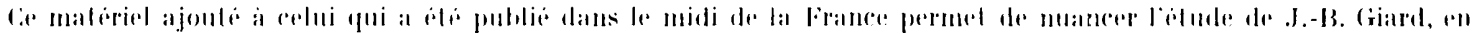
1970, exclusivement centree sur la moilie nord de la France. 
b) Is de Domitien.

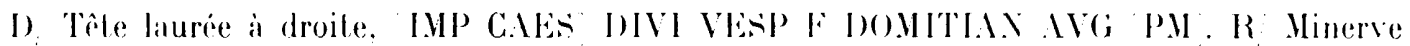
debout a droite tenant une lance et un bouclier. TRP Cos VII Hes VIII P P S G

Inventaire : $16(10,20 ; 26 ; 27 ; 2,5) ; \vdots)$.

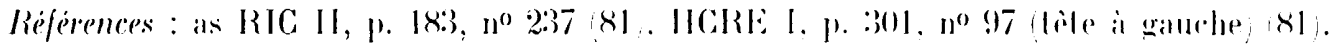

F. Nerva.

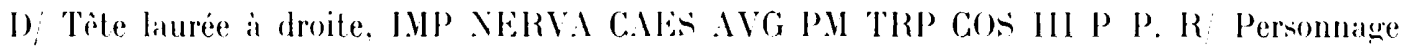
debout a gauche.

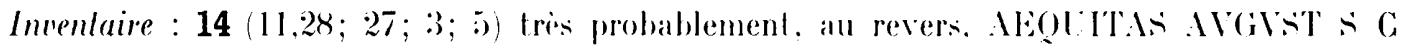
tenant une corne d'abondance el une balance) 163 (8.24; 27; 2 ; 6 ; type du revers identique au précédent ou FoRTVXI AVGSTT s G lenanl une corne d'abondance et un gouvernail.

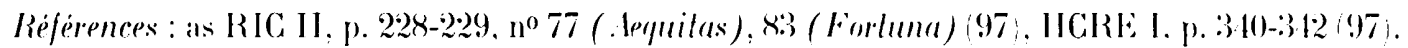

(i. 'Trajan.

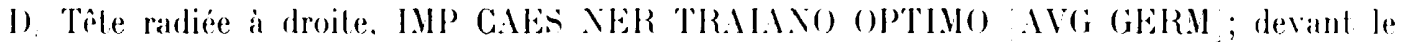
cou, contremarque. dans un carré (de part el d'aulre d'une tige verticale deux reliefs punctiformes;;

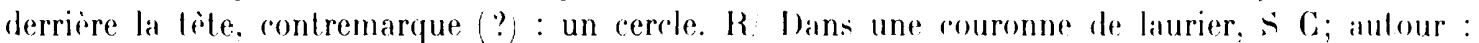
I)AG PARTHIGO PM TRLPOT NTX GOS VI PP

Inventaire : $12(7.72 ; 24 / 2 ;) ; 2.5) ;(6)$.

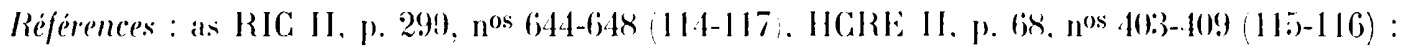
atelier de l'Est, (Chypre?). La contremarque de forme carré figure sur un exemplaire du British Vuseum (11. Mallingly. Coins of the roman empire in the British Musenm. III. Terra Lo Madrian londres, 1936. p. 2:32. no 1095) qui présente aussi. derriere la tible, la seconde contremarque circulaire au centre de laquelle se trouve un bucrane; W. E. Metralf, I note on Trajan's latin aps from Intioch. dans . Wuseum Voles, 22. 1977, p. 67-70, pl, 6-9.

II. Hadrien.

a) Sesterce d'Hardrien.

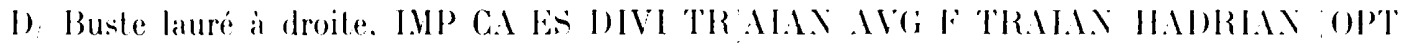
IVG Gik. R la Fortune assise a gauche lenant un qouvernail et une corne d'abondance,

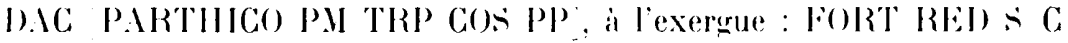

Inventaire: $145(23,62 ; 3233): 4 ; 6$;.

Reférences : sesterce RIC II. 1. 40), no :30) (117). HCRE II, p. I.IX (117:.

b) Is d'Harlrien.

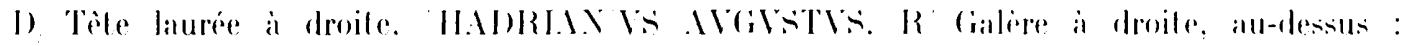
Cosi III ; au-dessous : : $\mathrm{C}$

Invenlaire: 11 (11.69; $16 ;: 3 ; \vdots)$ :

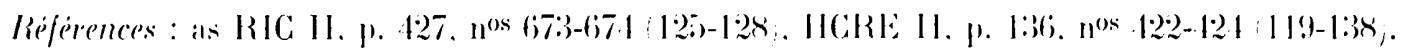

1. Intonin le Pieus.

a) Is d'intonin le Pieux.

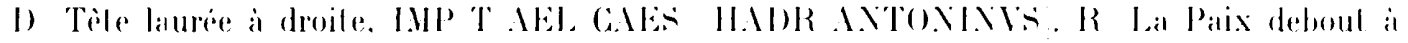
qauche lenant une branche ef une corne dabondance, PM, TR POT COS IDS II S G 


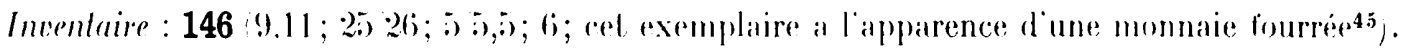

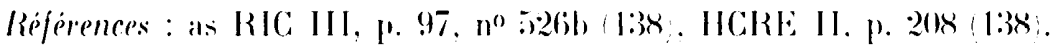

b) Is de Faustine 1 .

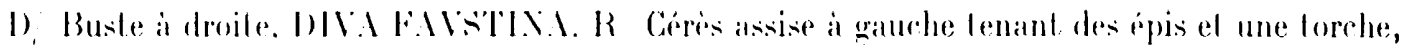

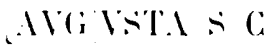

Ineenlaire : $31(8.73) ; 2) ; 2: 3 ; 6$.

References: as RIC 111. p. 167. no 1170 apres 141 , IICRE II, p. 269, nos 126-127 (apros 141 ).

J. Monnaies du na sicicle.

a) I) Tale radiée a droile, frusle. $\mathrm{K}$ fruste.

Imenlaire : 108 (brisie en deux morceaux; 2.1:3;20; 2; ?.

lieferences: : Il sagit d'un antoninianus.

b) I) Buste rarlie it gauche. IMIP C PROBBVsi... K Fruste.

Ineenlaire : $10 \%(3,09 ; 2) ; 1,5 ; ?)$.

References : RIC V. 2. p. 1-121; IICRL: IV. p. 158-202 : antominianas de Probus (276-282).

li. Ilomaies du we siriele.

a) Xummus, Rome.

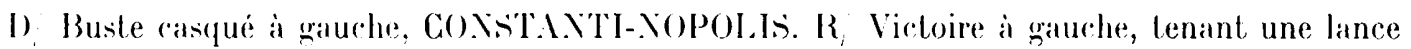
et un bouclier, sur une proue; a l'exerue : $\mathrm{R} * \mathrm{P}$

Inentaire : $111(2,18 ; 16 ; 2 ; 12)$.

References: I.RBG I, p. 15, no 372 (3:35)-337), RIC VII, p. 341, no 371 (33)-3336).

b) 1) Tite a droite. R Personnage debout, légende : Pictoria angg (?).

Invenlaire : $6(1,67 ; 14 ; 1, \overline{5} ; 12$.

Réferences: : .

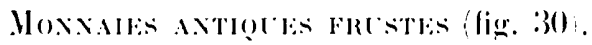

labal de conservation des exemplaires suivants n'a pas permis une identilicalion précise : il sagit en toul cas de monnaies antiques.

Imenlaire : $10(1.21 ; 1213 ; 2 ; ?) .15(3,8 ;) ; 1718 ; 2,5) ;$; au droil, tète à gauche, au revers, animal a droile, tète levée; cellique (?)), $19(4,46(1 ; 2) ; 24 ; 3) ; 11$; ibérique (?)), $22(7,5) 8(1 / 2)$; $27 ; 3 ;$ ?; ibérique (?)). $48(2.74 ; 15 ; 2 ; ?$; argent (?)), $49(1,5) ; 1: 3 ; 2 ; 2 ;$ Marseille (?)), 67 (2,8:3; $1415 ; 2,5 ; 3), 69(9,32 ; 2 ; 26 ; 2,5) ; ?$. Rome, Haut-Empire (?)), $104(2,() 8 ; 14 / 15 ; 3 ;$ ?), 110 (argent allie; 1,$74 ; 12 ; 2 ; ?), 124(1,58 ; 1112 ; 2 ; ?), 125(6,28(12) ; 28 ; 29 ; 6 ; ?), 148$ (argent allié; 1,87; $1214 ; 2.5 ; ?), 172(4.66(12) ; 24 ; 3 ; ?), 183(10.93 ; 25) 26 ; 3 ; ?) 189(3.73 ; 1213 ; 4 ; ?)$.

Tous res exemplaires proviennent du niveau Cayla $V$ (7) av.-200 ap. J.-C. . a l'exreption de fiT ef 18:3 qui nont pas de contexle archéologique précis.

1 res 192 monnaies antiques qui ont éte découvertes sur loppidum du Cayla il faut ajouter une monnaie qui provient d'un remaniement moderne observe dans la fouille $40^{46}$.

15 Seule une analỵse permella didentifier les mólaux. Sur l'existence durant l'Fmpine de monnaies fourrées de milaux vils: M. Tumox, Bronzes romains à ame le fer lroures en Belgique, dans Bull. Cercle d Éludes . Vumismaliques, 1:, 1975, p. 41-4.4 e1 J.-L. Deswir, Nolueau bronze a ame de fer, ibidem, 13, 1976, p. 30-3:.

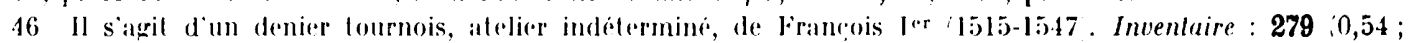

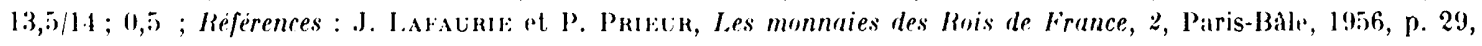
n 7:27. Détermination de. M. M. I)hénin 'fig. 29 . 

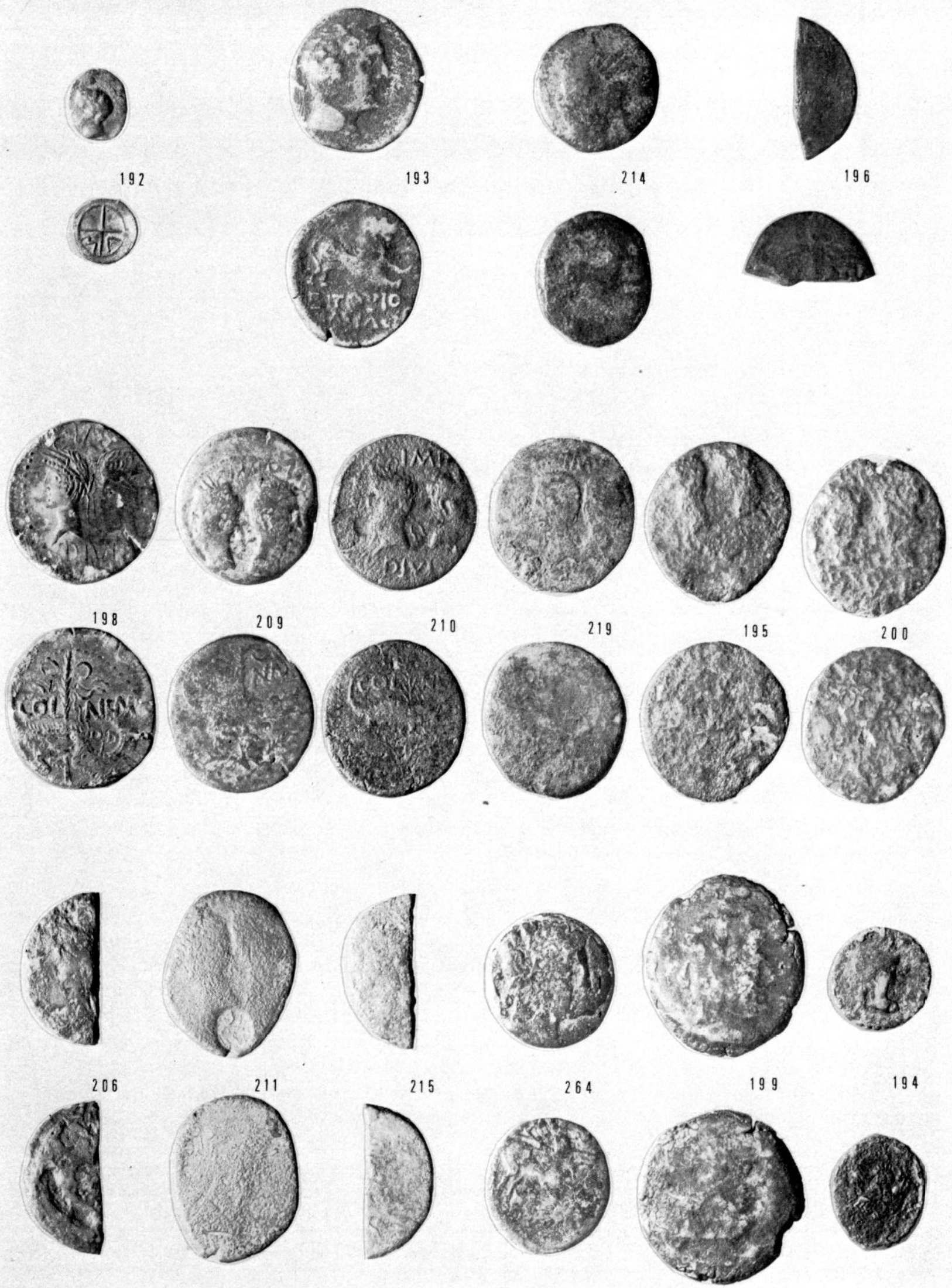

194

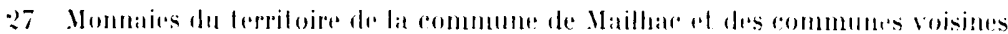




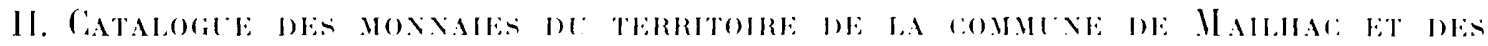
COMMINAS VOSINES.

Nous regrompons an un soul alalogur loutes les découvertes qui ont éte faites en dehors de loppidum du Cayla. Cirs se doeuments permoltront de completer l'histoire monetaibe dre la régiom mailharcienne.

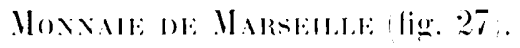

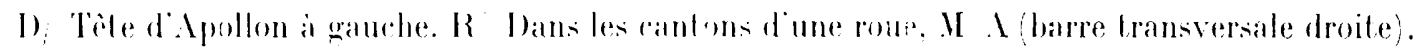
Intenlaire : 192 iarent; $10.6 \% ; 11,12 ; 1: 9$.

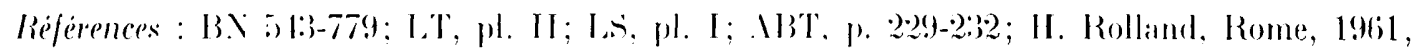
p. 11:3-115: (1. supra. p. 1017.

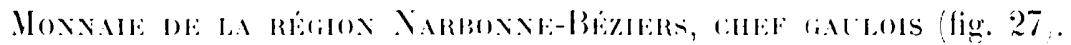

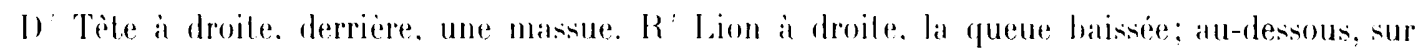

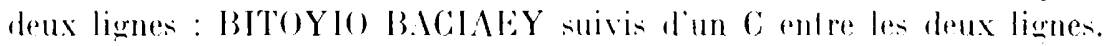

Ineenlaire : $193(8.0): 24 ; 2.5 ; 2$.

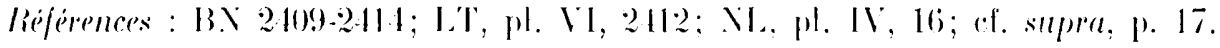

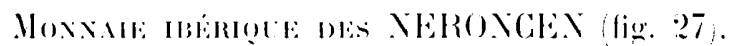

I) The feminine a droile, devant : E-B.A. R Taurean bondissant a droite; au-dessus, rouronne; all-dessous, en lettres iberiefues: $\mathrm{X}-\mathrm{E}$-R-O-N-CF-N

In!enlaire : $214(8,80 ; 202) ; 2 ; 10$;.

liejerences : c. snprat. p. 18, .1.

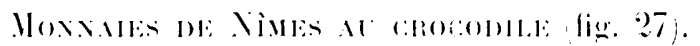

fer type $(\cdot f$. stupra, p. $2 \cdot 2, a$.

Inventaire : $196(1.10(12) ; 2: 3 ; 3 ; 9 ; 198(10.29 ; 26 \% 27 ; 3 ; 1$; variéte dile au cimier; au revers contremarque I)I), 209 (1423; $26 ; 3 ; 7 ;$ au droit, au-dessus des letes, contremarque reclangulaire :

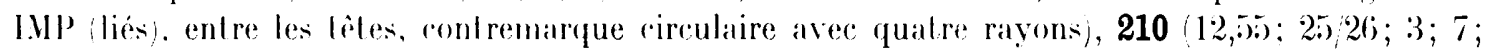
an droit. contremarque rirculaire ? $219(13.109 ; 25 / 26 ; 3 ; 12$; variété aux bustes relies par la base.

Les exemplaires suivants apparliennent an for ou au 2 type : $195(8,73 ; 2126 ; 2,5 ; 1,200$ $10 . \overline{1}+4 ; 25) 2(3 ; 3,5 ; 3 ;$.

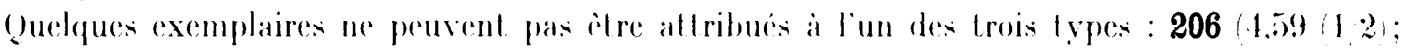

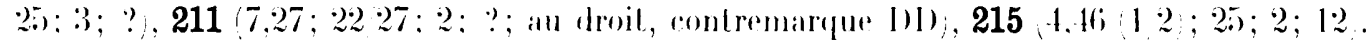

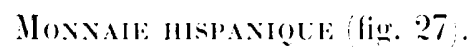

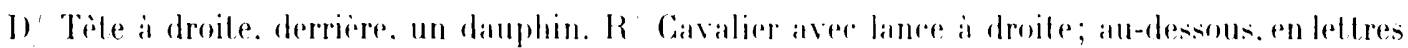

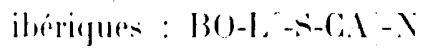

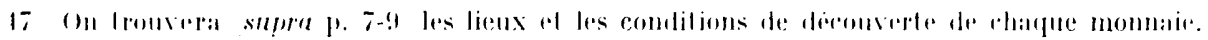




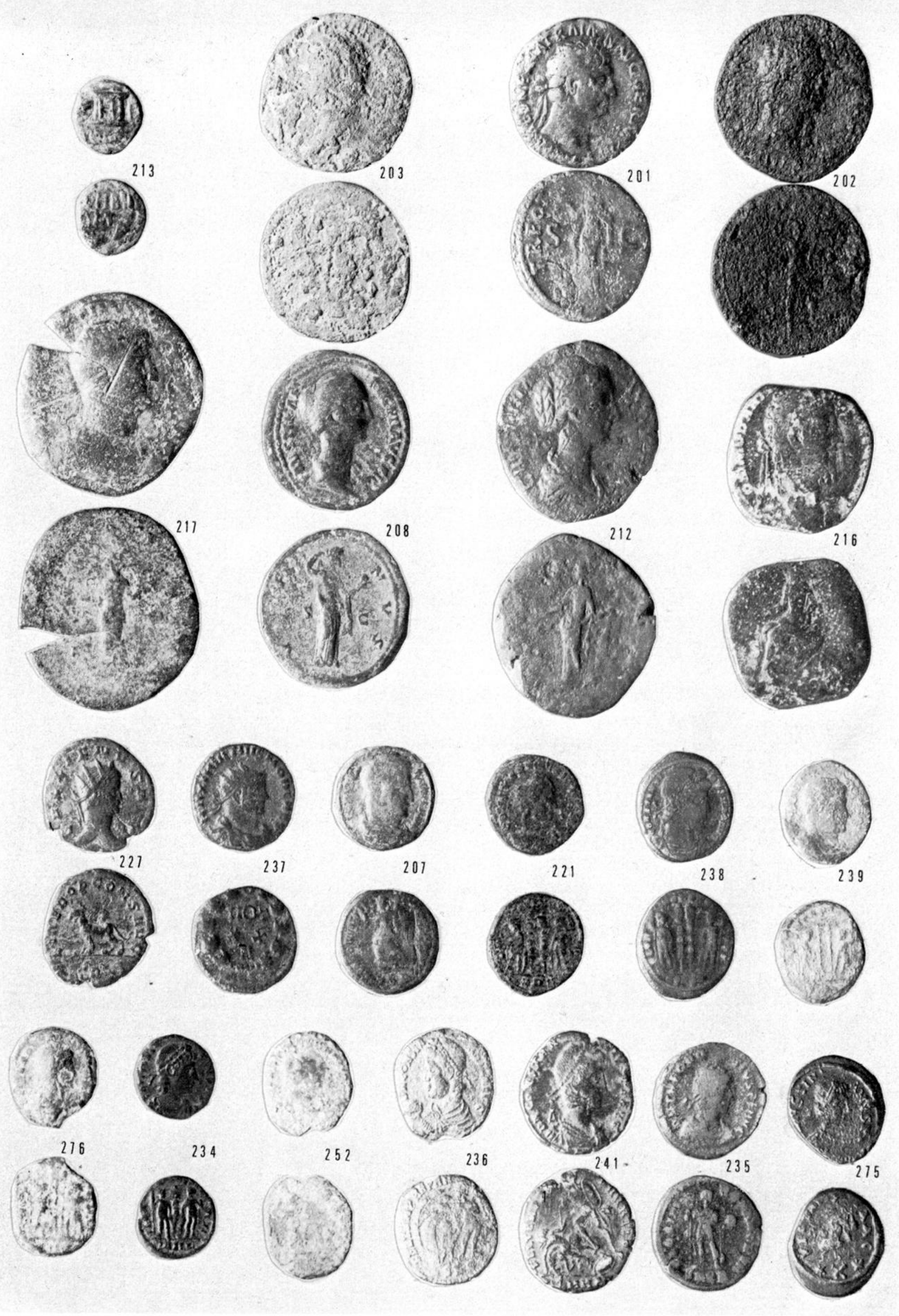

ix Momnates du ferriloire de la commune de Mailhare of des communes voisines. 
Invenlaire : $264(\overline{1}, 18 ; 22: 2: 2 ; 2 ;$.

Références : A. Vives y Escudero. op. cil. pl. XI.III; 1. M. de Guadan, op. cil., p. 202, 139, $1.15: 1105-40$ ar. .J.-C.

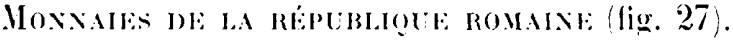

a) Bronze, atelier de Rome.

I) Têle de Janus. R Proue. fruste.

Imentaire : 199 /13.22; $2830 ; 3 ; 9)$.

Références : en raison de l'élat d'usure et malgré son poids il s'agit probablement d'un as oncial, (f. sup)ra, p. 29 a.

b) Arcrent, denier C X.LE B.AIB.

I) Tate de Venus à droite, derriere : s $\mathrm{C}$. R. Victoire dans un trige à droite; à l'exergue : ¿G. NAL (liés).B.\IB (liés); au-dessus, marque de contròle : 1 ..

Invenlaire : 194 (fourré; $2.15 ; 17: 18 ; 2 ; 3$ ).

Références: :RRC. p. :397. no:382/1b: 79 av. .J.-C.

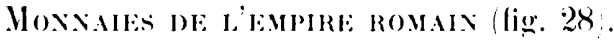

A. Auguste.

I) Autel rond, au centre : $\mathrm{K}(=20$ drachmes), KAIS AP . R I)ans une couronne de laurier: CEBAGT OL!

Invenlaire : $213(2,16 ; 13 ; 2 ; 3)$.

Références : atelier d'Alexandrie sous Juguste (27 ar.-14 ap. J.-G) : G. Dattari, Monete imperiali greche. Numi Lugg. Llexandrini, I.e Caire, 1901, p. 1-2; J. G. Milne, Calalogue of Alexandrian Coins. Oxford, 1971, p. 1; Sylloge . Nummorum Graecorum, The Royal collection of coins and . Kedals, Danish Vational .Maseum. 41, .lexandria-Cyrenaica, Copenhague, 1974, no 12.

13. Glaude.

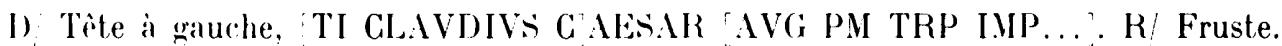

Inenlaire : $203(7,17 ; 27,29 ; 2,5) ; ?)$.

Références : as $(41-\overline{0}) 4)$.

C. Trajan.

a) I) Tôle laurée a droile, IMP GALs NERVA TRAIAN AVG GERM PM. R Pietas debout à gauche, TR PO'T GOS II is C

Inventaire : $201(11,14 ; 26 ; 3 ; 6)$.

Références : as RIG II, p. 27:), no $39: 3$ (98-99). IICRE II, p. 36, no 215 (98-99).

b) I) Tìte laurée a droite. IR Personnage debout.

Imenlaire : $202(8.76 ; 29: 30 ; 2.5 ; 6)$.

Références : as $(98-117)$. 
J). IIadrien.

I) Buste à droite. $\mathrm{K}$ Personnage debout.

Inventaire : $217(23,32 ; 333 ; 34 ; 4 ; 5)$.

Références : sesterce (117-138;.

k. Antonin le Pieux.

I) Buste a droite, FIVSTINAE AVG PII AVG FIL. R/ Venus debout à droite, VE.TVS is C Inventaire : $208(10,29 ; 27 / 28 ; 3 ; 11)$.

Références : as de Faustine II, sous Antonin le Pieux, RIC III, p. 194, n 1410, HCRE II, p. $298-300)$ (c. $147-161$ ).

F. Commode.

a) I)/ Buste a droite, CRIsPINA AVGVsTA? R Laetitia debout i gauche tenant une couronne el un gouvernail, [L.AETITIA is $\mathrm{C}$.

Inventaire : $212(17,28 ; 30 ; 31 ; 3 ; 12)$.

Références : sesterce de Crispine. sous Commode, RIC III, p. 442, no 669, HCRE 1I, p. 452, nos $31-36$ (180)-18:3 ou plus récent:

b) I) Buste lauré a droite, M; GOMMOH ANT P FELIX AVG BRIT ? ; R; Personnage assis a gauche.

Inventaire : $216(19.27 ; 25 ; 27 ; 4 ; 12)$.

Reférences: : sesterce de Commode RIC III, p. 428-4333 (189-191). HCRE II, p. 433-444 (188-191).

G. Monnaies du in sibcle.

a) Gillien.

D) Tète radiée à droite, GitLILENV' AV(i. R Panthere marchant a gauche, LIBBERO P

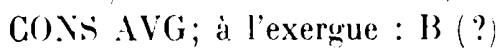

Inventaire : $227(2,80 ; 19 ; 21 ; 1,5 ; 1)$.

Références : antoninianus RIC V, 1, p. 151, no 230 : émission dite du bestiaire, 267-268; R. (Göb), Der Aufbau der römischen Münzprägung in der Kaiserzeit, V2, dans . Vumismalische Zeilschrifl, 75, 1953), p. 17 : milieu 267-début 268 .

b) Maximien.

I); Buste radié el drapé a droite, MAXIMIANVs NoB C.AEs. R Dans une couronne. VOT XX, au-dessous : $\Delta$

Inventaire : $237(2,90 ; 1819 ; 1,5) ; 6)$.

Références: fraction de follis RIG VI, p. 360), $\mathrm{n}^{0} \times 8 \mathrm{~b}$ (atelier de Rome, 297-298).

H. Monnaies du re siecle.

a) I) Buste a droite, GONSTAN-TINV' AVG. R: Victoire a gauche tenant une couronne, palme, VIGTORLA-AVGGili; a l'exergue : Ts. 1

Inventaire : $20 \%(3,07 ; 18 ; 19 ; 2 ; 11)$.

Références : follis RIG VII, p. 506, no 59 (atelier de Thessalonique, 319/. 

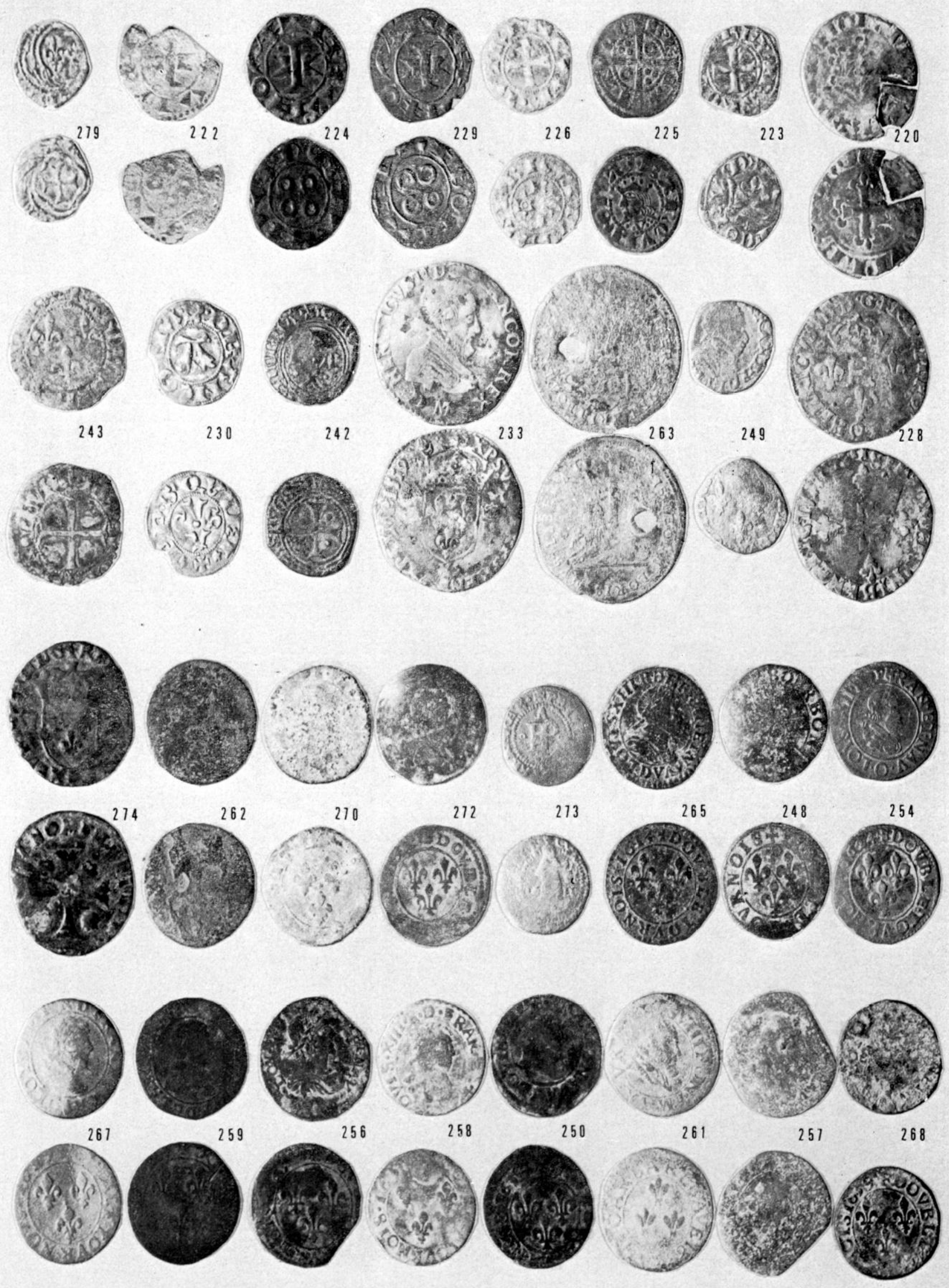

:9 Mailhac. Monnaies médiévales in morlernes. 


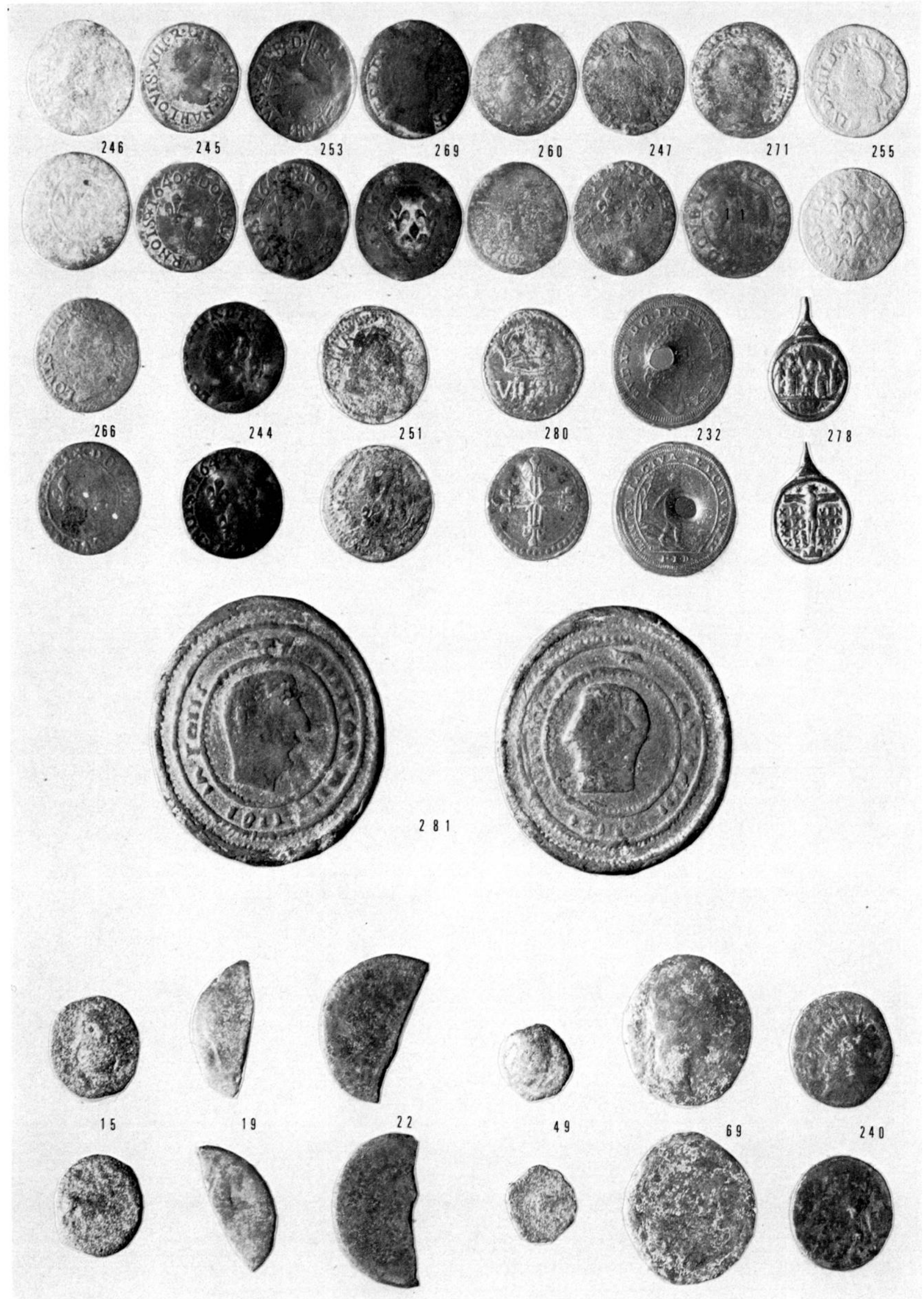

30 Mailhace. Yonnains modernes et contrmporaines, momnates non identifiess. 
b) 3:30-305. type ciloria exercilus. deux enseignes.

Inrenlaire : $221(2,4) ; 18 ; 1.5 ; 7$.

Rieferences: L.RBC I. p. 15, no 5.1:) : atelier de Rome.

Intentaite : 238 (2.39; $1819 ; 1 ; 5$.

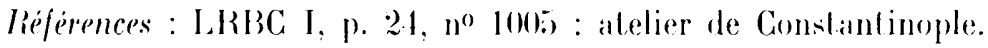

Inrentaire : 239 (2,09);17 18; $1 ; 5) .276$ (2,21; 16:17; $2 ; 6$.

c) 3:36-341, type tilorin exercilus. une enseigne.

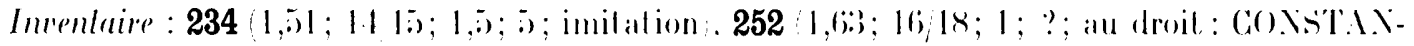
TINS ITI?

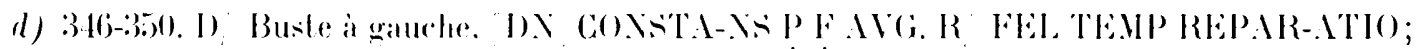
a l'exergue : $\approx$ sldi

Inventaire: 236 (2.60) $1819 ; 2 ; 7$.

References: aes 2 I.RBC II, p. 19, $\mathrm{n}^{\circ}$ I80); atelier de L, anon.

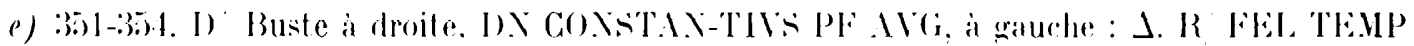

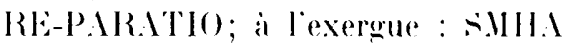

Inrenluire : $241(1,14 ; 21 ; 1.5 ; 11$.

Réferences: aps 2 I.RBC; 11, p. 8:3, no 1896 : atelier d'Iteraclée.

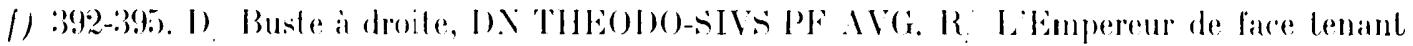

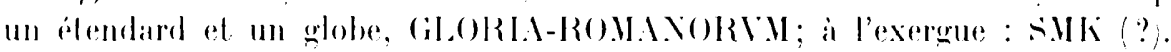

Inrentaire : 235 (5)(15; $20121 ; 2 ; 7$.

Rejerences: aes 2 RIC IX, p. 216, no 27 (a) : alelier de Cyzique.

I. Yonnaie du vie siecle.

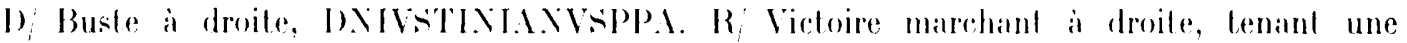
couronne et un onlobe, VICTORIMAC; i l'exergue : $x$.

Invenlaire : 275 (1.14; $1719 ; 2 ; 7$;.

Rieferences: : C. Morrisson. Calalogne des monnaies byzanlines de la Bibliolhionue Vationale,

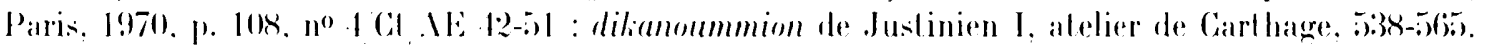

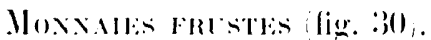

Létal de conservation des monnaies suivantes a rendu impossible une identification precise.

Inrentaire : 240 (6.19; 20 ; 2.5); 12; au droit, lite radiée a droite au revers, personnage debout:

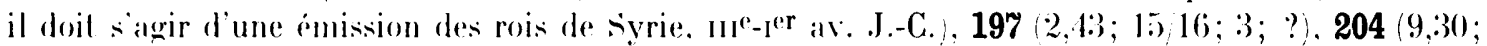
$2(i ; 4 ; ? 205(9.19 ; 2(6) 27 ;) ; ? 218(7,5) ; 2 \times 29 ; 2 ; ?$.

1 rel ensemble de 12 monnaies antiques derouverles en dehors de l'oppidum du Canyla. on doil ajouter un wroupe de lfi doruments médievaux, moderness el contemporains qui complitent ce minlaillier ${ }^{48}$

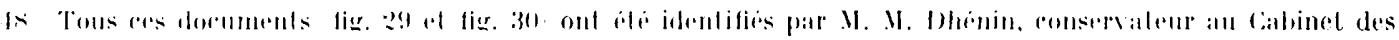

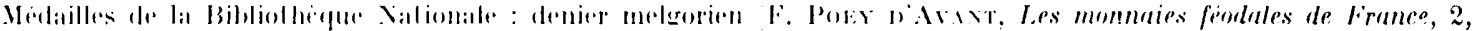

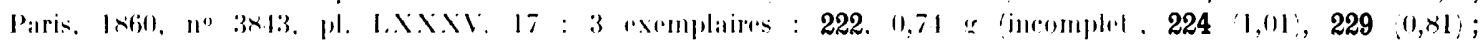

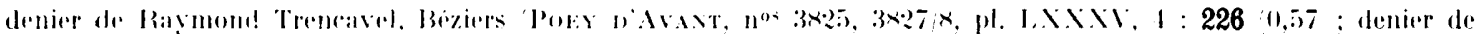




\section{C. - LA CIRGILATTON MIONETAIRL}

Les monnaies antiques découvertes à Mailhac de 19831 à 1977 occupent une période qui va du ve siecle av. J.-C. au vie siecle ap. J.-C. cet atterignent un total de 2:34 individus sur lesquels 192 proviennent de l'oppidum du Ciayla.

En regroupant les éléments typologiques, chronologriques at quantitatifs de tout le médaillier, nous obtenons un tableau global qui permet de presenter quatre pourcentages $^{49}$ :

I pourcentage de chaque série par rapport aux deux ensembles 1993 el 281 exemplaires;

Il pourcentage par rapport aux mèmes totaux mais en groupant les séries par atelier, métal, émission ou région;

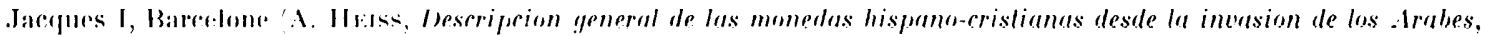

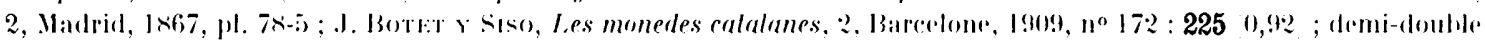

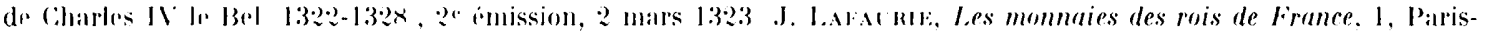

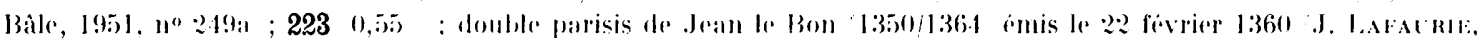

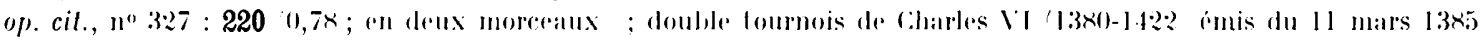

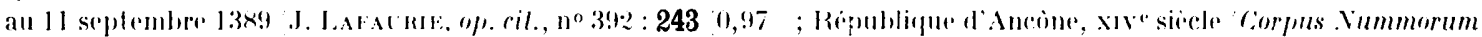

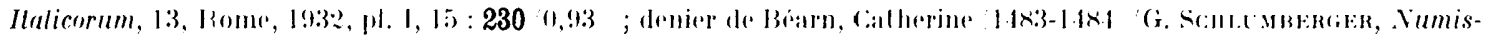

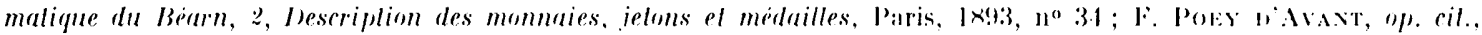

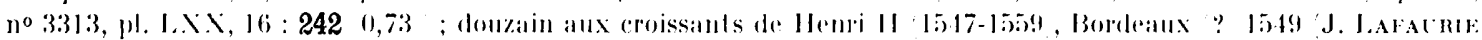

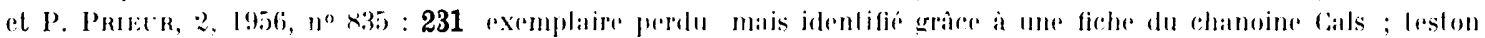

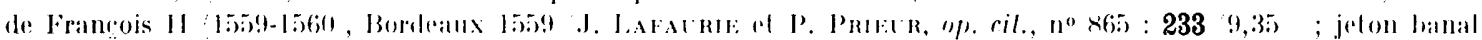

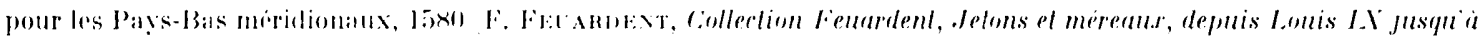

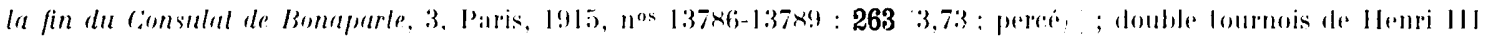

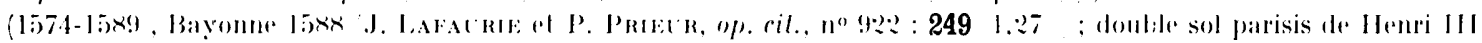

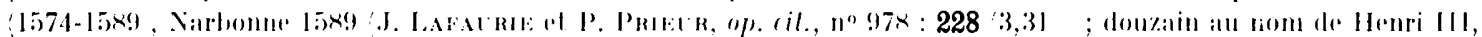

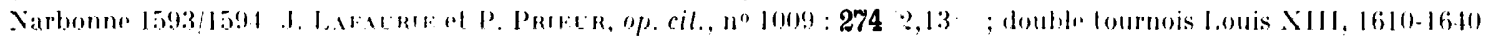

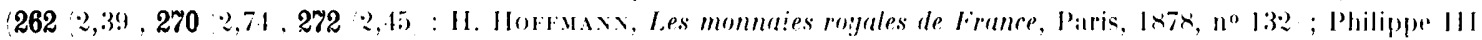

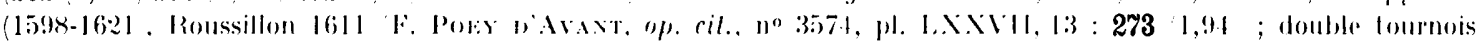

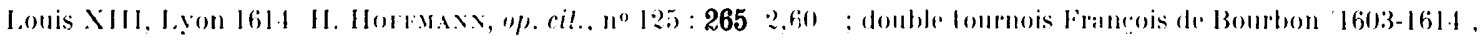

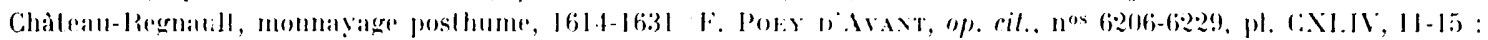

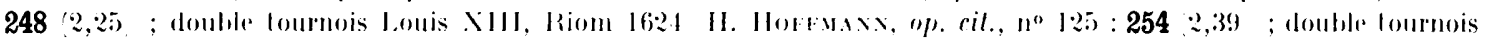

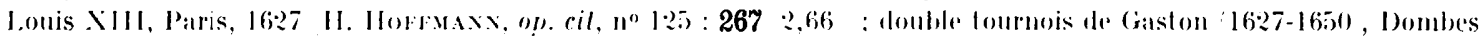

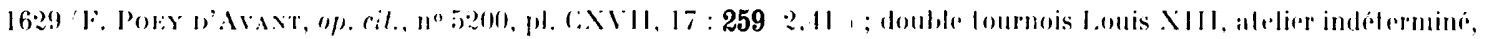

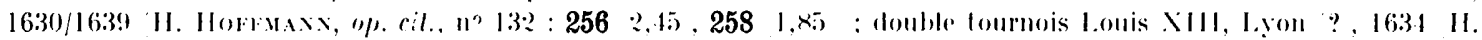

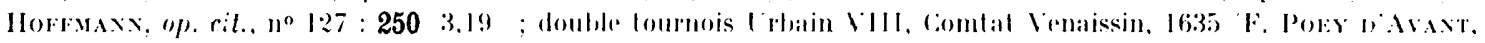

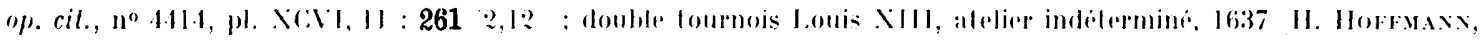

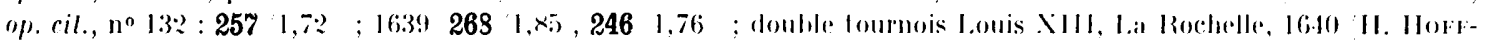

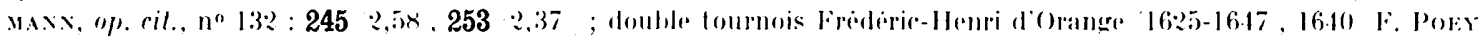

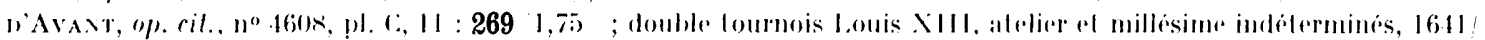

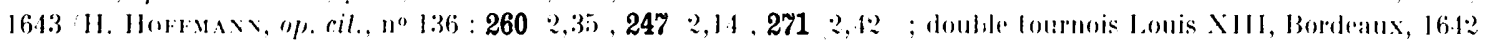

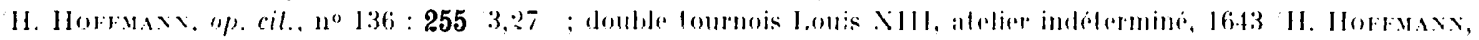

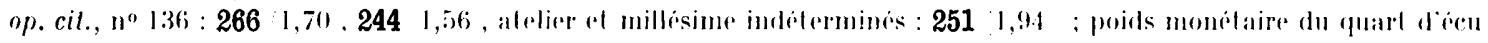

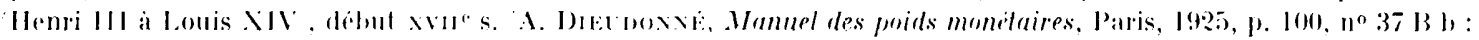

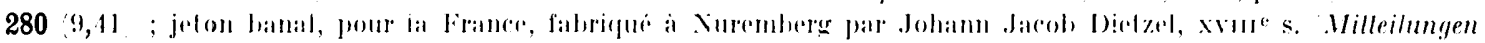

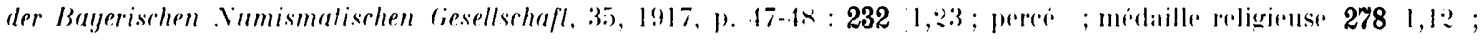

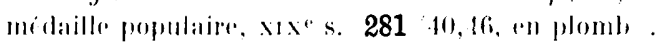

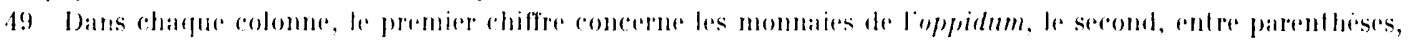

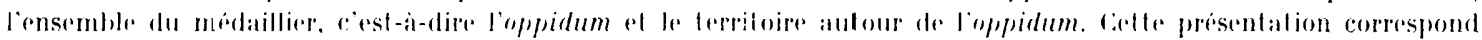

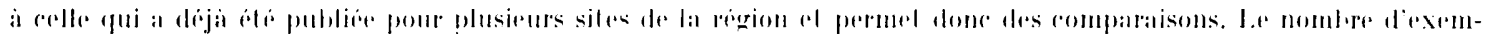

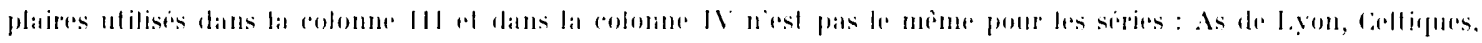

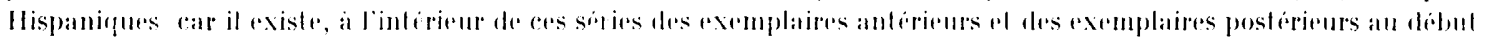

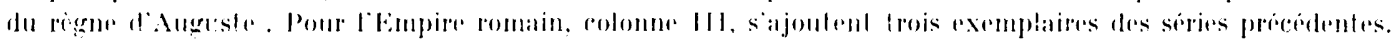


III pourcentage par rapport à l'ensemble constitué par loutes les émissions jusqu'à celle de Claude I exclues, en laissant de còté les monnaies frustes et les monnaies postérieures à l'Antiquité (157 el 174 exemplaires);

IV pourcentage par rapport à l'ensemble constitué par toutes les émissions jusqu'à celles d'Auguste exclues, en laissant de còté les monnaies frustes et les monnaies postérieures a l'Antiquité 1121 et 127 exemplaires $\}$.

\begin{tabular}{|c|c|c|c|c|c|c|c|c|c|}
\hline \multirow{2}{*}{$\begin{array}{l}\text { Séries et nos d'inventaire } \\
\qquad 1-281) \\
\text { MARsEille } \\
\text { oboles : } 184,3,134,154,185, \\
181,192 . \\
\text { imitation : } 156 . \\
\text { drachmes : } 41,42,43,1 .\end{array}$} & \multirow{2}{*}{ 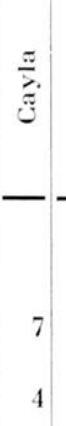 } & \multirow{2}{*}{ 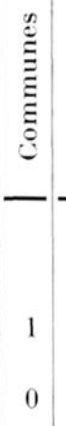 } & \multirow{2}{*}{ 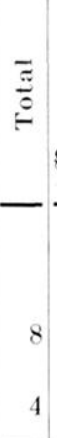 } & \multirow{2}{*}{$\begin{array}{c}\text { I } \\
\begin{array}{c}\text { Pourcentage par } \\
\text { rapport au total } \\
\text { général } 193(281)\end{array} \\
\\
3,62 \%(2,84 \%) \\
2,07 \%(1,42 \%)\end{array}$} & \multirow{2}{*}{$\begin{array}{c}\text { II } \\
\text { Groupement des } \\
\text { séries par rap- } \\
\text { port au total } \\
193(281) \\
\\
\\
5,69 \%(4,27 \%)\end{array}$} & \multicolumn{2}{|c|}{$\begin{array}{l}\text { III } \\
\text { Pourcentage par } \\
\text { rapport à } 157(174) \\
\text { des origines à } \\
\text { Claude }\end{array}$} & \multicolumn{2}{|c|}{$\begin{array}{c}\text { IV } \\
\text { Pourcentage par rap- } \\
\text { port à } 121(127) \\
\text { des origines à } \\
\text { Auguste }\end{array}$} \\
\hline & & & & & & $\begin{array}{c}7 \% \\
(6,89 \%)\end{array}$ & $15,92 \%$ & $\begin{array}{c}9,09 \% \\
(9,44 \%)\end{array}$ & $20,66 \%$ \\
\hline $\begin{array}{l}\text { P. B. taureau : } 2,8,32,71, \\
73,100,149,174 . \\
\text { P. B. taureau passant : } 101 \text {, } \\
102,159 . \\
\text { P. B. caducée : } 4,188 . \\
\text { P.B. tion : } 27 .\end{array}$ & $\begin{array}{l}3 \\
2 \\
1\end{array}$ & $\begin{array}{l}0 \\
0 \\
0\end{array}$ & $\begin{array}{l}3 \\
2 \\
1\end{array}$ & 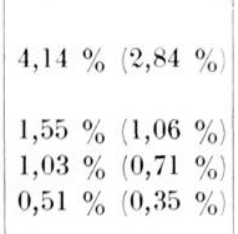 & $7,25 \%(4,98 \%)$ & $\begin{array}{c}8,91 \% \\
(8,04 \%)\end{array}$ & $(14,94 \%)$ & $\begin{array}{c}11,57 \% \\
(11,02 \%)\end{array}$ & $(20,47 \%)$ \\
\hline $\begin{array}{l}\text { NARBONNE-BÉZIERS : } 123, \\
173,122,193 . \\
\text { NERONCEN }: 140,141,175, \\
20,7,21,109,5,90,187,89, \\
121,214 .\end{array}$ & 12 & 1 & 13 & $6,21 \%(4,62 \%)$ & $\begin{array}{l}1,55 \%(1,42 \%) \\
6,21 \%(4,62 \%)\end{array}$ & $7,64 \%$ & $7,47 \%$ & $9,91 \%$ & $10,23 \%)$ \\
\hline $\begin{array}{l}\text { Volques arécomiques : } 36 . \\
\text { Namazat : } 26,54,55,99,178\end{array}$ & 5 & 0 & & 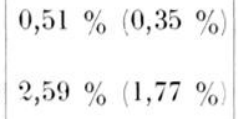 & $3,10 \%(2,13 \%)$ & $3,82 \%$ & $(3,44 \%)$ & $4,95 \%$ & $4,72 \%)$ \\
\hline $\begin{array}{l}\text { NEM COL : } 161 . \\
\text { As DE NIMES : } 18,29,44,46, \\
56,77,78,115,138,165,166, \\
169,179,196,198,209,210, \\
219, /, 75,137,139,167, /, \\
45,57,116,170,171,195, \\
200, /, 30,70, /, 23,76.153, \\
168,206,211,215 .\end{array}$ & 28 & 10 & 38 & $\begin{array}{c}14,50 \% \\
(13,52 \%)\end{array}$ & $\begin{array}{c}15,02 \% \\
(13,87 \%)\end{array}$ & $18,47 \%$ & $(22,41 \%)$ & $0,82 \%$ & $0,78 \%)$ \\
\hline 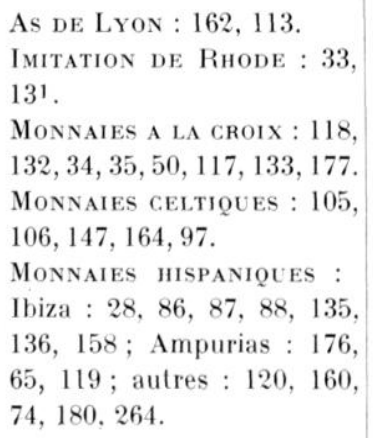 & 2 & 0 & $\begin{array}{l}2 \\
2 \\
8\end{array}$ & 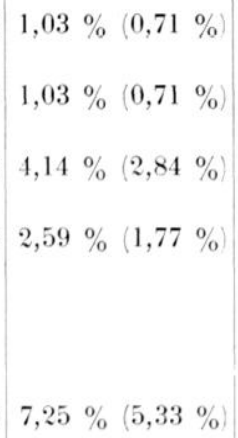 & $\begin{array}{l}1,03 \quad \%(0,71 \%) \\
1,03 \quad \%\left(\begin{array}{ccc}0,71 & \%\end{array}\right) \\
4,14 \%(2,84 \%) \\
2,59 \%\left(\begin{array}{ccc}1,77 & \%\end{array}\right)\end{array}$ & $\begin{array}{l}1,27 \% \\
1,27 \% \\
5,09 \% \\
3,18 \%\end{array}$ & $(1,14 \%)$ & $\begin{array}{l}0,82 \% \\
1,65 \% \\
6,61 \% \\
3,30 \%\end{array}$ & $\begin{array}{l}0,78 \%) \\
1,57 \%) \\
6,29 \%) \\
3,14 \%)\end{array}$ \\
\hline
\end{tabular}




\begin{tabular}{|c|c|c|c|c|c|c|c|}
\hline $\begin{array}{l}\text { Séries et } \mathrm{n}^{0 \mathrm{~s}} \text { d'inventaire } \\
\qquad(1-281)\end{array}$ & $\stackrel{\frac{\pi}{2}}{i}$ & 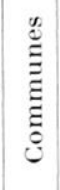 & $\frac{\pi}{0}$ & $\begin{array}{c}\text { I } \\
\text { Pourcentage par } \\
\text { rapport au total } \\
\text { général } 193(281)\end{array}$ & $\begin{array}{l}\text { II } \\
\text { Groupement des } \\
\text { séries, par rap- } \\
\text { port au total } \\
193 \text { (281) }\end{array}$ & $\begin{array}{c}\text { III } \\
\text { Pourcentage par } \\
\text { rapport à } 157(174) \\
\text { des origines à } \\
\text { Claude }\end{array}$ & $\begin{array}{c}\text { IV } \\
\text { Pourcentage par rap- } \\
\text { port à } 121(127) \text { des } \\
\text { origines à } \\
\text { Auguste }\end{array}$ \\
\hline 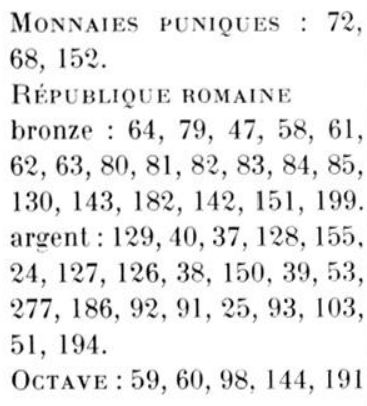 & $\begin{array}{r}38 \\
5\end{array}$ & $\begin{array}{l}2 \\
0\end{array}$ & $\begin{array}{r}40 \\
5\end{array}$ & $\begin{array}{c}1,55 \%(1,06 \%) \\
\\
\\
\end{array}$ & $1,55 \%(1,06 \%)$ & \begin{tabular}{|}
$1,91 \%(1,72 \%)$ \\
\\
$27,38 \%(25,86 \%)$
\end{tabular} & $\begin{array}{r}2,47 \% \quad(2,36 \%) \\
35,53 \% \quad(35,43 \%)\end{array}$ \\
\hline $\begin{array}{l}\text { Empire romain. Auguste : } \\
94,96,157,213 \text {; Caligula : } \\
95,190 .\end{array}$ & 5 & 1 & 6 & $2,59 \%(2,13 \%)$ & $2,59 \% \quad(2,13 \%)$ & $3,18 \% \quad 3,44 \%)$ & \\
\hline 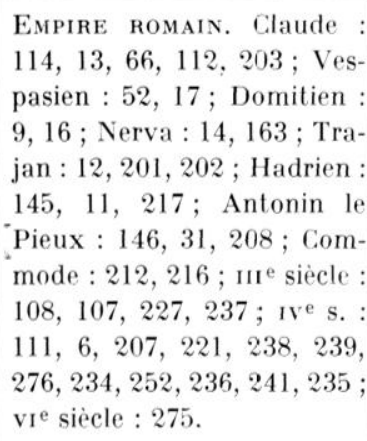 & 19 & 20 & 39 & $\begin{array}{r}9,84 \% \\
(13,87 \%)\end{array}$ & $\begin{array}{r}9,84 \% \\
(13,87 \%)\end{array}$ & & \\
\hline $\begin{array}{l}\text { Frustes: } 10,15,19,22,48, \\
49,67,69,104,110,124, \\
125,148,172,183,189,240, \\
197,204,205,218 .\end{array}$ & 16 & 5 & 21 & $8,29 \%(7,47 \%)$ & $8,29 \%(7,47 \%)$ & & \\
\hline $\begin{array}{l}\text { MÉdiévales - Modernes - } \\
\text { Contemporaines : } 220,222- \\
226,228-233,242-251,253- \\
263,265-274,278-281 .\end{array}$ & 1 & 46 & 47 & $\begin{array}{r}0,51 \% \\
(16,72 \%)\end{array}$ & $\begin{array}{c}0,51 \% \\
(16,72 \%)\end{array}$ & & \\
\hline TOTAL........... & 193 & 88 & 281 & & & & \\
\hline
\end{tabular}

Ce tableau doit être interprété à la lumière de quelques observalions préliminaires. 11 regroupe en effet des monnaies d'origine archéologique diverse car sont réunies des: monnaies provenant d'un niveau stratigraphique et des monnaies sans contextr on de surface. De plus, la datation de chacun des niveaux de l'oppidum du Cayla est encore large et il est probable que de nouvelles fouilles permettraient, a l'intérieur de chaque niveau distingué, d'individualiser des niveaux intermédiaires dans une stratigraphie 
plus fine ${ }^{50}$. Nous savons que, pour ètre veritablement recevable, un pourcentage devrait se rapporter à des monnaies d'un même niveau stratigraphique ce qui permettrait alors d'apprécier la durée d'utilisation de chaque série et les concomitances dans la circulation.

Quoiqüil en soit ces pourcentages manifestent globalement les tendances générales des apports monétaires à Vailhare. Il est important de relever qu'en considérant seulement les monnaies de loppidum (premier pourcentage) ou en ronsidérant celles-ci an même temps que les monnaies des environs de l'oppidum deuxieme pourcentage, entre parenthèses) less variations sont minimes sinon mème négligeables si bien que nous ne retiendrons iri que le premier pourcentage. La différence la plus importante réside dans les sièrles qui ont suivi le ${ }_{1}{ }^{\mathrm{e}}$ siècle ap. J.-li., après l'abandon de l'oppidum, au moment où l'habitat est certainement situé dans les plaines.

Lensemble des découvertes de Mailhac peut ètre présenté à l'aide d'histogrammes qui font immédiatement apparaitre les moments d'abondance monétairesis.

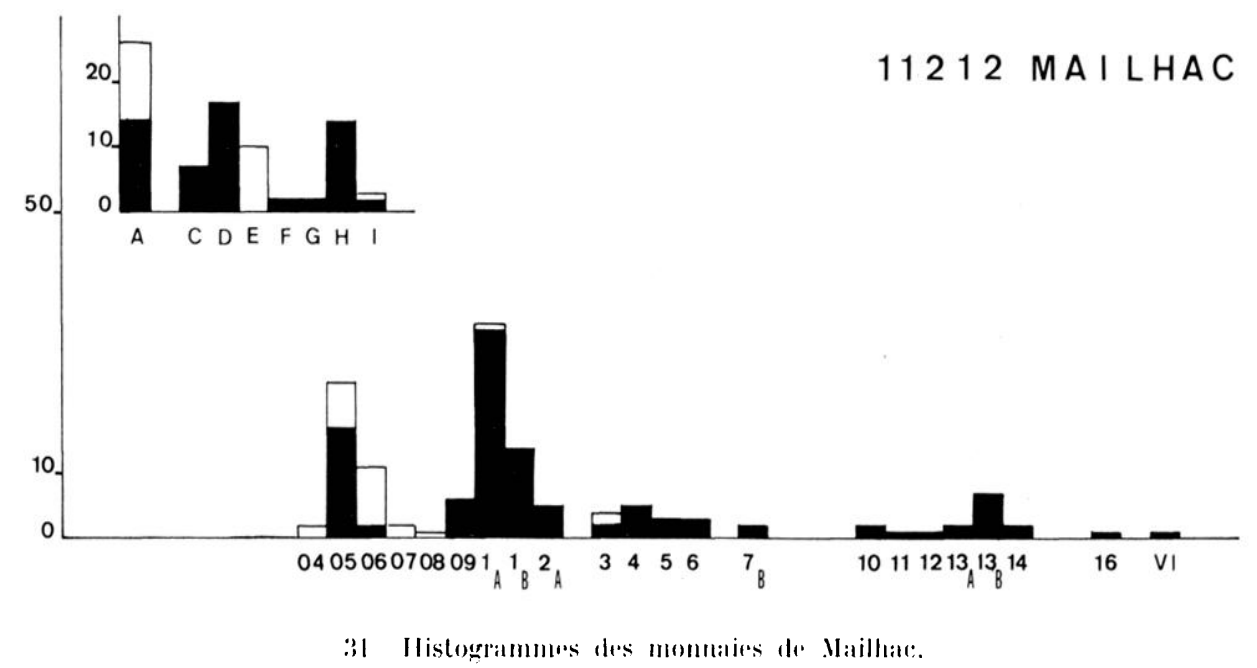

En fonction du tableau des pourcentages et des histogrammes et comple tene des reserves que nous avons exprimés, il est possible de faire quelques remarques sur er médaillier. Antérieurement à 32:) as. J.-C. L'oppidum de Mailhar n’a donné que deux

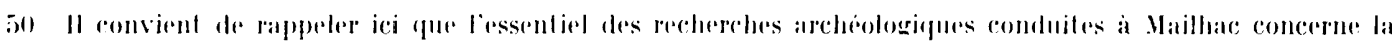

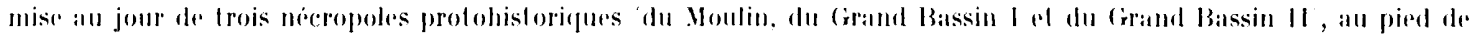
loppirlum e les travaux necessaires a leur pulolicalion.

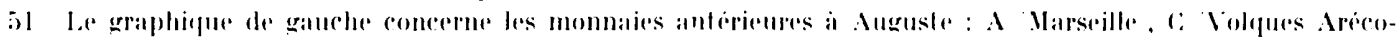

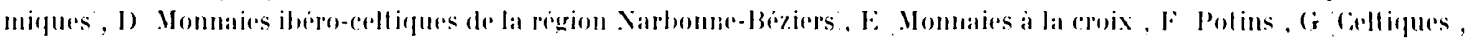

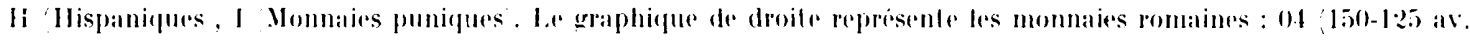

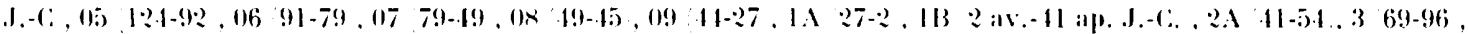

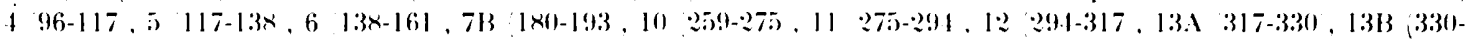

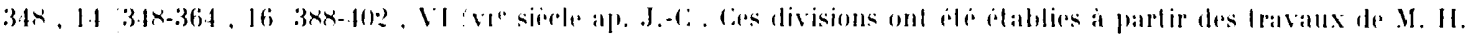

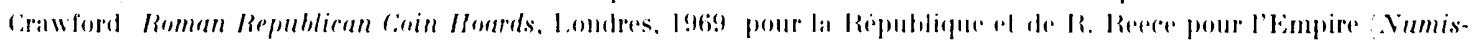

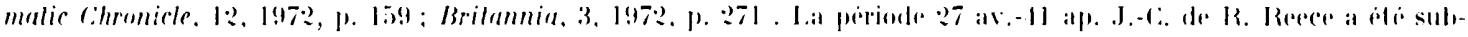

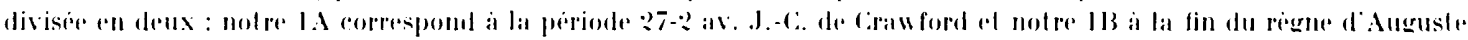

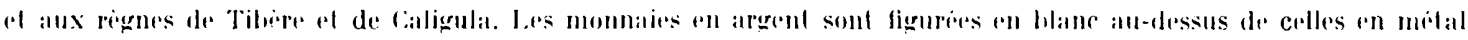
vil qui sont figuries an noir. Il n'y a pas de monnaie on or. 
monnaies : une obole an crabe et pent-ible. une obole imiter de lobole de Narseille

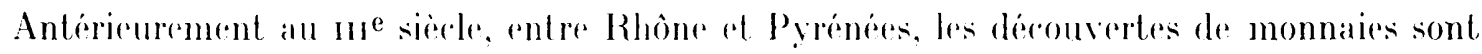
uniquement ronstitues par des esperes massalietes do dont il est difficile de savoir si elles marquent deja une éonomir monétaire ce qui nons semble peu probable. Toutes les autres

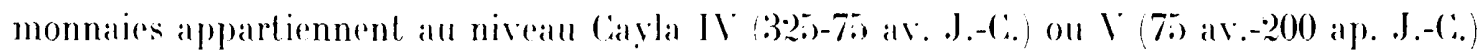
et nous les ronsidererons ici par serie.

Jans les monnayages preaugusténs, cest lo monnayage de Marseille qui a la part la plus importante avec un poureentage de $20.66 \%$ poureentage qui est faible cependant si on le compare à celui dautres sites de la région : Vurviel-lès-Montpellier (Hérault) $(52,2.3 \%)^{54}$, Iattes (Herault) $(71,07 \%)^{5.5}$. Villetelle (Herault), oppidum d'Ambrussum $(44.70 \%)^{56}$, Nages (Garl) $(47.81 \%)^{57}$ malis superieur à celui de loppidum de Ruscino, Perpignan (Pyrénés-0rientales) $(6.30 \%)^{58}$. Par contre, le monnayage des Neroncen aver $9.91 \%$, renforce si lon ajoule relui des émissions de la région Narbonne-Béziers $(2.47 \%)$, soit $12.38 \%$. est nellement superieur a ceux des sites places entre Mailhate et le Rhònese mais proche de celui de loppidum de Ruscino (14,41\%). Nous avons done: les signes d'une alimentation monétaire direretement liée a la position géographique et allx interèts économiques.

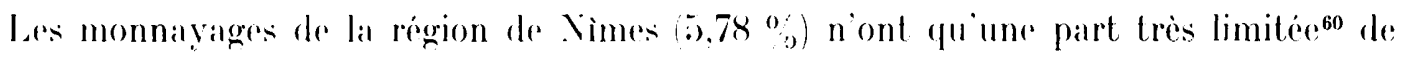
mème que les monnaies a la croix (6.61\%), les monnaies celtiques $(33,30 \%$ \%) at les monnaies puniques $(2.47 \%)$ : a trois derniers poureentages so trourent toujours situés au-dessous des $10 \%$ dans toute la region. les monnaies hispaniques (11.5\% \% sont plus abondantes

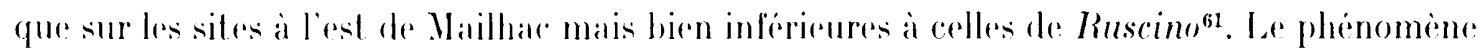
le plus interessant reside dans le poureentage des monnaies de la liépublique romaine

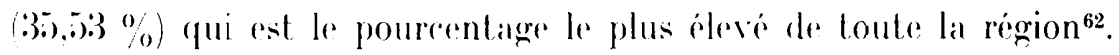

Vous pouvons conclure que. anterieurement a Auguste, les circuits d'alimentation monetaire, proviennent des environs immédiats a travers les émissions locales el les émissions de Rome mais probablement a partir de la cite des Nerencen et de la colonie de Narbonne, distante deune vingtaine de kilometres (fig. 1).

Sous l'Empire romain, jusquà Ciaurle I, les asses de Nimes au crocodile ot reux de

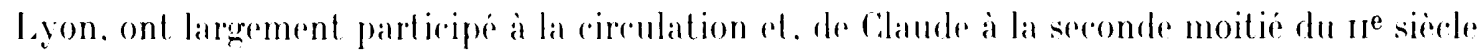

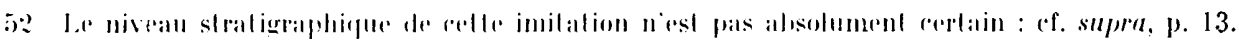

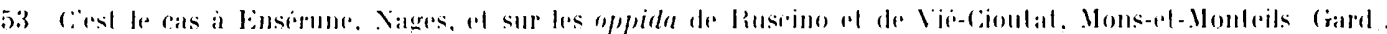

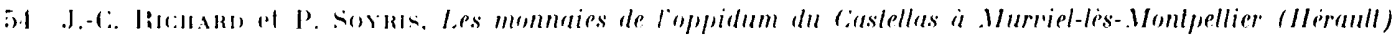

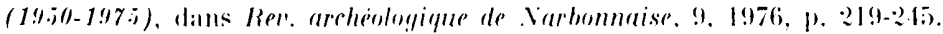

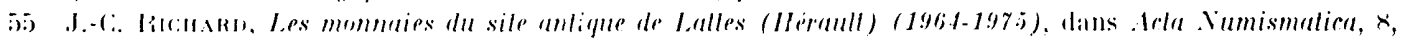
$197 \times, 17-17 \%$

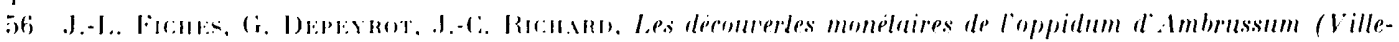

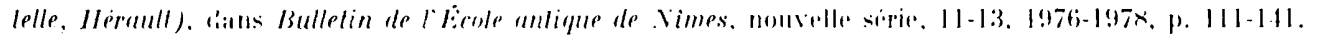

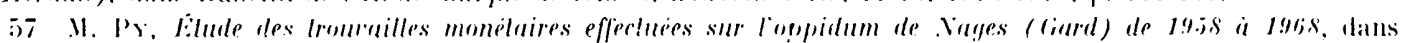
Arla Numismalim, 1. 1974, p. $97-153.3$.

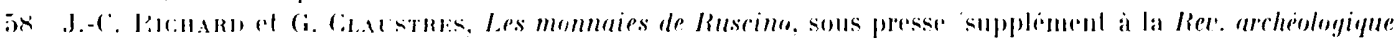
de Narbonnuise.

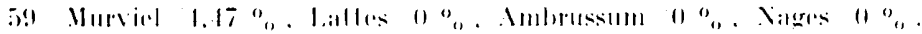

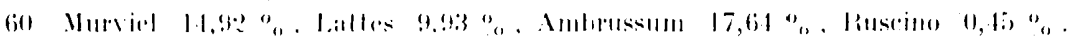

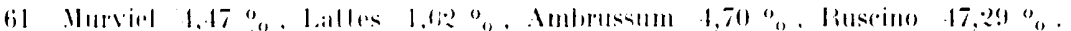

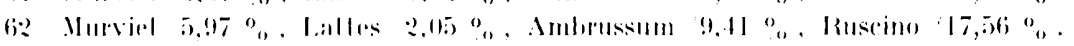


ap. J.-C., malgré quelques périodes encore non représentées. le monnayage de Rome, avec quelques imitations, circule à Vailhace. Si l'habitat sur l'oppidum se termine aux environs de :200 ap. J.-C., la ruplure monétaire est normale ${ }^{63}$ : les quatre monnaies postérieures ne signent pas nécessiarement une réocerupation mais peut-ètre seulement des passages. Les séries de la seronde moitié du nir siècle, faiblement représentées, et celles du we siècle ${ }^{64}$ marquent loccupation des plaines environnantes où l'habitat s'était deplacé.

Bien que nous ignorions le statut de l'oppidum du Caayla dans la géographie politique des II $^{\mathrm{e}}$ et $\mathrm{I}^{\mathrm{er}}$ siècles ar. J.-to, cést de ses environs et plus particulièrement de Xarbonne que proviennent les monnaies. Xous ne pouvons mème pas exclure le fait que ce soit de Xarbonne que proviennent toutes les séries quels que soient leurs lieux d'émission. Si, apres l'établissement de la colonie romaine en 118 av. J.-C. ${ }^{65}$. Narbonne ast alors. comme le rapporte Cicéron ${ }^{66}$, specula populi Romani ac propugnaculum istis ipsis nationibus oppositum et objectum ", l'oppidum de Mailhac, situé davantage à l'intérieur des terres. au contact de laarriere-pays et des avant-monts. semble se comporter comme un poste avancé de la colonie, dess sal fondation ou peut-ètre seulement à partir des années 76-74 avant J.-C:67. Quelle quen soit la date, il faut rappeler que la renturiation de Narbonne a divisé tout l'espare mailhacien ${ }^{68}$ al que cette dépendance territoriale est aussi révélée par les monnaies qui, a l'exception des deux exemplaires du Catyla III, n'ont peut-ètre atteint Mailhac qu'à la fin du Ie $^{e}$ siècle ar. J.-C. Il y a là une incertitude qui deva ètre résolue car il serait important de pouvoir déterminer de facon précise le moment de l'entrée de ce site indigène dans une économir monétaire.

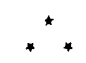

Les 281 monnaies de Mailhace et, plus particulièrement, celles qui ont été mises au jour, de 1931 à 1977, dans les fouilles de l'oppidum, apportent des informations préeises à l'étude de la circulation monétaire dans la région narbonnaise. Certes nous ne pouvons pas encore en tirer toutes les conchusions diachroniques at synchroniques mais cet ensemble complète la cartographie numismalique de la région entre les Pyrénées at le Rhòne, et permet des pourcentages précis qui peuvent ainsi ètre substitués à des intuitions. L'oppidum du Calyla ot la région do Mailhace, situés à un point nérralgique, contribuent ainsi à enrichir Thistoire monétaire de la Gaule méridionale.

Odette et Jean TaFavis. Jean-Cilaude Richord.

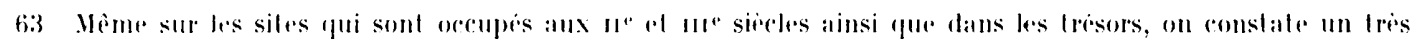

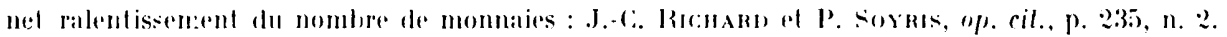

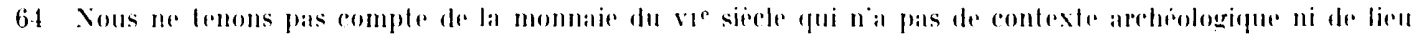
precis de deromineme.

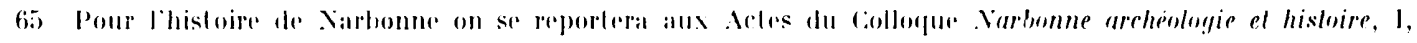

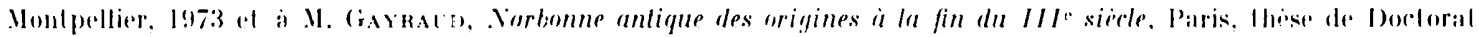
d'Elal, 1977, sous presse supplement a la Rere archeologique de . Varbonnaise.

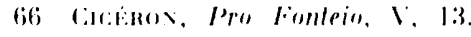

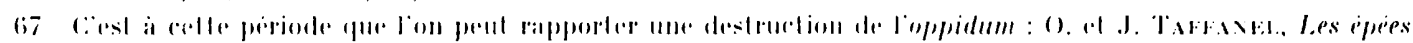

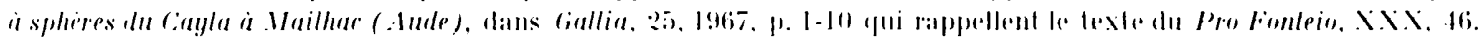

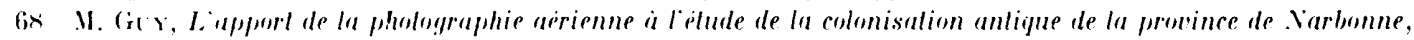

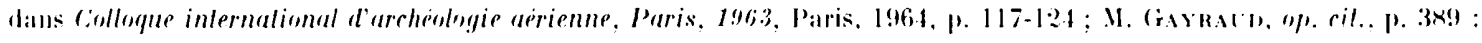
Carle de la centuriation de ba colonie de Xiarhonne. 